\title{
Climate Change, Risk and Productivity: Analyses of Chinese Agriculture
}

\author{
Dissertation \\ zur Erlangung des Doktorgrades \\ der Fakultät für Agrarwissenschaften \\ der Georg-August-Universität Göttingen \\ vorgelegt von \\ Rainer Holst \\ geboren in Buchholz in der Nordheide
}

Göttingen, Juli 2013 
1. Referent: J.-Prof. Xiaohua Yu, Ph.D.

2. Korreferent: Prof. Dr. Bernhard Brümmer

Tag der mündlichen Prüfung: 11. Juli 2013 


\section{Table of Contents}

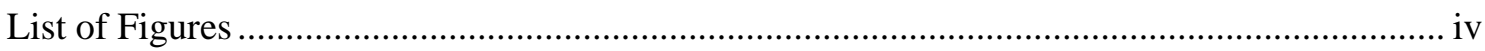

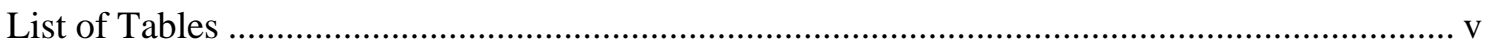

List of Abbreviations ................................................................................................. vi

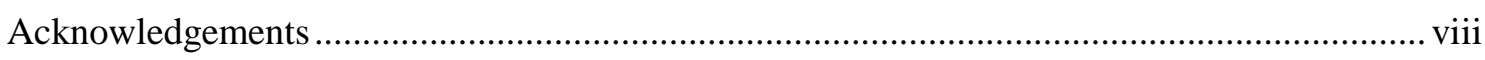

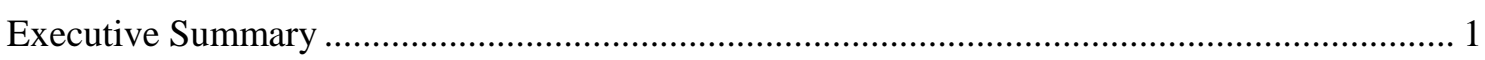

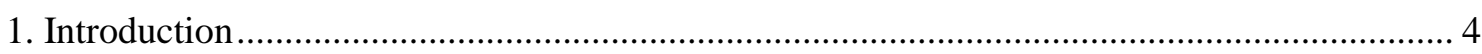

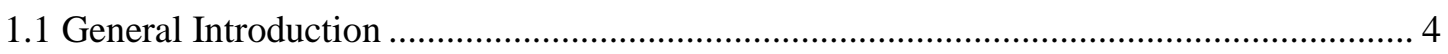

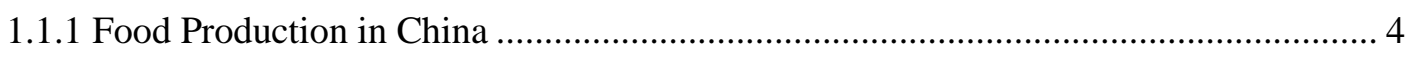

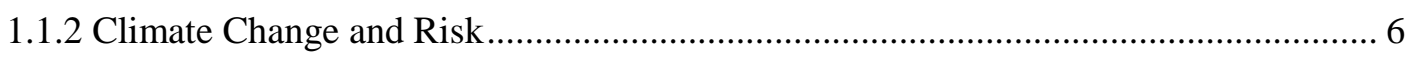

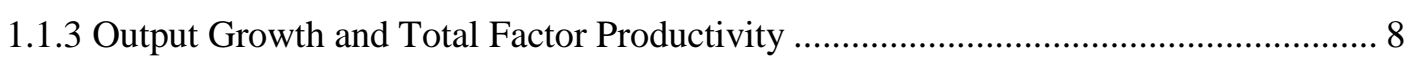

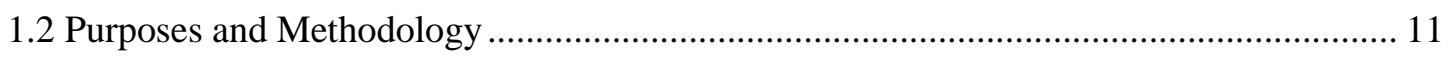

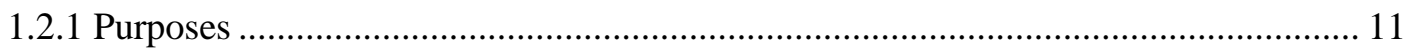

1.2.2 Methodology I: Analysis of Climate Change and Risk ........................................... 12

1.2.3 Methodology II: Analysis of Total Factor Productivity and Technical Efficiency .... 14

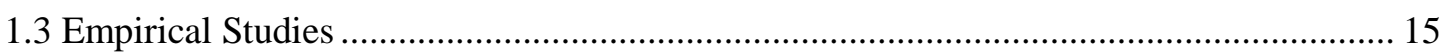

1.3.1 Study I: Climate Change and Risk in Chinese Inland Aquaculture .......................... 15

1.3.2 Study II: Climate Change, Risk and Grain Yields in China........................................ 16

1.3.3 Study III: Total Factor Productivity and Technical Efficiency in Chinese Inland

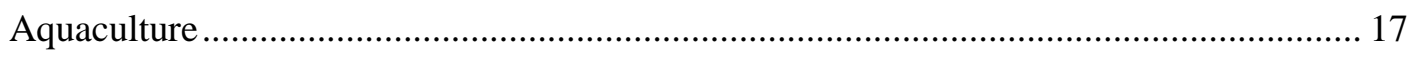

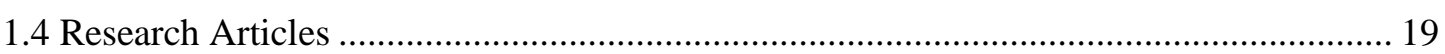

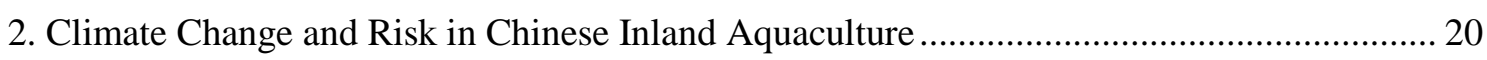

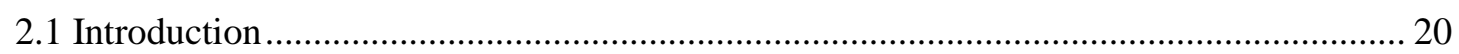

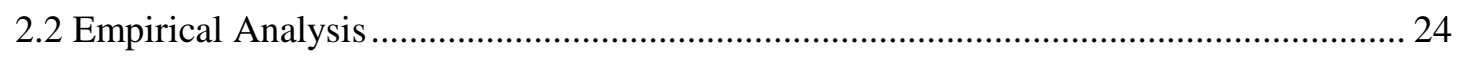

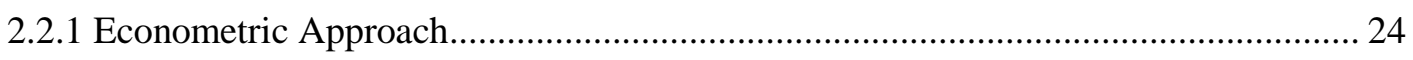

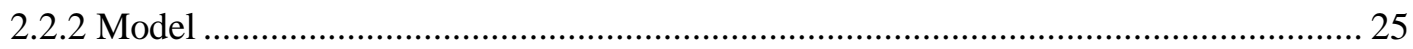

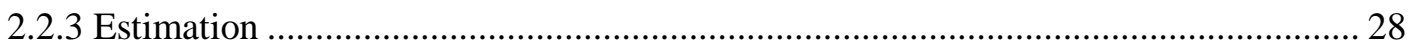

2.2.4 Quantification of the Impact of Climate Change ...................................................... 28

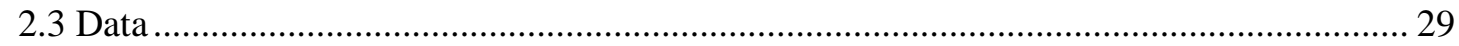

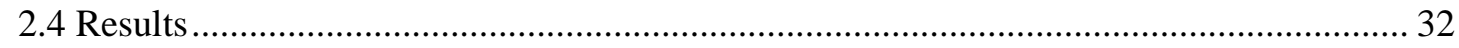

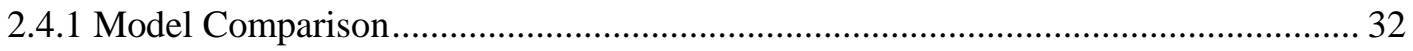

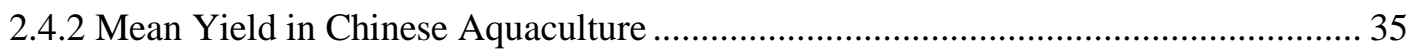




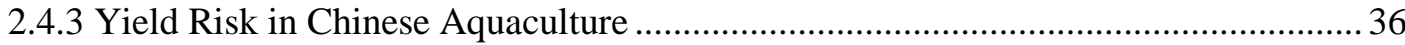

2.4.4 Marginal Impacts of Climate Change on Mean Yield.................................................. 37

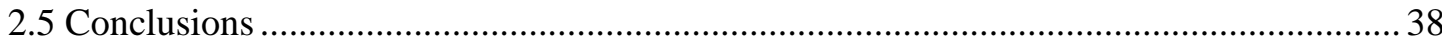

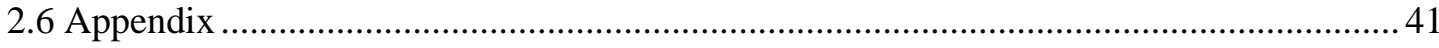

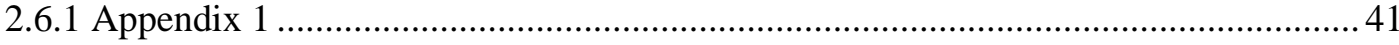

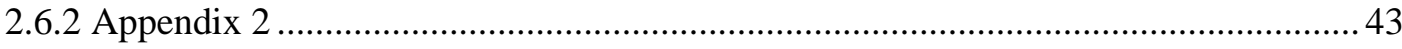

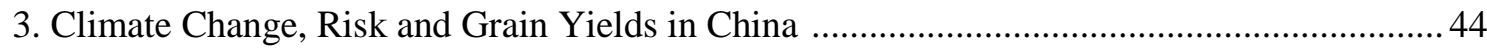

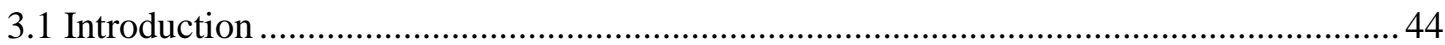

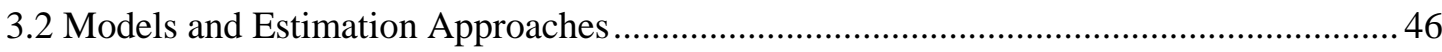

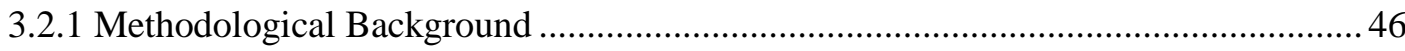

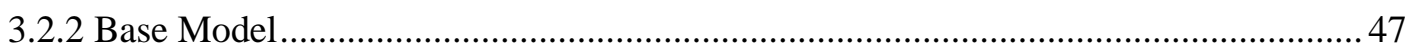

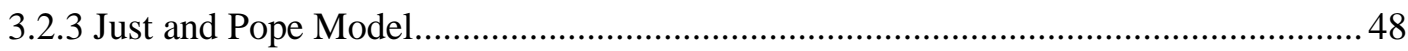

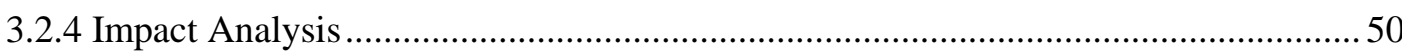

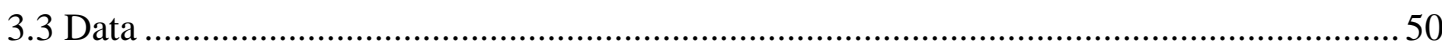

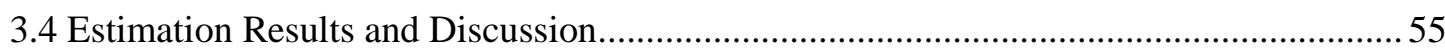

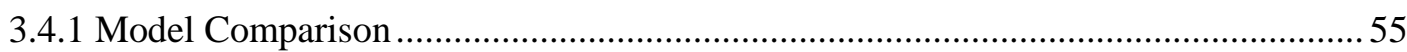

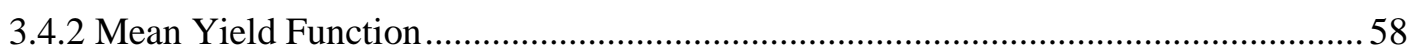

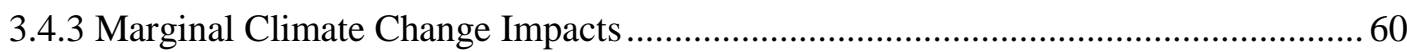

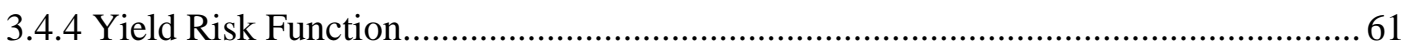

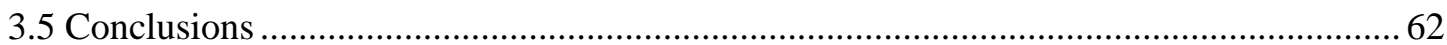

4. Total Factor Productivity and Technical Efficiency in Chinese Inland Aquaculture................65

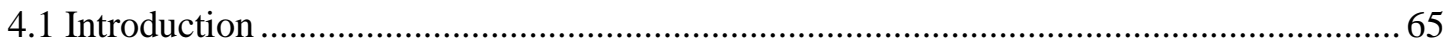

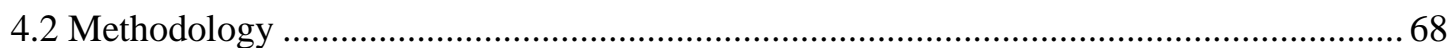

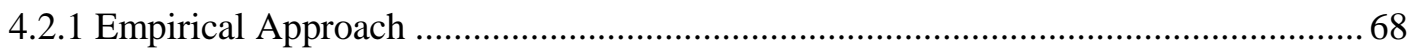

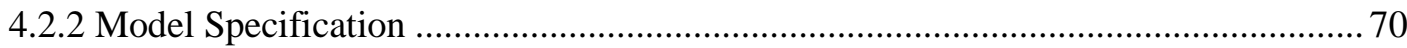

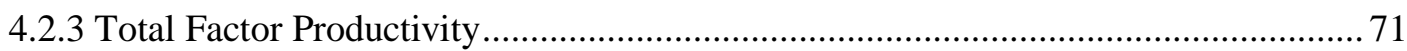

4.2.4 Distribution and Determinants of Technical Efficiency ............................................. 73

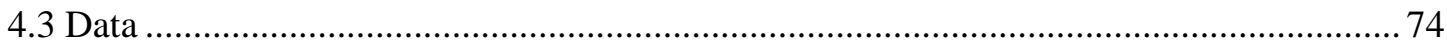

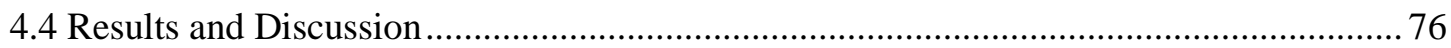

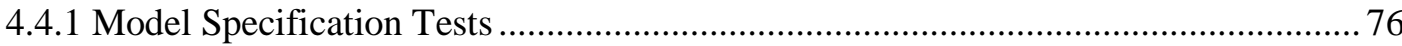

4.4.2 Stochastic Frontier Model Estimation Results .......................................................... 77

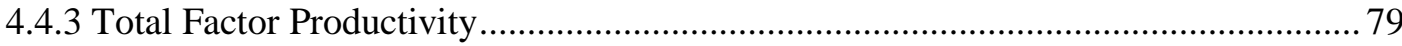

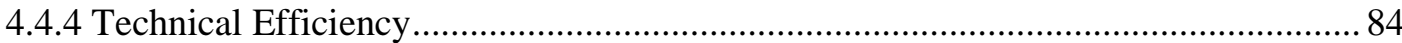

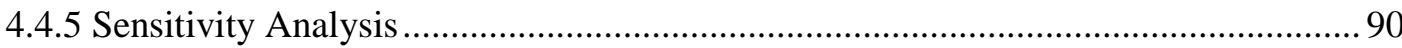

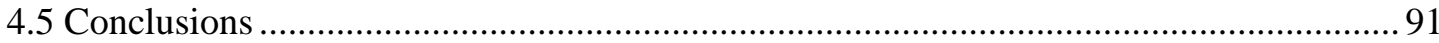

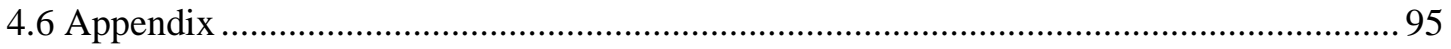




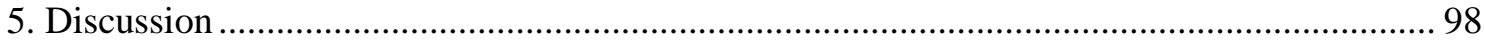

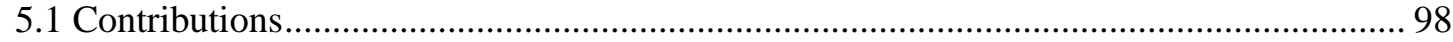

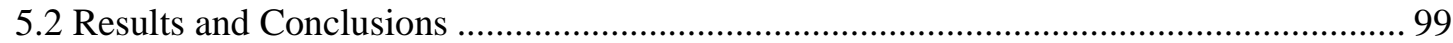

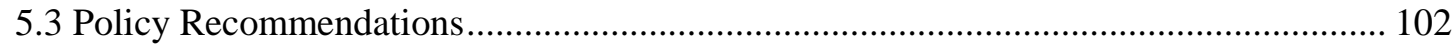

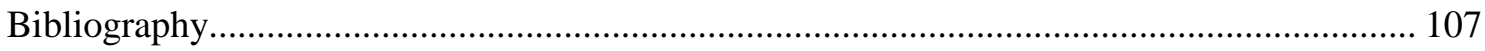




\section{List of Figures}

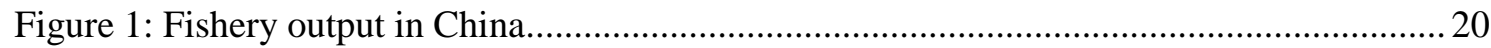

Figure 2: Annual average temperature (sample average) ............................................................ 23

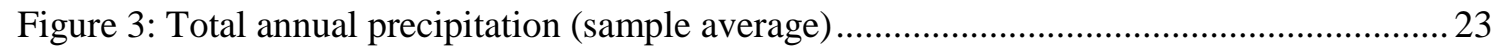

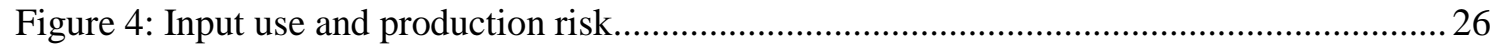

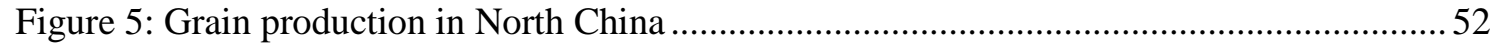

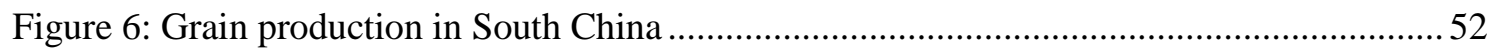

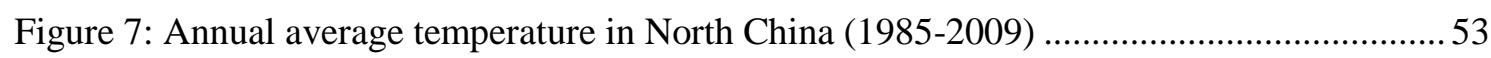

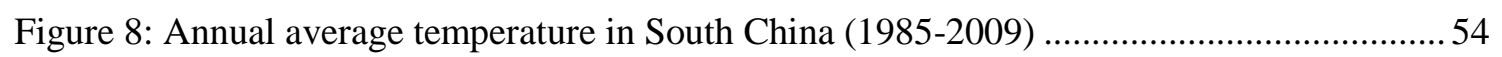

Figure 9: Total annual precipitation in North China (1985-2009) ............................................... 54

Figure 10: Total annual precipitation in South China (1985-2009) ............................................ 54

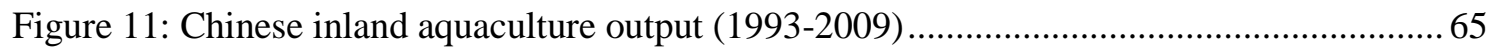

Figure 12: Cumulative change in total factor productivity and its components .......................... 81

Figure 13: Technical efficiency in Chinese inland aquaculture (2009)...................................... 84

Figure 14: Technical efficiency in Chinese inland aquaculture (average: 1993-2009)............... 85

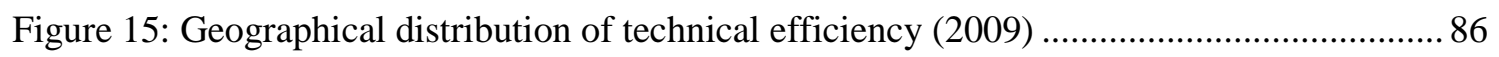

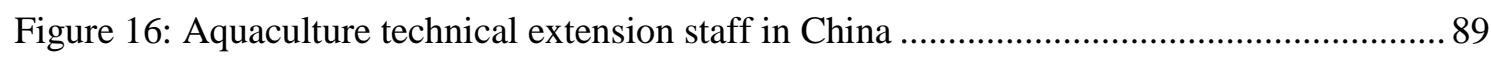

Figure 17: Technical efficiency in Chinese inland aquaculture (2009) (sensitivity test) .............97 


\section{List of Tables}

Table 1: National inland aquaculture production and climate data......................................... 30

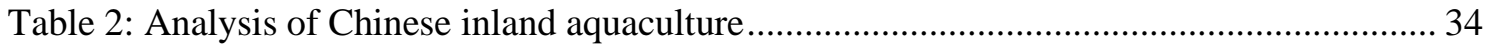

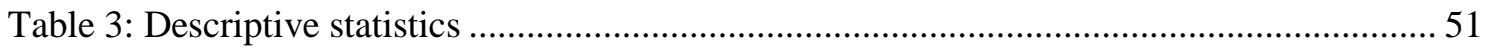

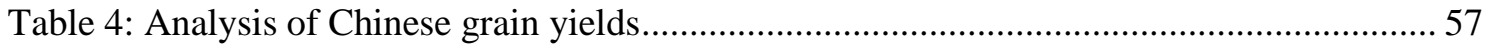

Table 5: Marginal impacts of climate change on grain production in China ................................ 61

Table 6: Descriptive statistics of Chinese inland aquaculture production ................................... 75

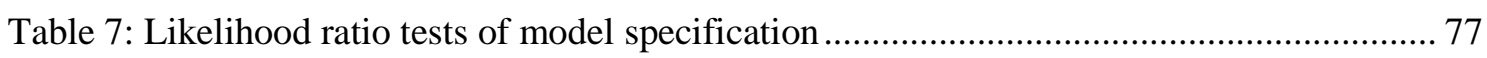

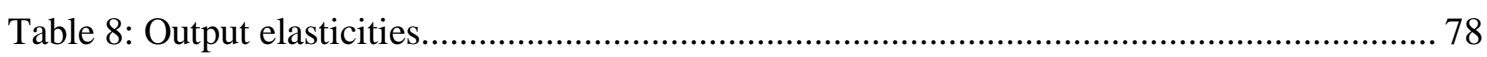

Table 9: Change in total factor productivity and its components............................................. 80

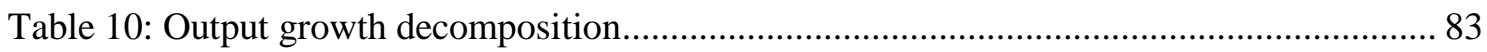

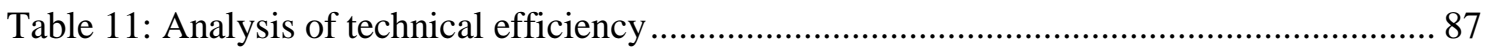

Table 12: Stochastic frontier model estimation results .............................................................. 95

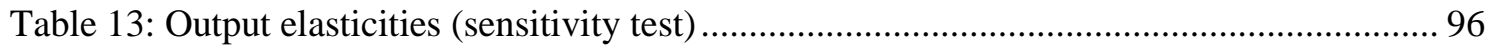

Table 14: Change in total factor productivity and its components (sensitivity test) ................... 96

Table 15: Analysis of technical efficiency (sensitivity test) ......................................................... 97 


\section{List of Abbreviations}

ABS

average share of the total weight of boats used for aquaculture

avg.

average

$\mathrm{BF}$

boats used across all sub-sectors of fishery

BIA

boats in inland aquaculture

$\mathrm{BM}$

boats in marine fishery

CNY

Chinese yuan

CPYEC

China Price Yearbook Editorial Committee

cum.

cumulative

DEA

data envelopment analysis

Eq.

equation

FAO

Food and Agriculture Organization of the United Nations

FE

fixed effects

FGLS

feasible generalized least squares

GNLS

generalized non-linear least squares

ha

hectare

$\mathrm{HE}$

high efficiency

HRS

Household Responsibility System

IPCC

Intergovernmental Panel on Climate Change

$\mathrm{J}-\mathrm{P}$

Just-Pope

LE

low efficiency

LME lower middle efficiency

MLE maximum likelihood estimation

NLS non-linear least squares

OLS ordinary least squares

PAES public agricultural extension system

precip. precipitation

SC scale change

SIDS Small Island Developing States

SFA stochastic frontier analysis

TC technical change

TE technical efficiency

TEC technical efficiency change

temp. temperature 


$\begin{array}{ll}\text { TFP } & \text { total factor productivity } \\ \text { TFPC } & \text { total factor productivity change } \\ \text { tot. } & \text { total } \\ \text { UHI } & \text { urban heat island } \\ \text { UME } & \text { upper middle efficiency } \\ \text { UN } & \text { United Nations } \\ \text { USD } & \text { United States dollar }\end{array}$




\section{Acknowledgements}

I would like to thank my advisor, J.-Prof. Xiaohua $\mathrm{Yu}$, for sending me on an academic voyage that has not only led to my successful completion of this dissertation, but has also enriched me in many personal ways. I am most grateful for his dedicated mentorship as well as his encouragement over the past years.

In addition, I would like to thank Prof. Bernhard Brümmer and Prof. Matin Qaim for their committed teaching and for acting as my examiners.

I am also grateful to all my friends and colleagues at the Courant Research Centre "Poverty, Equity and Growth in Developing Countries", the Department of Agricultural Economics and Rural Development as well as the Department of Economics who have accompanied me over the years, and to my friends outside the university.

Finally, I would like to thank my family and my girlfriend for their unwavering belief in me. 


\section{Executive Summary}

Over the past decades, China's agricultural sector has made great progress in supplying the country's large population with sufficient amounts of food. However, as a consequence of continuing population growth and an increasing wealth, it is generally expected that the demand both for basic food commodities, such as grain, and for higher-value food commodities, including meat and aquatic products, will continue to increase. If domestic supply is supposed to meet this increasing demand, it is necessary to obtain a clear picture of the state and prospects of Chinese agricultural production and to identify possible challenges, which could endanger its ability to reliably supply increasing quantities of important food commodities. To this end, three major issues are studied in the present thesis: (1) The effects of climate change on the inland aquaculture sector, (2) the effects of climate change on grain farming and (3) the development of the total factor productivity and its determinants in the inland aquaculture sector.

More specifically, the first study sheds light on the question of how climatic changes will affect the expected output and the level of output risk in Chinese inland aquaculture production. For this purpose, the method proposed by Just and Pope $(1978,1979)$ is adapted and applied to analyze the effects of changing temperatures and precipitation levels on the mean yield and the yield variance in the inland aquaculture sector.

In the second study, the above method is applied to determine the effects of changing temperatures and precipitation levels as well as of changes in climatic variability on the mean yield and the yield risk in Chinese grain farming.

In contrast with prior studies, which adopt variants of the Just and Pope method for the purpose of climate change impact assessments, the influences of regular input factors on the production process are also considered in the studies contained in this thesis.

Inland aquaculture and grain farming were chosen to be subjected to the above analyses due to their major contributions to overall food security and due to their expected sensitivity to climatic changes. While the effects of climate change on the Chinese grain sector have already received a certain amount of attention in the agricultural economics literature, this is not the case for the inland aquaculture sector. The impacts of climate change on output risk in turn have not been systematically analyzed in the literature on 
either of these sectors. Hence, the climate impact studies in this thesis serve to fill important knowledge gaps.

In the third study, Chinese inland aquaculture production is analyzed with respect to the development of total factor productivity and its determinants (i.e. technical change, technical efficiency change and scale change). For this purpose, a variant of the parametric stochastic frontier production models, which have been pioneered by Aigner et al. (1977) as well as Meeusen and van Den Broeck (1977), is estimated in a panel data context under the assumption of time-varying technical inefficiency. In addition to permitting an analysis of total factor productivity and its determinants on the sector level, this model also provides the necessary estimates for a detailed analysis of the development, geographical distribution and determinants of provincial technical efficiency scores.

Given that the current literature is characterized by a lack of systematic attempts to determine the contributions of total factor productivity and its determinants to the development of the Chinese inland aquaculture sector, the results of these analyses will be important for agricultural policy making.

The first study in this thesis, which analyzes the effects of climate change on Chinese inland aquaculture production, most importantly reveals that both increasing annual average temperatures and increasing levels of total annual precipitation will result in rising mean yields in this sector. Moreover, the results show that the relationship between the annual average temperature and the mean yield is non-linear, as the marginal effect of increasing temperatures is found to be diminishing. Furthermore, it turns out that increasing annual average temperatures have a negative effect on the level of yield risk. The implied reduction in output variability represents a second benefit of higher temperatures. Consequently, Chinese inland aquaculture can, at least in the short run, be expected to become a beneficiary of the projected increases in annual average temperatures and total annual precipitation levels due to global climate change.

Based on the second study, which analyzes the effects of climatic changes on the Chinese grain sector, it can be concluded that North and South China will be affected in different ways. Both parts of the country would suffer from reductions in mean grain yields following marginal increases in annual average temperatures. The effect would, however, be stronger in North China, which might be related to the marked water scarcity in this part of the country. Correspondingly, North China would benefit from a 
rising level of total annual precipitation, whereas South China would experience reductions in mean yield if this were to happen. Moreover, it emerges that North China would suffer from reductions in mean yield following an increase in the variability of precipitation. With respect to yield risk, the results indicate that increasing temperatures and precipitation quantities would reduce the yield variability in South China. In addition, climatic variability, both with respect to temperatures and precipitation levels, is positively correlated with the levels of yield risk in North and South China, though the relationships do not reach conventional levels of statistical significance.

The analysis of total factor productivity and its determinants in the context of Chinese inland aquaculture production shows that the sector has benefited particularly from improvements in technology. Technical efficiency, however, has decreased over the observation period. An analysis of the determinants of technical efficiency indicates that a decreasing number of aquaculture technical extension staff per unit of labor in aquaculture production and increasing annual average temperatures contribute to the negative development of technical efficiency.

Nevertheless, even after accounting for the negative contributions of changes in the scale of production to total factor productivity change, total factor productivity has nearly doubled between 1993 and 2009. Moreover, technical efficiency in inland aquaculture production turns out to be quite heterogeneous across the Chinese provinces. Specifically, the provinces in Southeast and East China reach the highest technical efficiency scores, whereas North and West China are the least efficient regions. 


\section{Introduction}

\subsection{General Introduction}

In this section, the topics and issues addressed in the present thesis are introduced. In a first step, information regarding Chinese food production in general and regarding inland aquaculture and grain production in particular are provided. Thereafter, the issues of climate change and production risk (i.e. output risk ${ }^{1}$ ) are discussed before turning to the topics of output growth and total factor productivity.

\subsubsection{Food Production in China}

After several decades of substantial growth, the population of the People's Republic of China had reached a size of around 1.36 billion people in the year 2010. Based on the medium-variant projections of the United Nations, population growth in China will continue until around 2030 when the population is expected to have reached a size of approximately 1.45 billion people (UN, 2013). As a consequence of this development and of China's increasing wealth, projections by Zhao et al. (2008) show an increase in aggregate food demand of around 18\% between 2010 and 2030. While Chinese agriculture has certainly made great progress in supplying sufficient food to the country's population, which is exemplified by the fact that per capita food output is now 3.5 times higher than 50 years ago (Godfray et al., 2010), it is also a fact that the slow agricultural growth prior to the agricultural reforms beginning in 1978 resulted in difficulties in expanding grain production at a rate above or equal to the growth rate of the population (Lin, 1992). The agricultural reforms, which involved the introduction of the household responsibility system, price reforms and other measures, marked the beginning of the gradual introduction of market mechanisms into Chinese agricultural production and led to considerable improvements in productivity and total output (Brümmer et al., 2006; Yu and Zhao, 2009). Overall, China managed to increase its

\footnotetext{
${ }^{1}$ The terms output risk and production risk are used synonymously in this thesis. 
grain output from around 305 million tons in 1978 to slightly more than 571 million tons in 2011 (National Bureau of Statistics of China, 2012).

China has traditionally striven to be largely self-sufficient with respect to food. This was initially rooted in a political ideology holding that import dependence, especially with respect to basic food commodities, is an undesirable strategy for sustaining the country's large population (Yang and Tyers, 1989). China's current goal to maintain a food self-sufficiency rate of around 90-95\%, however, does not only have political reasons. It is also a fact that due to the magnitudes involved, changes in the demand for and supply of food in China can potentially have strong impacts on global markets if they force the country to resort to importing increasing amounts of food to satisfy domestic demand (von Braun, 2007; Simelton, 2011). In order to be able to also satisfy the future food demand of its growing population, China will have to continue to increase its output of important food commodities. Two particular developments currently stand out regarding changes in demand. On the one hand, the ongoing population growth will keep increasing the total demand for grain as the most important basic food commodity, and on the other hand China's strong economic growth and the concomitantly increasing wealth of its population will lead to an increasing consumption of meat as well as aquatic and other higher-value food products (Zhao et al., 2008; Ortega et al., 2009).

In China, aquatic products make a particularly strong contribution to overall food supply. Over the past decades, the Chinese fishery sector has experienced an enormous development. Its contribution to global fish output rose from just 7\% in 1961 to around $35 \%$ in 2010. The strong supply and the rising income level in China allowed annual per capita fish consumption to increase at an average annual rate of $6 \%$ between 1990 and 2009 and to reach a level of $31.95 \mathrm{~kg}$ in 2009, which is well above the average supply situation in the rest of the world (15.4 kg per capita in 2009) (FAO, 2012). The importance of aquatic products for Chinese consumers is also reflected in the fact that they accounted for around 30\% of the country's animal protein supply in 2004 (Weimin and Mengqing, 2007). Within the fishery sector, aquaculture production in general and inland aquaculture production in particular have traditionally played important roles. However, despite the fact that pond aquaculture has been known in East China for 2500 years (Chen et al., 1995), the strong expansion in scale and improvements in output quantities, technology and farming systems, which allowed the country's aquaculture sector to become a major contributor to overall food production, only began with the 
agricultural and economic reforms ${ }^{2}$ (Weimin and Mengqing, 2007). The overall output of Chinese inland aquaculture rose from just 0.81 million tons in 1979 (FAO, 2005a) to around 22.17 million tons in 2009 , which corresponded to $43.3 \%$ of China's total output of aquatic products in 2009 (Chinese Ministry of Agriculture, 2010) and makes inland aquaculture by far the most important sub-sector of Chinese fishery.

Given the past development of Chinese agriculture, projections of food security by Zhao et al. (2008) show that China might be able to keep up with the food demand of its growing population over the next few decades. There is, however, a considerable degree of uncertainty involved in such general long-term projections and evidence is mounting that agricultural production in China is already confronted with several challenges, some of which could have a significant effect on the country's ability to expand its future food supply. A selection of important challenges will be discussed in the following two sections.

\subsubsection{Climate Change and Risk}

Global climate change is among the major issues that recently received increasing attention in the literature on agricultural production. According to Wang et al. (2010), Chinese researchers expect that the annual average temperature in China could increase by around $2.3-3.3^{\circ} \mathrm{C}$ until 2050 , as compared to the year 2000 , whereas the national precipitation level could increase by $5-7 \%$ over this time period. Furthermore, extreme climate events could become more frequent and more severe ${ }^{3}$. Of course there is uncertainty involved in these projections and it is anticipated that regional climate change patterns and impacts will vary greatly. Regarding the economic effects of climate change on Chinese agriculture and particularly on grain production, Liu et al. (2004) find that under the majority of the climate change scenarios considered in their study, agricultural net revenues would increase in most regions of China, except for the Northwest, the Southwest and parts of the Northeast, as a result of the projected increases in temperatures and precipitation levels. Hence, they draw the conclusion that Chinese agriculture as a whole could benefit from climate change. The results of Wang

\footnotetext{
${ }^{2}$ As noted by Leung and Shang (1993), the introduction of the household responsibility system and the accompanying creation of economic incentives for agricultural producers, including the incentive to invest, also affected aquaculture producers as members of the wider agricultural sector.

${ }^{3}$ Similar but somewhat slower developments are expected by the Intergovernmental Panel on Climate Change for East Asia as a whole (Christensen et al., 2007). The predictions, however, depend strongly on the assumed climate change scenario.
} 
et al. (2009), however, lead to different conclusions. According to them, Chinese crop producers would on average benefit from increases in precipitation levels but would over time increasingly suffer from rising temperatures. Based on a differentiation of farmers into those with access to irrigation and those relying on precipitation, Wang et al. (2009) find that higher temperatures would particularly hurt rainfed farms, whereas they would be beneficial for irrigated farms, except for those in the northwest and northeast of the country. Higher levels of precipitation would only have negative effects on rainfed farms in the Southeast of China but would be beneficial everywhere else.

What is pointed out in both studies is that water plays a key role because gains from increasing temperatures often rely on parallel increases in precipitation or at least on a general level of water availability that is sufficient to cope with the effects of warming. Specifically, rising temperatures increase water losses in agriculture due to evapotranspiration, which might particularly harm agricultural production in areas that are already experiencing a pronounced water scarcity like the North China Plain or the country's northwestern region (Wang et al., 2010).

Economic studies on the impact of climate change on Chinese aquaculture production, however, are virtually absent, despite the growing body of literature on the possible vulnerabilities of fisheries and aquaculture production towards changes in climatic conditions. Specifically, most of the expected effects of climate change on aquaculture are either directly or indirectly linked to changes in temperatures or precipitation patterns. Among the most frequently anticipated negative impacts are an increasing degree of heat stress following the warming of water habitats, an aggravated toxicity of widespread pollutants in warmer waters and a higher incidence of diseases (Ficke et al., 2007). Other effects of climate change include an uncertain future water supply following changes in precipitation patterns and an increasing incidence of extreme climatic events, which might kill cultured fish populations or destroy other productive assets (De Silva and Soto, 2009; Ficke et al., 2007). However, according to Brander (2007), positive effects are likely as well: Global warming could make it possible to set up aquaculture operations in regions that formerly were too cold, or to benefit from an expansion of production made possible by an extended frost-free season. In addition, some fish species might experience accelerated growth along with an improved ability to convert feed. 
What is neglected in most studies regarding the impacts of climate change on agricultural production, be it in the context of crop production or of aquaculture, is the issue of output risks (i.e. of unexpected variations in output). It is well known that agricultural producers cannot precisely predict their output in any given year, which results among other reasons from the fact that their production processes are subject to numerous endogenous and exogenous uncertainties over the course of a growing season (Just and Pope, 1979; Kumbhakar and Tsionas, 2008; Meyer and Yu, 2013). The exact temperatures and precipitation levels in any year are important exogenous uncertainty factors. They cannot be predicted by agricultural producers as they not only experience changes in their expected values as a result of changes in global climate but also display considerable and partly unpredictable inter-annual variability.

In their studies on yield variability in the U.S., Chen et al. (2004) as well as Isik and Devadoss (2006) confirm that annual climate conditions (temperature and precipitation) affect output variability in crop production, though the exact effects are found to be crop-specific. Similarly, aquaculture production is also likely to experience increasing output variability due to climate change. This is supported, for example, by Tveterås (1999) and Tveterås and Wan (1999) who note that changes in water temperature or other climate-related events cause output risk in Norwegian Salmon aquaculture.

Nevertheless, due to insufficient empirical attention in the literature it is as yet unknown whether and to what extent changes in climate factors will affect output risk in the different sub-sectors of Chinese agriculture.

\subsubsection{Output Growth and Total Factor Productivity}

Climate change, however, represents an external influence on agricultural production, which is beyond the control of producers and hence only leaves them the possibility to react to changing conditions. If China wants to exert an active influence on its future food supply, it will also be important to know which economic factors have driven output growth in the past and to devise agricultural policies accordingly.

A review of the corresponding literature shows that the strong growth in Chinese agricultural production since the late 1970's is mainly due to increases in the use of input factors as well as to improvements in total factor productivity (TFP) and its determinants (especially technology), though there exists an extensive debate regarding 
the contributions of individual factors to total factor productivity and output growth (Lin, 1992; Kalirajan et al., 1996; Fan and Pardey, 1997; Jin et al., 2002; Fan et al., 2004; Brümmer et al., 2006; Tian and Yu, 2012; Chen et al., 2013).

Regarding the future growth of China's agricultural output, Jin et al. (2002) point out the highly important role of technical change and hence of improvements in total factor productivity because they consider it to be unlikely that an intensification in the use of input factors will continue to contribute to output growth as strongly as it used to during the 1980's and 1990's. As reasons for this they see for example already high levels of input use, particularly with respect to agrochemicals, resource contraints, environmental issues and increasing wages. Chen (2007) moreover considers the facts that urbanization in China causes a substantial loss of agricultural land and that it creates additional competition for water resources to aggravate the resource constraints on Chinese agricultural production. If it should really become increasingly difficult to expand production by means of increasing the quantities of inputs used in the production process, a positive development of technology and hence of total factor productivity will naturally become more important.

Another essential determinant of total factor productivity is technical efficiency, which, as Kalirajan et al. (1996) explain, describes the degree to which producers are able to use the potential of the available production technology. Kalirajan et al. (1996) moreover point out that if the majority of producers is unable to fully employ technological advances, promoting technical change will not be an effective measure to improve TFP. This shows the need not only to determine the development of total factor productivity itself but also to obtain detailed knowledge on its determinants.

However, most of the present literature on total factor productivity change and other sources of growth in agricultural output, including the studies discussed above, deals with grain or more generally crop production. Economic studies analyzing Chinese inland aquaculture are scarce and do not provide a comprehensive picture of the sources of growth. Generally, as Leung and Shang (1993) note, aquaculture producers are confronted with broadly the same institutional and economic framework as the remainder of the agricultural sector. Hence, developments that affect overall agricultural production, could also have a bearing on aquaculture production, which is why comparisons to studies on other sub-sectors of agricultural production could aid in the analysis of aquaculture. However, given the nature of its products and the special 
environmental conditions under which aquaculture takes place, sector-specific analyses are necessary to facilitate an accurate understanding of the driving forces in the development of aquaculture production.

It has been stated in different studies that the Chinese inland aquaculture sector has benefited from the introduction of modern production technologies, the development of a specialized support industry and from an increasing knowledge regarding management and production techniques among producers (Leung and Shang, 1993; Weimin and Mengqing, 2007). Hence, one would expect Chinese inland aquaculture production to be characterized by increasing levels of total factor productivity, driven both by positive technical change and by improvements in technical efficiency. The latter should in particular be related to improved knowledge and abilities among producers. However, empirical evidence regarding these factors is missing in the two aforementioned studies. Regarding integrated aquaculture (i.e. aquaculture practices that are integrated into other livestock or crop production systems), Chen et al. (1995) find that productivity, which in their study is just represented by the yield per hectare, varies considerably within and across the Chinese provinces. Generally, they find that the provinces in Southeast China and the eastern coastal provinces feature higher levels of productivity, which they assume is particularly due to the more advanced level of economic development, better infrastructure and more favourable environmental conditions, particularly with respect to water availability, in those provinces. A study by Sharma et al. (1999) provides additional insights. They find that technical efficiency in Chinese inland fish polyculture (an aquaculture practice, which involves rearing multiple fish species in the same pond at the same time) also varies considerably across producers and that producers from more developed provinces tend to be more technically efficient. According to their overall results, improvements in technical efficiency could considerably increase output.

Nevertheless, from an economic point of view, the literature on Chinese inland aquaculture leaves many important questions unanswered and does not provide a comprehensive picture of the development of the sector. Specifically, the available studies are mostly rather outdated, often focus only on specific forms of aquaculture in specific regions, mostly feature no analysis of temporal developments and tend to neglect total factor productivity as well as technical change in their analyses. 


\subsection{Purposes and Methodology}

In this section, the purposes of the present thesis and of the individual studies contained in it are outlined. Moreover, the methodological background of each study is discussed given these purposes.

\subsubsection{Purposes}

It is the purpose of the present thesis to contribute to the literature on agricultural production in China along two major lines. First, the issue of climate change is addressed. It emerges from Section 1.1.2 that climate change is, on the one hand, likely to have an impact on the general production conditions (i.e. on the expected output) in different sub-sectors of China's agriculture and, on the other hand, might affect the level of output variability (i.e. the level of output risk) in those sub-sectors. Since yield risks can on the national or regional level potentially have strong influences on the food supply situation, it is obvious that the impacts of changing temperatures and precipitation levels on yield risk represent an important additional aspect of climate change. In order to obtain a clear picture of the different impacts of climate change on agricultural production without neglecting the contributions of the regular input factors, yield functions based on Just and Pope (1978, 1979) are adapted and estimated. Moreover, based on the projected directions of climate change with respect to temperatures and precipitation levels, yield and output responses to marginal changes in climate are calculated and valued at market prices.

Given the great importance of both domestic inland aquaculture and grain production for supplying sufficient food to the Chinese people and given their likely sensitivity to climate change, these two sub-sectors are selected to be separately subjected to climate impact analyses employing the above approach. Due to their different production systems, it has to be expected that climate change will affect aquaculture and grain production in different ways. Hence, different policy measures would be required in the different sectors to cope with or to adapt to climate change. The two sector-specific climate impact studies in this thesis are intended to provide important knowledge on the influences of climate change and thereby to facilitate the development of suitable policies. The studies are carried out on the basis of province-level data covering all regions of China, which allows gaining new insights regarding the current state and the 
development prospects of Chinese inland aquaculture and grain production on the sector level.

In Section 1.2.2, the methodological background of the climate impact studies is introduced in more detail. Sections 1.3.1 and 1.3.2 give a brief overview of the empirical findings with respect to inland aquaculture and grain production, respectively. The complete studies are contained in Sections 2 and 3.

Next, attention is directed at the development and determinants of total factor productivity in Chinese inland aquaculture ${ }^{4}$. The discussion in Section 1.1.3 has revealed only fragmentary and often empirically unsubstantiated insights regarding the development of total factor productivity and its determinants in this sector. Hence, so far there exists only insufficient knowledge regarding the factors, which have driven the development of Chinese inland aquaculture as a whole in the past. An accurate assessment of possible sources for future growth would, however, require such knowledge. To remedy this deficit and to contribute decision-relevant information for policy making in this field, a variant of stochastic frontier analysis is applied. On the one hand, this allows the estimation of the determinants of total factor productivity and hence of total factor productivity itself. On the other hand, it additionally permits a detailed analysis of the development, geographical distribution and determinants of technical efficiency scores. Again, the study is carried out on the basis of province-level data from all regions of China, which permits drawing conclusions regarding China's inland aquaculture sector as a whole.

The methodological background of this study is introduced in Section 1.2.3. Sections 1.3.3 and 4 contain a brief overview of the empirical findings and the complete study, respectively.

\subsubsection{Methodology I: Analysis of Climate Change and Risk}

According to Deschênes and Greenstone (2007), temperatures and precipitation quantities are input factors in the context of agricultural production. Hence, it is a common practice in the literature on the effects of climate change on agriculture to include climate or weather variables into economic models to analyze the influences of

\footnotetext{
${ }^{4}$ As emerged from Section 1.1.3, the analysis of total factor productivity in Chinese grain farming has already received considerable attention in the literature. Hence, the productivity analysis in the present thesis is focused exclusively on inland aquaculture.
} 
changes in these variables on yield, output, revenue or other relevant quantities (e.g. Zhang and Carter, 1997; Lippert et al., 2009; Wang et al., 2009; Chen et al., 2013).

As the climate impact studies in the present thesis are concerned with the effects of climate change on agricultural production, a yield model is proposed, which, similar to the models of Zhang and Carter (1997) and Chen et al. (2013), simultaneously incorporates both climate variables and regular input variables. This approach on the one hand allows to directly estimate the effects of climate change on yield levels, and on the other hand permits a more accurate modeling of the true production process than would be possible if the important influences of climate on agricultural production were neglected.

However, as discussed in Section 1.1.2, agricultural production faces numerous endogenous and exogenous uncertainty factors. Specifically, it is known that the applied quantities of regular input factors as well as climate-related variables can affect the level of output risk (i.e. the yield variance) in agricultural production (Just and Pope, 1979; Chen et al., 2004; Isik and Devadoss, 2006; Kumbhakar and Tsionas, 2008).

Hence, in the climate impact studies in this thesis, the general approach proposed by Just and Pope $(1978,1979)$ is adopted, which involves the construction and estimation of a flexible composite production function that allows to analyze the marginal effects of the independent variables on both mean yield and on yield risk. This specific functional form is necessary because, as Just and Pope $(1978,1979)$ show, many of the common production functions, particularly those with log-linear disturbance terms, impose the unrealistic constraint of a positive correlation between the applied quantity of any input factor with a positive marginal product and the yield variance. The Just and Pope specification does not impose such a constraint.

In past studies employing the approach proposed by Just and Pope $(1978,1979)$ it has, however, been common to focus either on estimating the marginal contributions of regular input factors to mean output and to output risk (e.g. Asche and Tveterås, 1999; Kato et al., 2011) or on estimating the corresponding contributions of climate factors (e.g. Chen et al., 2004; Isik and Devadoss, 2006). By specifying the components of Just and Pope's composite production function according the aforementioned yield model, which incorporates both sector-specific regular input factors and climate factors, the climate impact studies presented in this thesis combine these two strands of analysis. 
The Just and Pope yield models are estimated as non-linear fixed-effects panel data models, using a three-stage estimation procedure that represents an adaption of the procedure proposed by Just and Pope (1979).

\subsubsection{Methodology II: Analysis of Total Factor Productivity and Technical}

\section{Efficiency}

The explanation of total factor productivity growth, or in other words, of output growth that is not attributable to changes in input use, has received considerable attention in the literature. An early measure of productivity was proposed by Solow (1957) who introduced a Hicks-neutral technical change parameter that is supposed to capture all influences, which lead to a shift of the production function. In the same year, Farrell (1957) conceptulaized the idea of technical efficiency, which allows to measure to what extent producers fall short of the maximum possible output, given their input levels and given a production function representing perfect efficicency (i.e. a frontier production function). Recognizing that changes in technical efficiency have an effect on productivity, Färe et al. $(1992,1994)$ proposed a Malmquist index regarding total factor productivity growth, which they decompose into the contributions of technical change and of technical efficiency change. Their approach draws on the pioneering contribution of Caves et al. (1982) who initially proposed the Malmquist index. Subsequently, this framework has been improved and extended in several ways. Fuentes et al. (2001) for example demonstrate the decomposition and estimation of the Malmquist total factor productivity index in a parametric frontier production panel data context. In a related study, Orea (2002) in turn once more raises the issue of the appropriate composition of an index representing total factor productivity by pointing out the necessity to account for the influences of changes in returns to scale. Specifically, he proposes a way to extend the Malmquist total factor productivity index by a scale term that, under the assumption of variable returns to scale, captures the influences of changing input use on total factor productivity.

The study on total factor productivity in Chinese inland aquaculture presented in the present thesis draws on the above research and employs a specific variant of parametric production function analysis, namely stochastic frontier analysis (SFA), to obtain estimates of technical change, technical efficiency change and of the effect of scale changes. SFA, which has been introduced by Aigner et al. (1977) as well as Meeusen 
and van Den Broeck (1977), has the advantage that it incorporates a stochastic error term into the frontier production function to capture the influences of statistical noise. Moreover, by employing the time-varying technical inefficiency specification by Battese and Coelli (1992), the SFA model yields year- and panel unit-specific estimates of technical inefficiency. This allows to analyze the temporal development and geographical distribution of efficiency scores and might thereby provide important policy-relevant information. In various studies, including those of Pitt and Lee (1981) and Kalirajan (1984), an additional use for technical efficiency scores has been suggested. Regressing them on a set of explanatory variables in a second-stage regression might help to determine whether any factors emerge as determinants of technical efficiency.

\subsection{Empirical Studies}

This section contains summaries of the empirical studies included in the present thesis. In particular, in the following sub-sections the main results and basic conclusions of each study are presented.

\subsubsection{Study I: Climate Change and Risk in Chinese Inland Aquaculture}

Despite the fact that more than $60 \%$ of global aquaculture output is produced in China, the impact of climate change on Chinese aquaculture has not been well studied. Using an adaption of the Just and Pope $(1978,1979)$ method and a newly constructed data set comprising province-level aquaculture production data and climate information from 1993 until 2009, it is the purpose of this study to analyze the marginal contributions of regular input factors and climate factors to both mean yield and yield risk in Chinese inland aquaculture. The main findings include the following:

(1) The inland aquaculture sector as a whole would benefit from marginal increases in both annual average temperature and total annual precipitation in terms of an increasing mean yield. The specific relationship between the annual average temperature and the yield level, however, is found to be non-linear, so that the positive marginal effects of temperature increases will gradually diminish.

(2) Increases in annual average temperature reduce yield risk at the margin. 
(3) A $1{ }^{\circ} \mathrm{C}$ increase in annual average temperature would, ceteris paribus, increase the average yield in the Chinese inland aquaculture sector by $6.8 \%$. Given the total area under aquaculture, this would, on the national level, generate additional output with a value of around USD 2.97 billion. A $100 \mathrm{~mm}$ increase in total annual precipitation in turn would improve the average aquaculture yield by $1.2 \%$. The market value of the consequent increase in national output would be USD 0.52 billion.

(4) An intensification of production would help to increase mean yields.

(5) Adjustments in the use of regular input factors can be used to limit yield risk.

In summary, it can be stated that the projected changes in climate, at least in the short run, are not opposing further improvements in yield and overall output. To the contrary, marginal increases in both annual average temperature and total annual precipitation would even benefit the inland aquaculture sector. Moreover, it emerges that, after climate influences are accounted for, an intensification of production by employing more labor or using more fry would be suitable strategies to achieve further yield improvements without causing an increasing level of yield risk.

\subsubsection{Study II: Climate Change, Risk and Grain Yields in China}

Adopting yield functions based on the aforementioned adaption of the Just and Pope $(1978,1979)$ methodology, this study is intended to analyze the marginal impacts of regional climate change and of the use of regular input factors on mean yields and yield risks in the Chinese grain sector. For this purpose, a province-level panel data set on grain production and climate between 1985 and 2009 has been constructed. The results indicate that changes in climate will affect grain production in North and South China differently. Specifically, it emerges that

(1) Increasing annual average temperatures would at the margin lead to reductions in mean yields both in North and in South China, but North China would be more strongly affected.

(2) Higher levels of total annual precipitation would lead to higher mean yields in North China, but to slightly lower mean yields in South China. 
(3) Both increasing annual average temperatures and increasing levels of total annual precipitation would have a negative marginal effect on the level of yield risk in South China.

(4) $\mathrm{A} 1{ }^{\circ} \mathrm{C}$ increase in annual average temperature would reduce national grain output by $1.45 \%$ (1.74\% reduction in North China and 1.19\% reduction in South China), while an increase in total annual precipitation of around $100 \mathrm{~mm}$ would increase national grain output by $1.31 \%$ (3.0\% increase in North China and $0.59 \%$ reduction in South China).

(5) Increases in the use of fertilizer and irrigation would, in both North and South China, lead to yield improvements.

To sum up, the projected increases in temperatures and precipitation levels would have both positive and negative effects on China. Hence, the overall impact of climate change will depend strongly on the exact developments of temperature and precipitation over time. However, particularly due to the negative effects of increasing annual average temperatures on mean yields in both North and South China, a negative net effect is possible. After climate influences are accounted for, increases in the application of fertilizer and use of irrigation emerge as possible options to further increase mean yields and hence output in Chinese grain farming, though the associated risk effects should not be neglected.

\subsubsection{Study III: Total Factor Productivity and Technical Efficiency in Chinese Inland Aquaculture}

The Chinese inland aquaculture sector has grown substantially over the past decades. While it is clear that part of the massive growth in output is due to increases in the use of regular input factors, the development of total factor productivity (TFP) and its components, especially of technology and technical efficiency, has so far received little attention. Stochastic frontier analysis (SFA) is employed in the present study to estimate TFP change and its components. It moreover allows analyzing the development, geographical distribution and determinants of technical efficiency. Regarding the determinants of technical efficiency it is of particular interest in the present study whether the capacity of the extension system or climate variables affect the level of technical efficiency. For these analyses a province-level panel data set on Chinese 
inland aquaculture production between 1993 and 2009 is employed. The main results include:

(1) Technical efficiency in Chinese inland aquaculture has decreased notably between 1993 and 2009, while at the same time technical change has followed a strong positive trend. Overall, after additionally accounting for scale effects, TFP has nearly doubled over this period.

(2) After input growth has been the dominant driver of output growth in the beginning of the observation period, TFP change and changes in input use have in later years made contributions of similar magnitude, though the relative importance of the two factors varies from year to year.

(3) Technical efficiency is highest in Southeast China and decreases strongly towards the north and the west of the country.

(4) An increasing number of aquaculture technical extension staff per unit of labor in aquaculture production would have a positive marginal effect on technical efficiency, whereas increasing annual average temperatures would have a negative effect at the margin.

In summary, technical change has been the driver behind the substantial TFP growth between 1993 and 2009 and has thus become an increasingly important source of output growth. The decreasing degree to which aquaculture producers are able to make use of the potential of the available production technology, as evidenced by the negative trend in technical efficiency, and an observed slowdown in technical change, however, require policy attention. Among the reasons for the decrease in technical efficiency, a declining capacity of the extension system to offer services to aquaculture producers emerges as a particularly important issue. The wide range of the estimated technical efficiency scores of the different provinces reveals that Chinese inland aquaculture faces region-specific challenges, which might be aggravated by the negative effects of a climate change-induced warming on technical efficiency. 


\subsection{Research Articles}

The main part of this thesis, which is contained in Sections 2 to 4 , is based on the following research articles, which also constitute the foundation for the above introduction and the concluding discussion in Section 5:

- Holst, R., \& Yu, X. (2013). Climate Change and Chinese Fresh-Water Aquaculture. Working Paper (Submitted to Environmental and Resource Economics).

- Holst, R., Yu, X., \& Grün, C. (2013). Climate Change, Risk and Grain Yields in China. Journal of Integrative Agriculture 12(7) , 1279-1291.

- Holst, R., \& Yu, X. (2013). Total Factor Productivity and Technical Efficiency in Chinese Inland Aquaculture. Working Paper. 


\section{Climate Change and Risk in Chinese Inland Aquaculture}

\subsection{Introduction}

Fishery contributes on average about $20 \%$ of the animal protein consumed in developing countries. In extreme cases, like in Small Island Developing States (SIDS) or remote coastal areas, this figure can even reach up to $90 \%$ (FAO, 2005b). After having experienced several decades of substantial growth rates, China now is the world leader in terms of fish output. It produced about $35 \%$ of the global fish output in 2010. Aquaculture output in particular even amounted to 36.7 million tons in 2010, which corresponded to 61.4 percent of the world's aquaculture output (FAO, 2012). Around $60 \%$ of China's aquaculture output in turn is attributable to inland aquaculture ${ }^{5}$.

Figure 1: Fishery output in China

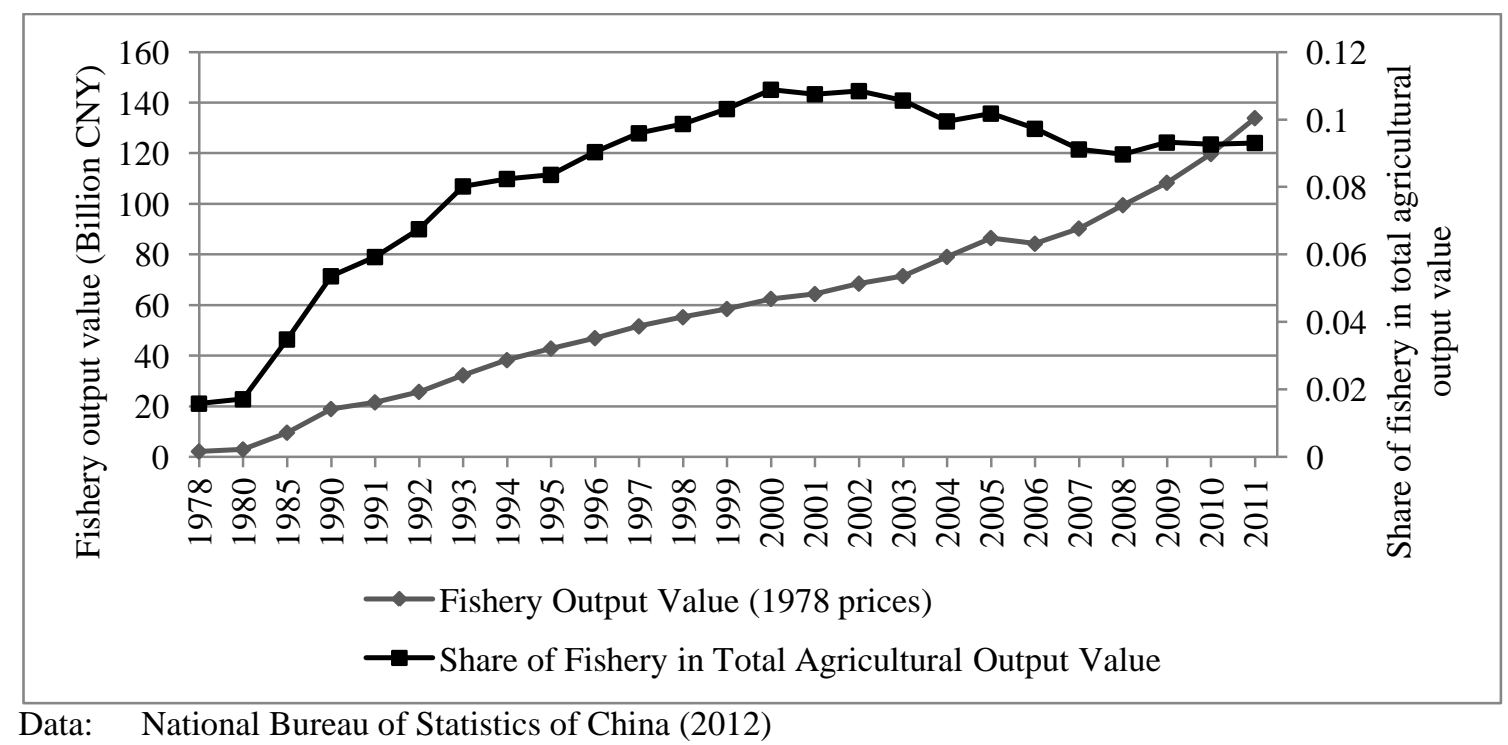

The fishery industry in general, and aquaculture in particular, play important roles in China. As shown in Figure 1, the value of Chinese fishery output has substantially risen from CNY 2.2 billion in 1978 to CNY 133.9 billion in 2011, which represents a nearly 61-fold increase. Moreover, it emerges that after the share of fishery in the total agricultural output value at first increased quickly from only $1.6 \%$ in 1978 to about

\footnotetext{
${ }^{5}$ According to the Chinese Ministry of Agriculture (2010), China produced 14.1 million tons of salt-water aquaculture products and 22.2 million tons of fresh-water aquaculture products in 2009.
} 
$10.9 \%$ in 2000 , it has since then been shrinking slightly but remains above $9 \%$. Aquatic products play an important role in the diet of the Chinese people. Studies show that the expenditures on this food category amount to about $3 \%$ and $10 \%$ of the total expenditures on food in rural and urban areas, respectively (Liao and Chern, 2007; Yu and Abler, 2009). Due to its substantial share in overall fishery output, inland aquaculture makes important contributions to satisfying the domestic demand for aquatic products.

Aquaculture operations, however, are very sensitive to climate conditions (FAO, 2012). In the current literature on the likely impacts of climate change, both positive and negative influences on aquaculture have been discussed, which can mostly be attributed either directly or indirectly to changes in temperature or precipitation (Brander, 2007; Ficke et al., 2007; De Silva and Soto, 2009). The fact that both positive and negative impacts on aquaculture are possible raises the question as to which influence on aquaculture production will be dominant at which time. It is well known that most agricultural production processes can only be conducted within certain ranges of climatic conditions and that the relationship between yields and temperatures is often non-linear (Quiggin and Horowitz, 1999; Schlenker and Roberts, 2009). Similarly, the relationship between the species-specific growth rates of fish and the water temperature is usually found to be non-linear, with fish growth initially increasing with temperature from a lower critical temperature up to the so-called pejus temperature, after which further increases in temperature result in decreasing growth rates (Pörtner and Knust, 2007; Neuheimer et al., 2011).

Moreover, it is important to note that in addition to their impacts on expected output (i.e. mean output), many climate factors are also likely to affect the variance of output (i.e. output risk) in aquaculture production. Brander (2007) discusses various effects of climate change that are relevant in this respect, including potential heat stress, uncertainties in water availability, extreme temperature or precipitation events, and a higher disease risk. All of these effects could increase the frequency and severity of unexpected output losses. The notion that climate-related factors, such as changes in water temperatures, are likely to have an impact on output risks in aquaculture production is also supported by Asche and Tveterås (1999), Tveterås (1999), and Tveterås and Wan (2000). So far, however, the results of most climate impact studies only apply to the effects on mean output (e.g. Neuheimer et al., 2011). 
Of course, climate factors represent an external influence on aquaculture production that should not be analyzed in isolation. It is of crucial importance to simultaneously consider the different influences of the use of regular input factors on the production process. Specifically, it is known that the applied quantities of regular input factors are not only determinants of mean output but are also relevant for the level of output risk inherent in an agricultural production process (Just and Pope, 1979; Kumbhakar and Tsionas, 2008; Holst et al., 2013). With respect to aquaculture, Asche and Tveterås (1999), for example, suggest that rising stocking densities might increase production risk due to an increasing oxygen consumption and waste production, whereas higher levels of labor input might decrease production risk due to improving capacities for monitoring, feeding or maintenance. Generally, different levels of input use will have implications for the intensity of aquaculture production. More intensive production due to an increasing use of a specific input factor could lead to an increasing output variance if the production process becomes more difficult, technically demanding or sensitive to external influences, which could lead to severe unexpected output losses. However, intensification might also lead to a reduction of the output variance if, for example, an increasing use of a specific input factor increases the degree of control over the production process and thereby prevents unexpected output losses.

Climatic changes have already occurred in China during the past two decades (see Figures 2 and 3) and according to the fourth assessment report of the IPCC, it is projected that East Asia could experience a median increase in annual average temperature of around $3.3^{\circ} \mathrm{C}$ until the year 2100 , along with possible increases in total annual precipitation and higher levels of climatic variability in terms of an increasing incidence of extreme weather events, which could lead to more droughts and floods (Christensen et al., 2007).

In light of the possible impacts of climate change on the mean output of aquaculture operations and on their levels of output risk, it thus is of crucial importance to determine, in which way the Chinese aquaculture sector as a whole will be affected. However, despite the aforementioned extreme importance of the country's aquaculture sector, studies on how it will be affected by climate change have been conducted only in a very limited way. In particular, the likely impacts of a changing climate on Chinese aquaculture have not yet been assessed by means of economic analyses simultaneously accounting for the influences of the regular input factors of aquaculture production. 
Figure 2: Annual average temperature (sample average)

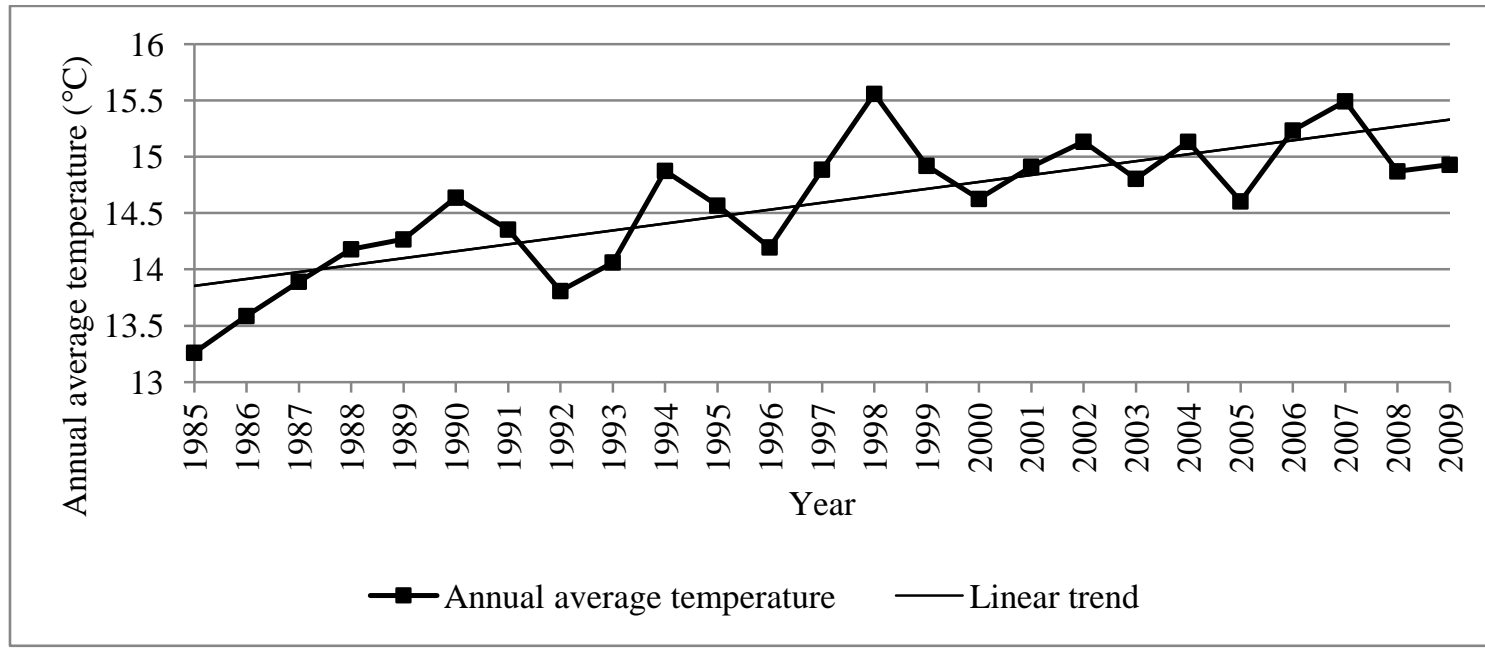

Note: Trend significant at 1\%-level, coefficient: 0.0614 , t-value: 30.71

Data: National Bureau of Statistics of China (1986-2010)

Figure 3: Total annual precipitation (sample average)

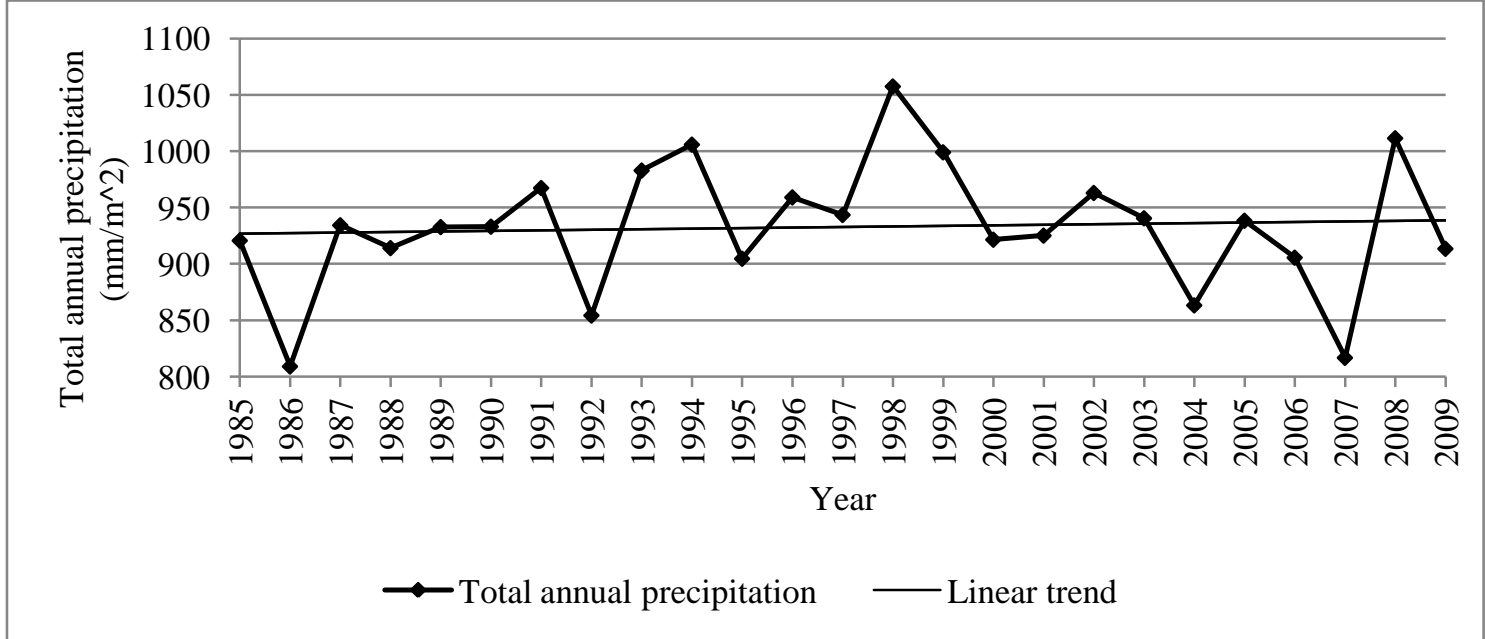

Note: Trend not significant, coefficient: 0.4845 , t-value: 1.52

Data: National Bureau of Statistics of China (1986-2010)

The present paper is intended to remedy this deficit and thereby provide new insights with respect to the question of whether Chinese aquaculture will be adversely affected by the expected changes in regional climate or whether it might become a net beneficiary. In particular, we focus on analyzing the effects on both the mean yield and the yield risk, while simultaneously taking the potentially non-linear relationship between aquaculture yields and climate into account. Furthermore, the yield responses and the changes in national output due to a $1{ }^{\circ} \mathrm{C}$ increase in annual average temperature and due to a $100 \mathrm{~mm}$ increase in total annual precipitation are calculated. 


\subsection{Empirical Analysis}

\subsubsection{Econometric Approach}

The general approach chosen in this study to estimate the effects of climate change on Chinese inland aquaculture is the production function approach (e.g. Zhang and Carter, 1997; Chen et al., 2013). It is preferred over the Ricardian approach, which represents an alternative for economic climate change impact assessments (e.g. Deschênes and Greenstone, 2007; Mendelsohn, 2009), for several reasons. First and foremost, it is the purpose of the production function approach to determine effects on output creation. Hence, by means of estimating suitable production functions, it can be employed to analyze the effects of climate change on both the mean and the variance of yield levels, which, as aforementioned, are the main concern of this study. Moreover, the production function approach is appealing as it provides a structural form and as its data requirements (production and climate data) can be satisfied in the present case.

The Ricardian approach, which aims at analyzing the effects of a changing climate on the value of agricultural land or on the profitability of farms (Mendelsohn et al., 1994), cannot be employed here, primarily because it is not intended to analyze effects on agricultural output ${ }^{6}$. The Ricardian literature, however, points to an important shortcoming of the production function approach, which the Ricardian approach itself is intended to avoid, namely the former's inability to take the adaption measures of producers in response to climatic changes into account, which could lead to biased estimation, for example by overestimating adverse climate effects (Mendelsohn et al., 1994; Deschênes and Greenstone, 2007).

In order to gain at least some flexibility with respect to adaption measures, we conduct yield regressions with aggregate aquaculture yield as dependent variable. This has the advantage that adaption measures, which involve changes in the output composition, are implicitly captured. Aquaculture operators could, for example, choose to raise other species, which are more suitable for the new climatic conditions. In as far as not all possible adaption measures are taken into account by this approach, the resulting climate impact estimates will still be conservative because they might either slightly understate climate-induced benefits or slightly overstate climate-induced damages. Such

\footnotetext{
${ }^{6}$ In addition, China possesses neither a functioning free market for agricultural land nor for water resources, so that all methods analyzing variables such as land value, be it of regular farm land or of water areas, are inherently problematic.
} 
prudence, however, seems appropriate given the importance of Chinese aquaculture for the country's food supply.

In choosing panel regressions incorporating non-linear climate impacts to analyze yields, our approach is similar to that of Schlenker and Roberts (2006). However, by embedding our climate impact analysis in a production function framework and by additionally analyzing output risks, we depart from it. Furthermore, we consider annual average temperatures instead of whole temperature distributions.

\subsubsection{Model}

Drawing on Zhang and Carter (1997), Schlenker and Roberts (2006), Tian and Yu (2012) and Chen et al. (2013), a panel data production function incorporating non-linear climate effects can be employed to model the effects of climatic changes on the yield level without neglecting the contributions of the regular input factors:

$$
\begin{gathered}
\ln y_{i t}=A_{i}+\alpha_{w} \ln w_{i t}+\alpha_{n} \ln n_{i t}+\alpha_{s} \ln s_{i t}+\alpha_{b} \ln b_{i t}+\alpha_{a} a_{i t}+\alpha_{a 2} a_{i t}^{2} \\
+\alpha_{p} p_{i t}+\alpha_{p 2} p_{i t}^{2}+\epsilon_{i t} .
\end{gathered}
$$

Here, $y_{i t}$ is the aquaculture yield in province $i$ in year $t, A_{i}$ captures province fixed effects, and $w, n, s$ and $b$ are the water area, labor per water area, stocking density and capacity of boats per water area, respectively. $\alpha_{w}, \alpha_{n}, \alpha_{s}$ and $\alpha_{b}$ can be interpreted as the elasticities of yield with respect to the corresponding regular inputs. In order to capture the possibly non-linear relationship between climate change and aquaculture yields, we include both the first-order and the second-order terms of annual average air temperature $^{7}(a)$ and total annual precipitation $(p) . \alpha_{a}, \alpha_{a 2}, \alpha_{p}$ and $\alpha_{p 2}$ are the corresponding coefficients. Similar approaches to capturing non-linear relationships have also been chosen in other studies (Schlenker \& Roberts 2009; Horowitz 2009). However, the non-linear relationships are tested in our econometric models. The error term $\epsilon_{i t}$ follows a normal distribution and represents the stochastic component of the model.

As aforementioned, inputs do not only determine the expected output, but also affect the variance of output. In a production function with a cross-sectional or a panel data

\footnotetext{
${ }^{7}$ Note that the climate factors are introduced in non-logarithmic form due to the possibility of negative temperatures.
} 
structure, production risk takes the form of deviations of the observed output levels of the different sample units from their predicted output levels.

Figure 4 illustrates the relationship between an input $x$ and output $y$ in the presence of output risk. Two sample units are assumed: $A$ and $B$. At the initial point, given an input level of $x_{0}$, the predicted output is $y_{0}$, but the observed output levels of the two units are $A_{0}$ and $B_{0}$, respectively. The risk level in that situation can be measured as the average distance between observed and predicted output $\left(\left(\overline{A_{0} y_{0}}+\overline{B_{0} y_{0}}\right) / 2\right)$. As shown in Figure 4, an increasing input use will usually result in an increase in expected output $y$. The associated change in risk, however, is not predetermined. Risk could either increase (as shown for the case $x_{0} \rightarrow x_{1}$ ), decrease (as shown for the case $x_{0} \rightarrow x_{2}$ ) or remain constant.

\section{Figure 4: Input use and production risk}

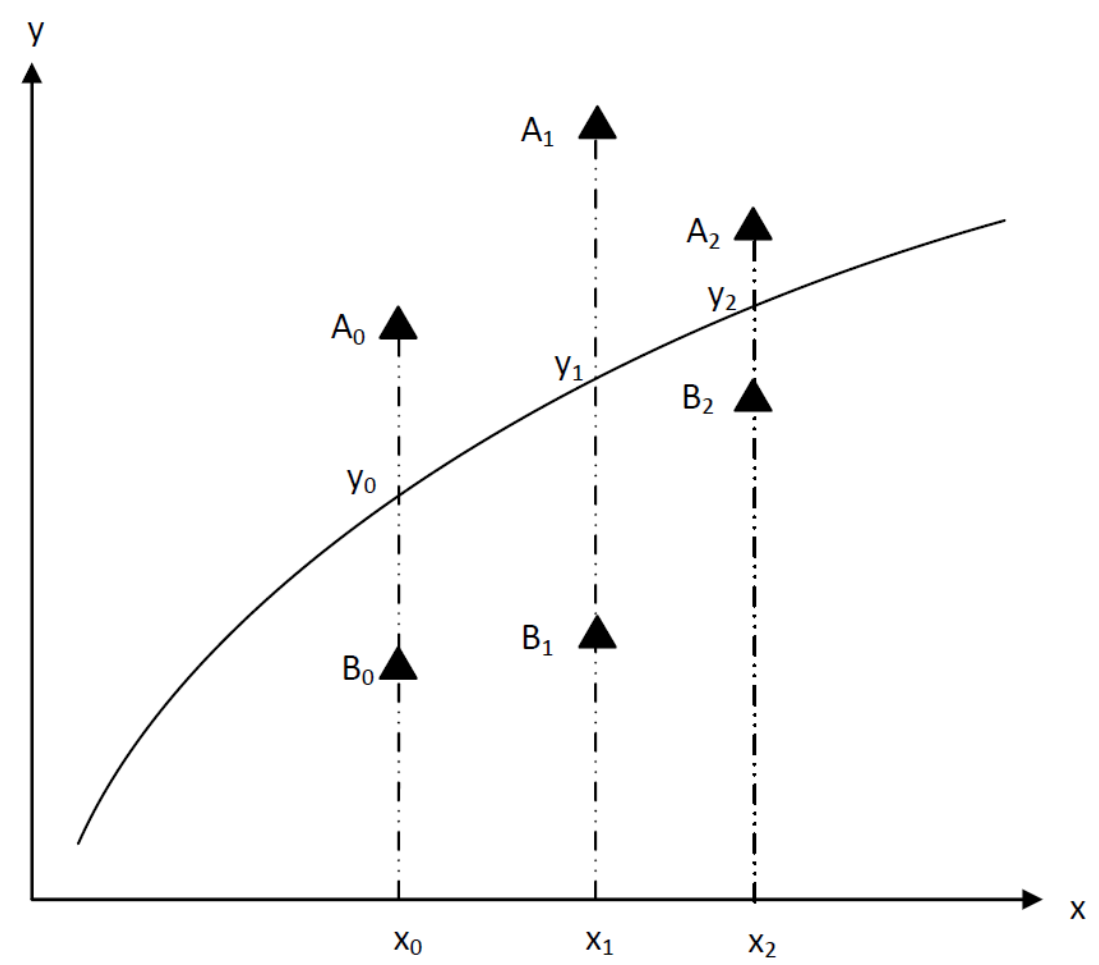

Just and Pope (1978), however, observed that many of the commonly used production function specifications, in particular those like Eq. (1), which feature log-linear error terms, are inappropriate for analyzing risks. According to Just and Pope (1978), this is due to the fact that these specifications do not allow input factors to affect output risk independently of their marginal effects on mean output (i.e. predicted output) (see Appendix 1 for further details). In terms of Figure 4, they are only capable of modeling 
the case of a change from $x_{0}$ to $x_{1}$, but not the case of a change from $x_{0}$ to $x_{2}$. This is a strong and unrealistic constraint, especially given that a review of the current literature shows that an increasing use of certain inputs results in decreasing levels of output risk (Just and Pope, 1979; Kumbhakar and Tsionas, 2008; Holst et al., 2013).

In order to overcome this unrealistic constraint, Just and Pope $(1978,1979)$ proposed a more flexible production function specification (henceforth J-P function). Adjusted to the panel data context of the present study it takes the following form:

$y_{i t}=f\left(X_{i t}\right)+\left(\sqrt{h\left(R_{i t}\right)}\right) \varepsilon_{i t}$,

where

$$
\begin{aligned}
f\left(X_{i t}\right)=\exp [ & A_{i}+\alpha_{w} \ln w_{i t}+\alpha_{n} \ln n_{i t}+\alpha_{s} \ln s_{i t}+\alpha_{b} \ln b_{i t}+\alpha_{a} a_{i t}+\alpha_{a 2} a_{i t}^{2} \\
& \left.+\alpha_{p} p_{i t}+\alpha_{p 2} p_{i t}^{2}\right]
\end{aligned}
$$

and

$h\left(R_{i t}\right)=B_{i}+\beta_{w} \ln w_{i t}+\beta_{n} \ln n_{i t}+\beta_{s} \ln s_{i t}+\beta_{b} \ln b_{i t}+\beta_{a} a_{i t}+\beta_{p} p_{i t}$.

The aquaculture yield in Eq. (2) now depends on two separate functions $f(\cdot)$ and $h(\cdot)$. These functions in turn depend on the vectors of independent variables $X_{i t}$ and $R_{i t}$, respectively, which draw on the set of variables introduced for Eq. (1). The fact that $\varepsilon_{i t}$ is a stochastic error term with a standard normal distribution results in an important property of this specification: The expected value of the yield, or in other words the mean yield, is not determined by the same function that determines the yield variance (i.e. the yield risk) (see Eq. (5)-(6)).

$E\left(y_{i t}\right)=f\left(X_{i t}\right)$

$V\left(y_{i t}\right)=h\left(R_{i t}\right)$

$f(\cdot)$ and $h(\cdot)$ will thus be termed mean yield function and yield risk function in the remainder of this paper. Most importantly, in as far as both functions feature unconstrained parameters, the signs of the marginal contributions to mean yield and to yield risk will be independent (Just and Pope, 1979). Hence, this specification allows us 
to analyze the determinants of both mean yield and yield risk free of the above constraint.

\subsubsection{Estimation}

For the purpose of comparison and in order to conduct a robustness check, we estimate both the standard production function (Eq. (1)) and the J-P function (Eq. (2)-(4)), even though the two models are not directly comparable due to their different error structures (Just and Pope, 1978).

In order to correct for the heteroskedasticity and serial correlation, which we detect in the estimation of Eq. (1) ${ }^{8}$, we resort to an FGLS (feasible generalized least squares) estimator to estimate the standard production function (Wooldridge, 2002).

Just and Pope (1979) proposed a three-stage procedure, which allows for consistent estimation of the J-P function specified in Eq. (2)-(4). We adopt this procedure in the present study in order to obtain estimates of both the mean yield function and the yield risk function. On the first stage, we estimate Eq. (3) using the method of non-linear least squares (NLS). On the second stage, a fixed effects panel regression of Eq. (4) is conducted in order to determine the marginal contributions to the yield variance (i.e. the yield risk) ${ }^{9}$. On the third stage, we use the estimates from the second stage as weights to re-estimate Eq. (3) as a generalized non-linear least squares (GNLS) model. Due to the climatic and structural heterogeneity of the Chinese provinces, it is necessary to consider province fixed effects on all stages of the estimation procedure, which represents a deviation from Just and Pope's (1979) original procedure.

\subsubsection{Quantification of the Impact of Climate Change}

After estimating the flexible J-P yield function, it is possible to use the coefficients of the climate variables from the mean yield function to quantify the impact of a given marginal change in a climate factor on the expected yield level. The result will likely hold important implications for food security in China.

\footnotetext{
${ }^{8}$ Breusch-Pagan test statistic: chi2(32)=404.96 (p-value $<1 \%$ ). The test has been conducted based on an OLS estimation of Eq. (1) including province dummies.

${ }^{9}$ The dependent variable on the second stage is calculated from the residuals of the first stage. 
However, according to Eq. (A.6) in Appendix 1, it is another drawback of many ordinary log-linear production functions, such as Eq. (1), that they do not allow to calculate the true expected marginal effects of changes in the independent variables due to a different error structure. The J-P method in turn can fulfill this task.

As an example, drawing on Eq. (2) and (3) and on the fact that the climate variables appear in the regression equations in non-logarithmic form, the change in the mean yield level of an individual province caused by a change in the annual average air temperature of that province can be calculated as follows:

$\Delta y_{i t a}=\frac{\partial E\left(y_{i t}\right)}{\partial a_{i t}}=\frac{\partial f\left(X_{i t}\right)}{\partial a_{i t}}=\left(\alpha_{a 1}+2 \alpha_{a 2} a_{i t}\right) f\left(X_{i t}\right)$

where $\Delta y_{i t a}$ represents the quantity by which the mean yield of province $i$ in year $t$ increases or decreases, following a marginal change in its annual average air temperature $\left(a_{i t}\right) . \alpha_{a 1}$ and $\alpha_{a 2}$ are the coefficients of the first-order and the secondorder term of the annual average air temperature, respectively.

If we have to statistically reject the assumed non-linear impact on the mean yield, this implies that $\alpha_{a 2}=0$. In that case, Eq. (7) reduces to

$\Delta y_{i t a}=\alpha_{a 1} f\left(X_{i t}\right)$

Given the different provincial $\Delta y_{i t a}$ and information on the water area used for inland aquaculture in each province, it is then possible to obtain the corresponding change in total national output as the sum of the provincial changes in output. The effects of a marginal change in total annual precipitation can be calculated analogously.

\subsection{Data}

For the purpose of the above analyses, a panel data set comprising the relevant aquaculture production and climate data of 24 Chinese provinces ${ }^{10}$, which covers the

\footnotetext{
${ }^{10}$ Province-level municipalities (Beijing, Chongqing, Shanghai, Tianjin), special administrative regions (Hong Kong, Macau) and the Tibet Autonomous Region have not been considered due to their special economic structures. The provinces Ningxia and Qinghai could not be considered due to data availability issues.
} 
time period 1993-2009, has been constructed. In particular, the provincial aquaculture production data provide information on the aggregate aquaculture output, the total weight of fry used for production, the capacity of fishery boats, the number of laborers as well as the size of the area under aquaculture. The climate data in turn include monthly observations of air temperatures and precipitation quantities. All data in this study are taken from the respective issues of the China Statistical Yearbook (National Bureau of Statistics of China, 1994-2010) and the Chinese Fishery Yearbook (Chinese Ministry of Agriculture, 1994-2010). Table 1 provides the exact units of measurement and shows the development of each variable over time.

Table 1: National inland aquaculture production and climate data

\begin{tabular}{r|rrrrrrr}
\hline Year & $\begin{array}{r}\text { Aggregate } \\
\text { output }\end{array}$ & $\begin{array}{r}\text { Water } \\
\text { area }\end{array}$ & Fry & Labor & Boats & $\begin{array}{r}\text { Annual avg. } \\
\text { temp. }\end{array}$ & $\begin{array}{r}\text { Tot. annual } \\
\text { precip. }\end{array}$ \\
& (tons) & (1000 ha) & (tons) & (number) & (tons) & $\left({ }^{\circ} \mathbf{C}\right)$ & $\left(\mathbf{m m}^{\mathbf{2}}\right)$ \\
\hline $\mathbf{1 9 9 3}$ & $6,211,184$ & 4,067 & $1,067,721$ & $1,754,882$ & 149,193 & 14.06 & 982.96 \\
$\mathbf{1 9 9 4}$ & $7,592,043$ & 4,353 & $1,271,190$ & $2,250,352$ & 163,522 & 14.88 & $1,005.98$ \\
$\mathbf{1 9 9 5}$ & $9,073,397$ & 4,573 & $1,369,860$ & $2,422,396$ & 175,640 & 14.57 & 904.73 \\
$\mathbf{1 9 9 6}$ & $10,648,373$ & 4,757 & $1,578,267$ & $2,707,096$ & 178,620 & 14.20 & 959.13 \\
$\mathbf{1 9 9 7}$ & $11,843,647$ & 4,798 & $1,790,723$ & $2,656,995$ & 206,120 & 14.89 & 943.56 \\
$\mathbf{1 9 9 8}$ & $12,648,355$ & 4,921 & $2,071,004$ & $2,746,435$ & 214,535 & 15.56 & $1,057.54$ \\
$\mathbf{1 9 9 9}$ & $13,608,709$ & 5,034 & $2,157,301$ & $2,839,356$ & 207,683 & 14.92 & 999.15 \\
$\mathbf{2 0 0 0}$ & $14,521,729$ & 5,109 & $2,425,157$ & $2,935,284$ & 193,852 & 14.63 & 921.63 \\
$\mathbf{2 0 0 1}$ & $15,256,300$ & 5,177 & $2,189,673$ & $3,039,418$ & 193,814 & 14.91 & 925.21 \\
$\mathbf{2 0 0 2}$ & $16,195,337$ & 5,286 & $2,622,511$ & $3,138,462$ & 175,676 & 15.13 & 963.08 \\
$\mathbf{2 0 0 3}$ & $16,952,858$ & 5,385 & $2,534,558$ & $3,336,385$ & 195,260 & 14.80 & 940.59 \\
$\mathbf{2 0 0 4}$ & $18,119,238$ & 5,477 & $3,082,515$ & $3,488,849$ & 182,394 & 15.13 & 863.33 \\
$\mathbf{2 0 0 5}$ & $19,245,516$ & 5,615 & $2,964,569$ & $3,481,126$ & 193,727 & 14.60 & 938.43 \\
$\mathbf{2 0 0 6}$ & $20,668,110$ & 5,790 & $3,314,401$ & $3,499,803$ & 230,659 & 15.23 & 905.64 \\
$\mathbf{2 0 0 7}$ & $18,990,442$ & 4,290 & $3,210,928$ & $3,902,571$ & 254,552 & 15.49 & 816.82 \\
$\mathbf{2 0 0 8}$ & $20,000,590$ & 4,819 & $2,889,664$ & $3,997,096$ & 302,185 & 14.87 & $1,011.60$ \\
$\mathbf{2 0 0 9}$ & $21,403,514$ & 5,235 & $3,063,225$ & $3,915,150$ & 354,336 & 14.93 & 913.55 \\
\hline
\end{tabular}

Note on labor in 1993: The observations for 6 out 24 provinces are missing or obviously incorrect and have therefore been excluded. Hence, this aggregate figure is not directly comparable to those of the other years.

Data:

Chinese Ministry of Agriculture (1994-2010); National Bureau of Statistics of China (1994-2010)

While the available data on output, fry and area are already specific to inland aquaculture, the data on labor and boats have to be adjusted. In order to obtain the total capacity, measured in terms of aggregate tonnage, of all boats used for the purpose of inland aquaculture, the total capacity of boats in ocean fishery has in a first step been 
subtracted from the total capacity of all fishing boats in China, leaving only the total capacity of boats in inland fishery. The result has then been multiplied by the ratio of the total capacity of boats used in the course of fish farming to the total capacity of fishing boats in China ${ }^{11}$. Similar simplifying approaches to adjusting input data have also been used in other studies on agricultural production, such as those of Lin (1992) and Zhang and Carter (1997).

So as to determine the number of laborers active in the coastal provinces' inland fish farming sectors, the number of laborers in marine fish farming has been subtracted from the total number of laborers in the fish farming sectors of the respective provinces. For the inland provinces, the required labor data were directly available.

The province-level temperature data stem from surface air temperature measurements taken in or around the capital cities of the respective provinces in our data set and were obtained using sheltered thermometers positioned 1.5 meters above ground. The monthly temperature observations represent the averages of the daily average temperatures in the respective months (National Bureau of Statistics of China, 2010). A similar choice of temperature data has been made by Horowitz (2009) who uses the temperatures in capital cities as proxies for the average temperatures of the corresponding countries in a cross-country study aimed at analyzing the impact of climate changes on economic growth.

At this point it should be noted that temperature measurements taken in the vicinity of cities are possibly biased upwards due to the urban heat island (UHI) effect. However, with respect to this study we have reason to assume that the UHI effect does not significantly bias the results. First, since we use province-level temperature observations, our temperature data capture differential warming trends across provinces, including those caused by regionally varying UHI effects. Second, Li et al. (2004) find only very small differences between the warming per decade measured by weather stations obviously affected by the UHI effect and the warming measured by stations not likely to be affected. Thus, over the period of less than two decades considered in this study, the UHI effect can be considered to be a nearly time-invariant province-specific

\footnotetext{
${ }^{11}$ As data on the total capacity of boats in fish farming were only available for the years from 2003 through 2007, it has been decided to use the average ratio of the total capacity of boats in fish farming to the total capacity of fishing boats in China over those five years for the above data adjustment.

By using the capacity of boats instead of their number as an input, we take into account that the boats used in fish farming to service cages in rivers or lakes or to harvest fish are usually much smaller than their counterparts used for catching wild fish. We furthermore assume that this variable can also at least partially capture the use of general production capital in aquaculture.
} 
increment on the true annual average temperatures. Third, there is no reason to believe that aquaculture production sites in individual provinces are generally located closer to cities than those in other provinces, especially since we excluded province-level municipalities from the data. Under these assumptions, fixed effects or province dummies should partly capture the UHI effect. Nevertheless, the inclusion of a secondorder temperature variable implies that the UHI effect may bias the temperature coefficient. This, however, does not affect the marginal effect of changes in temperature on aquaculture yields (proof: see Appendix 2).

In addition, the question arises whether the air temperature can be employed as explanatory variable in the present study instead of the water temperature, which is known to be a crucial determinant of aquaculture yields but which is not available in the data. Boyd and Tucker (1998) provide an answer to this question by pointing out that the temperature of water from surface sources is determined by local (i.e. air) temperatures. Hence, the air temperature variables in the present study can be assumed to correctly capture the effects of the water temperature on aquaculture production.

Precipitation is intended to serve as a proxy for water availability in general, which is essential for the viability and productivity of aquaculture operations. This approach seems justified because, as noted by Yoo and Boyd (1993), precipitation is the original source of all pond water.

In addition to the possible measurement errors with respect to temperature caused by the UHI effect or by the residual differences between air and water temperatures, some measurement errors may also exist regarding other variables due to the fact that we use highly aggregated data. For linear econometric models, instrumental variable estimation is often proposed to tackle this problem. However, due to the non-linear nature of the J-P method, it is impossible to identify the errors in the model given the limited information available (Chen et al., 2011).

\subsection{Results}

\subsubsection{Model Comparison}

Table 2 contains the estimation results of an FGLS model (Model I) and of the mean yield functions (Models IIa and IIIa) and the yield risk functions (Models IIb and IIIb) 
of two different non-linear J-P models. Model I is specified according to Eq. (1), whereas Models II and III are specified according to Eq. (2)-(4). Note, however, that, as aforementioned, the FGLS model (Model I) is reported only for reasons of comparison of the two approaches and in order to conduct a robustness check. The results of Model I are not directly comparable to those of Models IIa and IIIa due to the different model structures (see Eq. (A.3) in Appendix 1), even though all three models provide estimates of the mean yield. According to Models IIb and IIIb, the regular inputs and the temperature play statistically significant roles in the risk function. This implies that these factors do not only affect the mean yield of aquaculture production, but also have an impact on the yield variance (i.e. the yield risk). Hence, the J-P model is superior to the FGLS model in this study as it allows to analyze the driving factors behind yield risk. Especially, it thereby provides important additional insights regarding the influences of climate factors on aquaculture production in $\mathrm{China}^{12}$.

Models II and III differ in the set of climate variables included in their mean yield functions (Models IIa and IIIa). Model IIa considers the full set of climate variables (i.e. the first-order and second-order terms of both annual average temperature and total annual precipitation), whereas Model IIIa considers only a reduced set of climate variables, from which the second-order term of total annual precipitation has been excluded. It is important to note that the results of Model II indicate no statistically significant influences of the precipitation variables, despite the fact that a Wald test rejects the null-hypothesis of joint insignificance of the precipitation variables in the mean yield function ${ }^{13}$ (Model IIa). This implies that Model II might be incorrectly specified, possibly as a result of the inclusion of a second-order precipitation variable.

The results of Model III, which does not include this variable, show that the first-order term of precipitation has a statistically highly significant effect on the mean yield. Because of this clearer identification of climate influences, Model III becomes our preferred specification. Note, however, that all other results, except for the marginal effect of labor in the yield risk functions (Models IIb and IIIb), remain virtually unchanged.

\footnotetext{
${ }^{12}$ Moreover, the temperature estimates of the FGLS model turn out to be unreasonable because the positive coefficient of the first-order term of the annual average temperature and the positive coefficient of the second-order temperature term together imply that the overall response of inland aquaculture yields in China towards increasing temperatures is positive and exponential over the entire range of positive annual average temperatures. This finding is not supported by the current literature, in which the marginal effect of temperatures on fish growth is found to not only follow a non-linear relationship but to become negative after the pejus temperature has been reached (Pörtner and Knust, 2007; Neuheimer et al., 2011).

${ }^{13}$ Test statistic: $F(2,369)=6.20 ;$ Prob $>F=0.0022$.
} 
Table 2: Analysis of Chinese inland aquaculture

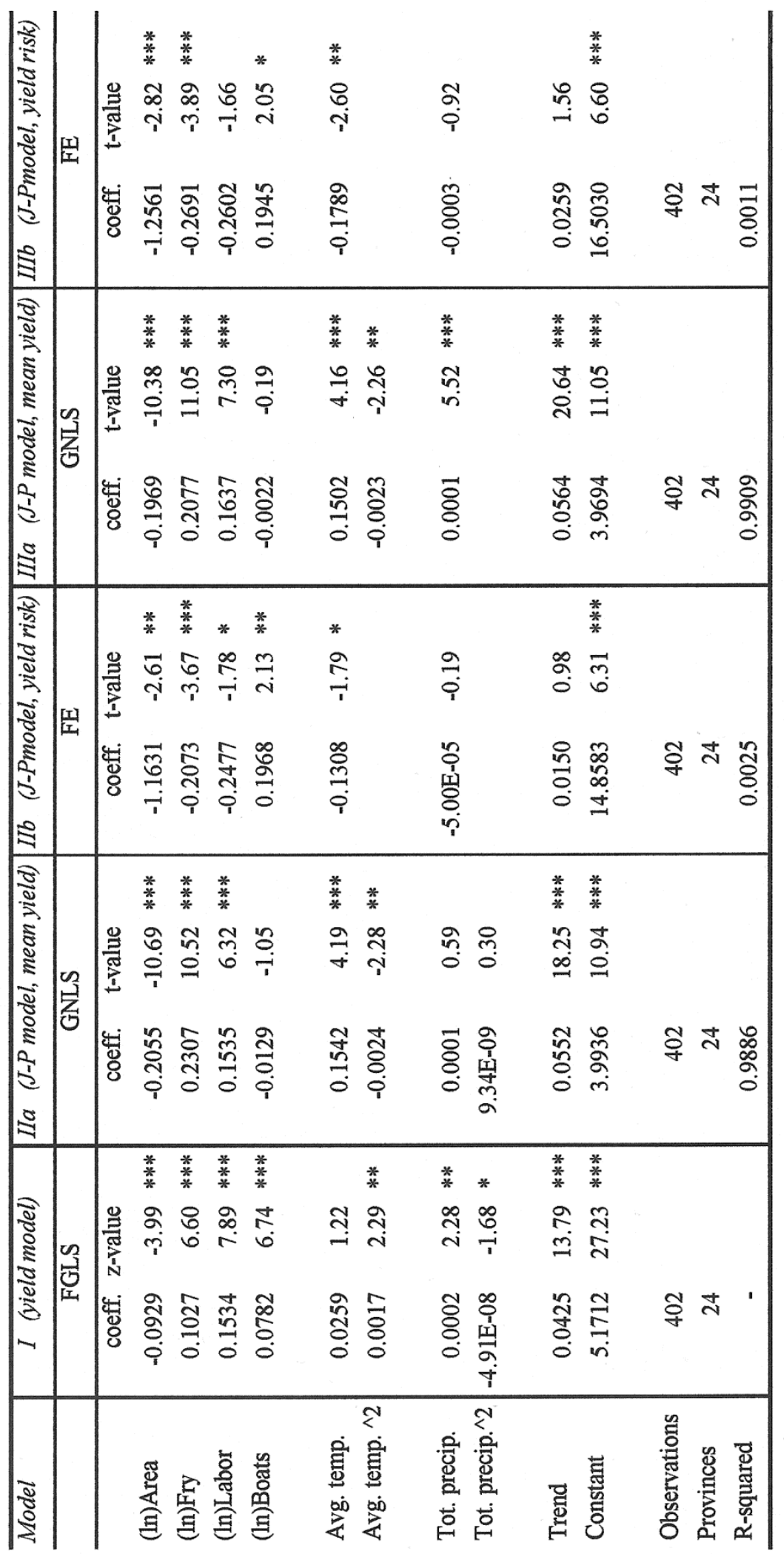

Notes:

1. * significant at $10 \%$-level; ** significant at $5 \%$-level; *** significant at $1 \%$-level

2. The R-squared in non-linear models is different from that in linear models, hence the high Rsquared values in Models IIa and IIIa are not surprising. 


\subsubsection{Mean Yield in Chinese Aquaculture}

According to the coefficient estimates from the mean yield function (Table 2, Model IIIa), the elasticities of yield with respect to fry and labor are around 0.208 and 0.164 , respectively, whereas the water area turns out to have a negative marginal effect of -0.197. This implies that, if yield improvements are to be realized, employing more fry or labor per hectare of water area would be effective measures. All three estimates are statistically significant at the $1 \%$-level. The coefficient for boats is -0.002 and statistically insignificant, which implies that the use of boats in inland fish farming has no significant impact on mean yields.

Looked at individually, all these results are reasonable. Using more labor or fry in the production process can be interpreted as an intensification of production, leading gradually away from traditional production methods with a comparatively low intensity towards high-intensity production systems, which are usually characterized by higher yield levels. Given that semi-intensive and extensive polyculture practices still account for the majority of Chinese inland aquaculture output (Weimin \& Mengqing, 2007), these results were to be expected.

The negative coefficient of the water area implies that inland aquaculture production in China turns out to be affected by negative scale effects, perhaps resulting from an increasing competition for water resources in general or from a lack of coordination among water users, which could reduce the mean yield when the water resources in a given region are, as is usually the case, limited.

Focusing now on the core issue of this paper, namely the marginal contributions of the different climate factors, it emerges that both the first-order and the second-order term of the annual average temperature are statistically highly significant. The coefficient estimates of the two terms are 0.150 and -0.002 , respectively. This clearly shows a nonlinear relationship between annual average temperatures and inland aquaculture yields in China. Similarly, non-linear effects of increasing temperatures have also been found in other current climate impact studies (Neuheimer et al., 2011; Horowitz, 2009; Schlenker and Roberts, 2009). Based on the exact coefficients, the theoretical turning point is $32.59^{\circ} \mathrm{C}$. This turning-point, however, is significantly higher than the national annual average temperature of $14.93^{\circ} \mathrm{C}$ in 2009 and also higher than the highest provincial annual average temperature in the data set, which is $25.40^{\circ} \mathrm{C}$ and which was recorded in Hainan province. Since it is not realistic to assume that annual average 
temperatures in China will reach the above turning point in the foreseeable future, we conclude that small temperature increases will lead to increasing aquaculture yields in China, even though the marginal effect will be diminishing. In other words, in terms of its mean aquaculture yield, China is likely to become a net-beneficiary of a limited regional warming, which we attribute mainly to positive effects of increasing temperatures on fish growth.

Another important result is that the level of total annual precipitation also turns out to have a positive marginal effect on mean aquaculture yields in China. The coefficient estimate of 0.0001 is highly significant. We interpret this as the beneficial effect of an increasing water availability on inland aquaculture production. Especially given that a number of regions in China today face a situation of water scarcity (Wang et al., 2009) and given the aforementioned negative scale effects in aquaculture production, which could well be related to water availability issues, it is reasonable to find that the Chinese inland aquaculture sector will benefit from the predicted increases in total annual precipitation levels.

\subsubsection{Yield Risk in Chinese Aquaculture}

The risk function of the J-P model makes it possible to estimate the marginal effects of both climate factors and regular input factors on yield risk. The results obtained by applying this procedure to Chinese inland aquaculture are presented in Table 2 (Model IIIb).

All regular input factors, except for labor, turn out to have a statistically significant marginal effect on yield risk. This not only confirms the a priori assumption that these factors indeed affect the variance of output but also implies that farmers can use changes in their input intensities to adjust their overall risk exposure.

Specifically, we find that an increasing use of water area and fry would lead to a reduction in yield risk. The corresponding coefficient estimates are -1.256 and -0.269 , respectively. The capacity of boats per hectare in turn has a positive marginal effect on the level of yield risk. It receives a coefficient estimate of 0.195 . These results are plausible, even though not completely in line with prior expectations. On the province level, a ceteris paribus increase in the water area could serve to alleviate risks stemming from overused water resources at the current production sites and could furthermore 
stabilize provincial yield levels because localized hazards like disease outbreaks would affect smaller shares of a province's aquaculture sector. Moreover, at the provincial or national level, the total area and the stocking density can be considered as indicators of the size and the development of the aquaculture industry. Hence, it can be assumed that these variables also reflect the development of the necessary infrastructure and support industry, including fry breeders as well as equipment and feed producers, which might offer some protection from yield risks. In addition, an intensification of production by means of increasing stocking densities could also result in the adoption of more managed and thus less risky production systems.

The risk-increasing marginal effect of an increasing use of boats in turn might arise because it could cause severe stress for fish and could thus disturb their growth or lead to unexpected output losses, even though more boats might be expected to increase the control of producers over the production process, which should reduce yield risks.

Moreover, the result that labor has a negative marginal effect on the level of risk involved in aquaculture production is consistent with our prior expectations. However, this effect is only marginally statistically significant.

Among the climate influences analyzed, only the first-order term of the annual average temperature turns out to have a statistically significant marginal effect on yield risk. Given a coefficient estimate of -0.179 , higher annual average temperatures would reduce yield risk to a non-negligible degree. This might be attributable to a higher resilience of fish towards environmental stresses if temperature increases move them to a more favorable position in their individual optimal temperature ranges. Especially in the northern more temperate regions of China, higher temperatures might furthermore reduce risks related to frost or, more generally, very low temperatures, which particularly threaten aquaculture production in shallow ponds early and late in the growing season.

\subsubsection{Marginal Impacts of Climate Change on Mean Yield}

As aforementioned, ordinary log-linear production functions are not suitable for calculating the true expected marginal effect of changes in the independent variables (see Eq. (A.6) in Appendix 1). However, drawing on the results of the J-P model this can be achieved. Employing Eq. (7) and the results obtained with respect to the first- 
order and the second-order term of the annual average temperature variable in the mean yield function (Table 2, Model IIIa), the impact of a $1^{\circ} \mathrm{C}$ increase in annual average temperature can be calculated. Given the required data from the last year of the data set (i.e. 2009), we calculate that the national average yield and hence the national output would increase by around $6.8 \%$. In absolute terms, this implies increases in yield and total output of around 0.28 tons $\cdot \mathrm{ha}^{-1}$ and 1.46 million tons, respectively. Since the grass carp represents one of the main fish species in Chinese aquaculture, we use its average price in 2009 of $13.895 \mathrm{CNY} \cdot \mathrm{kg}^{-1}$ (CPYEC, 2010) as an approximate price for all aquaculture output in China and thus calculate a market value of the additional output of approximately CNY 20.30 billion (about USD 2.97 billion $^{14}$ ).

Since the initial assumption of a non-linear relationship between the level precipitation and the aquaculture yield is not supported by our results, Eq. (8) is employed to calculate the marginal effects of a $100 \mathrm{~mm}$ increase in total annual precipitation. It turns out that this would raise the national average yield and the national output by approximately $1.2 \%$. In absolute terms, the yield improvement would be about 0.05 tons $\cdot \mathrm{ha}^{-1}$, whereas the total additional output would amount to about 255 thousand tons, which would have a market value of approximately CNY 3.54 billion (USD 0.52 billion).

\subsection{Conclusions}

The present study has made several novel contributions to the current literature on inland aquaculture in China. First, a newly constructed province-level panel dataset has been used to estimate the effects of climate change on aquaculture production, while simultaneously accounting for scale effects and the influences of regular input factors, including labor, fry and boats, all measured per unit of water area used for production. Second, because climate factors are likely to non-linearly affect aquaculture, both the first-order and the second-order terms of the annual average temperature and the total annual precipitation have been considered as inputs. Third, the estimation procedure proposed by Just and Pope $(1978,1979)$ has been adapted to analyze the marginal contributions of the above inputs to both the mean yield and to the level of yield risk.

\footnotetext{
${ }^{14}$ Exchange rate in 2009 (annual average) according to the People's Bank of China: 0.14639 USD.CNY ${ }^{-1}$ (http://www.pbc.gov.cn/publish/english/1141/index.html). 
Fourth, the yield responses and changes in national output due to a $1{ }^{\circ} \mathrm{C}$ increase in annual average temperature and a $100 \mathrm{~mm}$ increase in total annual precipitation have been determined.

Regarding the regular input factors, we find that, before a background of changing climatic conditions, an increasing use of fry and labor per hectare under aquaculture would have a positive and statistically significant impact on mean yield at the margin. Consequently, Chinese aquaculture could benefit substantially from an intensification of production and the concomitant development of the sector away from traditional lowintensity production methods. Judged by the output elasticities, increasing the stocking density (i.e. the number of fry per hectare) would have the greatest potential for increasing yields. However, in the longer term ever-increasing stocking densities might lead to aggravating problems with respect to water quality or disease transmission. Hence, striking the right balance between intensification and sustainability will be important for the future development of China's inland aquaculture sector.

Since aquaculture production is generally very sensitive and since it plays an important role for assuring food security in China, the decision on the best development path should also take the contributions of each input factor to yield risk into account. Importantly, according to our results, an intensification of production by means of increasing the stocking density, and possibly by employing more labor, would decrease yield risk at the margin, which lends additional support to this strategy. Increasing the scale of production (in terms of the water area) would also reduce yield risk. However, given the negative impact of scale expansions on the mean yield and the limited availability of suitable inland waters, the advisability of this approach is much more uncertain.

At the core of our analysis has been the question of how Chinese aquaculture yields will react to changes in climate conditions. Drawing on our results, we can confirm the hypothesis that the relationship between temperature and aquaculture yields is nonlinear. Specifically, limited increases in temperature will increase aquaculture yields in China, but at a decreasing marginal rate. Furthermore, it turns out that at present increasing annual average temperatures are associated with a marginal decrease in yield risk, implying less volatile future output quantities. Given that, in addition to the temperature effect, the level of total annual precipitation is also characterized by a positive marginal effect on mean yields, it can be concluded that, in the short run, 
China's aquaculture sector is likely to become a net beneficiary of the predicted increases in both average temperatures and total precipitation levels.

Regarding output responses to climatic changes, it has been calculated that a $1{ }^{\circ} \mathrm{C}$ increase in annual average temperature would, aggregated to the national level, lead to an increase in total output of around 1.46 million tons, which would have a market value of around USD 2.97 billion. A $100 \mathrm{~mm}$ increase in total annual precipitation would be associated with around 255 thousand tons of additional output, which would have a value of around USD 0.52 billion. 


\subsection{Appendix}

\subsubsection{Appendix 1}

If production risks are present, most commonly used production functions have two major drawbacks:

Following Just and Pope (1979) and using Eq. (3), we can rewrite Eq. (1) as

$y_{i t}=f\left(X_{i t}\right) \cdot \exp \left(\epsilon_{i t}\right)$,

where $\exp$ refers to the exponential function. Drawing on Eq. (A.1), the output variance $V\left(y_{i t}\right)$ (i.e. the output risk) takes the form

$V\left(y_{i t}\right)=f^{2}\left(X_{i t}\right) \cdot V\left[\exp \left(\epsilon_{i t}\right)\right]$

The marginal effect of a change in an input variable (e.g. $w_{i t}$ ) on the output variance then is

$\frac{\partial V\left(y_{i t}\right)}{\partial w_{i t}}=2 f\left(X_{i t}\right) \cdot \frac{\partial f\left(X_{i t}\right)}{\partial w_{i t}} \cdot V\left[\exp \left(\epsilon_{i t}\right)\right]>0$

for $f\left(X_{i t}\right)>0, \frac{\partial f\left(X_{i t}\right)}{\partial w_{i t}}>0$ and $V\left[\exp \left(\epsilon_{i t}\right)\right]>0$ (i.e. for well-behaved production functions).

In addition, if we want to obtain the marginal effect of a change in an input variable on mean output $E\left(y_{i t}\right)$ (i.e. on the expected value of output) from

$E\left(y_{i t}\right)=f\left(X_{i t}\right) \cdot E\left[\exp \left(\epsilon_{i t}\right)\right]$,

we get

$\frac{\partial E\left(y_{i t}\right)}{\partial w_{i t}}=\frac{\partial f\left(X_{i t}\right)}{\partial w_{i t}} \cdot E\left[\exp \left(\epsilon_{i t}\right)\right]$,

which indicates that 
$\frac{\partial E\left(y_{i t}\right)}{\partial w_{i t}} \neq \frac{\partial f\left(X_{i t}\right)}{\partial w_{i t}}$

for $E\left[\exp \left(\epsilon_{i t}\right)\right] \neq 1$. Note that $E[\exp (\epsilon)] \neq \exp [E(\epsilon)]$. For example, for the special case of $\epsilon \sim \mathcal{N}(0,1), E[\exp (\epsilon)]=\sqrt{e} \approx 1.64872$, where $e$ denotes Euler's number. 


\subsubsection{Appendix 2}

If a UHI Effect is present in the temperature data and takes the form of a constant province-specific mark-up $S_{i}$ on the true temperature $T_{i t}$, we can denote the measured air temperature as $a_{i t}=T_{i t}+S_{i}$. Rewriting Eq. (3) yields

$$
\begin{aligned}
\ln E\left(y_{i t}\right)=\ln \left[f\left(X_{i t}\right)\right] & =\alpha_{a} a_{i t}+\alpha_{a 2} a_{i t}{ }^{2}+Z_{i t} \theta \\
& =\alpha_{a}\left(T_{i t}+S_{i}\right)+\alpha_{a 2}\left(T_{i t}+S_{i}\right)^{2}+Z_{i t} \theta \\
& =\alpha_{a}\left(T_{i t}+S_{i}\right)+\alpha_{a 2}\left(T_{i t}{ }^{2}+S_{i}{ }^{2}+2 T_{i t} S_{i}\right)+Z_{i t} \theta,
\end{aligned}
$$

where $Z_{i t}$ is a vector comprising the remaining variables and $\theta$ is the corresponding coefficient vector. The marginal effect with respect to the biased air temperature measurement $a_{i t}$ then is

$$
\frac{\partial \ln E\left(y_{i t}\right)}{\partial a_{i t}}=\alpha_{a}+2 \alpha_{a_{2}}\left(T_{i t}+S_{i}\right)
$$

whereas the marginal effect with respect to the true temperature $T_{i t}$ is

$$
\begin{aligned}
\frac{\partial \ln E\left(y_{i t}\right)}{\partial T_{i t}} & =\alpha_{a}+2 \alpha_{a 2} T_{i t}+2 \alpha_{a 2} S_{i} \\
& =\alpha_{a}+2 \alpha_{a 2}\left(T_{i t}+S_{i}\right) .
\end{aligned}
$$

Eq. (A.8) is identical to Eq. (A.9), which implies that the UHI effect may bias the temperature coefficient but has no impact on the marginal effect. 


\section{Climate Change, Risk and Grain Yields in China ${ }^{15}$}

\subsection{Introduction}

Farmers usually have no knowledge of the precise output when they make their production decisions, which is mainly due to the fact that agriculture in general has a long production cycle and is affected by a large number of endogenous and exogenous uncertainty factors (Just and Pope, 1979; Kumbhakar and Tsionas, 2008; Meyer and Yu, 2013). The prevailing climate conditions for instance are important sources of uncertainty because factors such as temperature or precipitation are characterized by inter-annual variability, part of which can be explained by gradual shifts in mean climate conditions caused by global climate change, while another part is due to seemingly random fluctuations. Since the precise patterns of the variations are beyond farmers' control and their predictive capabilities, production risk emerges.

To our knowledge, currently no study exists that covers the influences of climate factors on both the general production conditions and on the level of production risk in Chinese grain farming, even though the impacts of food security issues in China on both domestic and world food markets can be substantial (von Braun, 2007; Simelton, 2011). $\mathrm{Yu}$ and Zhao (2009) as well as Tian and Yu (2012) provide good reviews of the existing studies on agricultural production in China. However, with the exception of Zhang and Carter (1997), Wang et al. (2009), Mendelsohn (2009), and Chen et al. (2013) most studies have not explicitly considered climate factors in their analyses of the state and prospects of Chinese agriculture. The issue of output risk receives even less attention.

The world climate is changing (Christensen, 2007; Parry et al., 2007; Shortle et al., 2009) and the consequences of this are expected to be considerable. However, the various existing studies on the impacts of climate change on agricultural production produce a multitude of different results. Some studies for instance find that increases in temperatures could benefit agricultural production in several developed countries, such as the US (Mendelsohn and Dinar, 2003; Deschênes and Greenstone, 2007; Shortle et

\footnotetext{
15 This section has been published as: Holst, R., Yu, X., \& Grün, C. (2013). Climate Change, Risk and Grain Yields in China. Journal of Integrative Agriculture 12(7) , 1279-1291.
} 
al., 2009) or Germany (Lippert et al., 2009). Others conclude that global warming could harm agricultural production, for example in many developing countries in Africa and South America (Féres et al., 2008; Mendelsohn, 2009). Regarding China, Mendelsohn (2009) finds that global warming could be harmful to famers in general by reducing their revenues, while Wang et al. (2009) conclude that global warming is harmfaul to farmers without access to irrigation, whereas it is beneficial to farmers with access to irrigation. Moreover, Chen et al. (2013) find that the contribution of climatic factors to grain production in China has been positive and significant between 2005 and 2009. In their review regarding the impacts of climate change on Chinese agriculture, Wang et al. (2010), however, caution that the overall net effects on production and rural income heavily depend on the assumed climate change scenario and the modes of production.

Regarding the future development of East Asia's climate, it is expected that annual average temperatures, total annual precipitation levels as well as climatic variability could increase (Christensen et al., 2007). In particular, the increase in China's annual average temperature could be as high as $2.3-3.3^{\circ} \mathrm{C}$ by 2050 , whereas the national precipitation level could increase by 5-7\% until then (Wang et al., 2010).

As a result of the country's exposure to the East Asian monsoon, its climate and particularly precipitation patterns are already characterized by a high degree of variability (Tao et al., 2004), which frequently leads to droughts and floods (Smit and Cai, 1996). The expected increase in climatic variability implies that even more extreme climate events are likely to occur in the future.

These changes will likely have profound impacts on Chinese agriculture. Hence, the main objectives of this paper are to develop a method, which uses yield functions of the Just and Pope $(1978,1979)$ type, to analyze (1) how climate change affects the expected grain output in China and (2) how the level of output risk immanent in grain farming is affected. In contrast to several prior studies, which adopt functions of the Just and Pope type for climate change impact assessments (e.g. Chen et al., 2004; Isik and Devadoss, 2006), we also control for the influences of regular input factors on the production process. For our analyses, we use a panel data set of 26 Chinese provinces comprising variables relevant for grain production and climate information from 1985 through 2009. 


\subsection{Models and Estimation Approaches}

\subsubsection{Methodological Background}

In the current literature, the production function and the Ricardian approach are the two predominant approaches to estimating the economic impacts of climate change. The Ricardian approach, which analyzes the influences of climate factors and other exogenous variables on the productivity of farmland as measured by land rent (Lippert et al., 2009), land value (Féres et al., 2008), net revenue per unit of land (Mendelsohn and Dinar, 2003; Mendelsohn, 2009) or profit per unit of land (Deschênes and Greenstone, 2007; Wang et al., 2009), has frequently been applied in recent years. However, when using this approach, heterogeneities related to unobserved variables are often embedded in the error terms. Certain inputs (e.g. fertilizers), landscape features or soil characteristics can be correlated with climate variables and can thus cause endogeneity problems in regressions, which would lead to inconsistent estimation results (Deschênes and Greenstone, 2007). Moreover, it is a fact that the agricultural land in China is equally distributed to farmers and that there is no open market for farmland, so that neither rents nor values of farmland can be observed. Nevertheless, in a study on China, Wang et al. (2009) use the Ricardian approach to analyze farmers' net income. However, since several important variables, such as land prices (or land rents) and food prices, are not included in their analysis, their results might be biased.

The production function approach, which has the advantage that it provides a good structural form, in turn suffers from the drawback that it, as pointed out by Deschênes and Greenstone (2007), cannot incorporate farmers' adaptations to climate change, which may bias the estimates with respect to long-run climate influences. However, this approach has the important additional benefit that it can be used to study the impacts of climate change on output levels and output fluctuations (i.e. risks), which are of great importance as it comes to food security considerations.

In light of the above facts, we resort to estimating aggregate grain yield with climate factors and normal agricultural inputs as independent variables. This represents a mixed approach as it on the one hand provides a structural model that enables us to analyze output quantities and risk levels, and on the other hand allows us to overcome some of the inflexibility that puts the production function approach at a disadvantage to the Ricardian approach. The reason for this is that combining all grain varieties in an 
aggregate output variable implies that farmers' possibilities to change their cultivated grain variety in response to a changing climate are accounted for.

\subsubsection{Base Model}

In this study, following the discussions about agricultural production by $\mathrm{Yu}$ and Zhao (2009), Tian and Yu (2012) and Yu (2012) and the production functions of Zhang and Carter (1997) and Chen et al. (2013), we specify the basic model, which draws on the Cobb-Douglas functional form, as follows:

$\ln y_{i t}=\alpha_{0}+\sum_{k=1}^{K} \alpha_{k} \ln x_{k i t}+h\left(C_{i t}\right)+\varepsilon_{i t}$

where $y_{i t}$ is the grain yield in region $i$ in year $t, x_{k i t}$ is the input quantity of factor $k$ per unit of land area under grain cultivation in the respective region and year and $\alpha_{k}$ are the parameters to be estimated with respect to the various conventional input factors. $h\left(C_{i t}\right)$ in turn is a polynomial function, which models the influences of a vector of climate variables $\left(C_{i t}\right)$ on the grain yield and thus turns the model into a weather and input yield function similar to the function used by Zhang and Carter (1997). A comparable integration of external factors into a production function framework can also be found in Chen et al. (2013). Finally, $\varepsilon_{i t}$ is a normally distributed error term.

The model, however, needs to be adjusted in the presence of yield risks, which doubtlessly affect agricultural production, and which can be assumed to take the form of heteroskedasticity in the yield function (Just and Pope, 1979). The most important issue is that many stochastic production functions with log-linear disturbances, such as Eq. (9) or the conventional Cobb-Douglas function, impose the strong constraint of a positive correlation between the use of any input factor and the yield variance ${ }^{16}$ (i.e. the level of yield risk) (Just and Pope, 1978, 1979) ${ }^{17}$, which is a rigid assumption and is obviously unrealistic. This clearly also has implications for the suitability of conventional estimation procedures, such as fixed effects (FE) or feasible generalized least squares (FGLS) estimation. Moreover, both FE and FGLS estimation of Eq. (9)

\footnotetext{
${ }^{16}$ Assuming positive marginal products for the input factors.

${ }^{17}$ Just and Pope $(1978,1979)$ also provide detailed proof.
} 
would not be informative with respect to the specific marginal effect of any input factor on the level of output risk. Hence, a more flexible functional form and a suitable estimation procedure are necessary.

\subsubsection{Just and Pope Model}

Following Just and Pope (1978, 1979), we develop a flexible non-linear fixed-effects panel data model, which is suitable for separately analyzing each input factor's marginal contribution (considering both standard and climate inputs) to the mean yield as well as to the yield risk in Chinese grain farming without imposing constraints on the signs of the coefficients. Based on Just and Pope's generalized production function, our model is specified as follows:

$$
\begin{gathered}
y_{i t}=\exp \left(\alpha_{0}+\sum_{k=1}^{K} \alpha_{k} \ln x_{k i t}+\gamma t+h_{1}\left(C_{1 i t}\right)\right) \\
+e_{i t} \sqrt{\beta_{0}+\sum_{m=1}^{M} \beta_{m} \ln x_{m i t}+h_{2}\left(C_{2 i t}\right)} .
\end{gathered}
$$

A major property of this model is that the expected yield (often also referred to as mean yield) and the variance of the yield (yield risk) are determined independently:

$$
\begin{aligned}
& E\left(y_{i t}\right)=\exp \left(\alpha_{0}+\sum_{k=1}^{K} \alpha_{k} \ln x_{k i t}+\gamma t+h_{1}\left(C_{1 i t}\right)\right) \\
& V\left(y_{i t}\right)=\beta_{0}+\sum_{m=1}^{M} \beta_{m} \ln x_{m i t}+h_{2}\left(C_{2 i t}\right) .
\end{aligned}
$$

In Eq. (10)-(12), $y_{i t}, x_{k i t}$ and $\alpha_{k}$ have the same definitions as in Eq. (9). $x_{m i t}$ denotes a standard input factor, which can influence the risk level, and $\beta_{m}$ is the corresponding coefficient. $t$ is a linear time trend and $\gamma$ consequently is a coefficient capturing the influence of technological progress. $h_{1}\left(C_{1 i t}\right)$ and $h_{2}\left(C_{2 i t}\right)$ are polynomial functions 
modeling the impacts of different climate variables on the mean yield and the yield variance, respectively. Thus, the vector $C_{1 i t}$ contains climate variables, which are deemed important for the determination of the mean yield, whereas the vector $C_{2 i t}$ comprises climate variables, which are likely to affect yield risk. $e_{i t}$ now is a stochastic error term following a standard normal distribution.

Just and Pope (1979) also proposed a three-stage procedure for consistently estimating models based on their flexible functional form, which we will apply with some modifications that account for the panel-data nature of our study to estimate Eq. (10): (I) Non-linear least squares estimation of the mean yield (Eq. (11)) with province dummies included, (II) estimation of Eq. (12) as a fixed-effects model for which the residuals from the first stage are used to calculate the dependent variable, and (III) re-estimation of the mean yield utilizing a generalized non-linear least squares model with the estimates from stage (II) serving as weights and again with province dummies included. Introducing province dummies on stages (I) and (III) and resorting to fixed effects estimation on stage (II) is necessary because China's provinces, which will be our panel units, are quite heterogeneous in terms of geographical features, climate regimes, economic development and various other aspects. However, the climatic differences and the differences with respect to cropping systems between the country's subtropical south and its temperate north are likely to make a decisive difference with respect to the impact of climate change (Lin, 1992; Wang et al., 2009). Specifically, the main grain in South China is rice, and usually more than one cropping season per year is possible, while the main grain in North China, where usually only one cropping season is possible, is wheat. Rice generally prefers high temperatures, a high-humidity environment and short durations of sunshine, while wheat grows better under long durations of sunshine and a relatively dry weather. Therefore, we will split the sample into northern ${ }^{18}$ and southern ${ }^{19}$ provinces and will separately apply the above procedure to those subsamples.

\footnotetext{
18 Northern provinces: Gansu, Hebei, Heilongjiang, Henan, Jilin, Liaoning, Neimenggu, Ningxia, Qinghai, Shaanxi, Shandong, Shanxi, Xinjiang.

${ }_{19}$ Southern provinces: Anhui, Fujian, Guangdong, Guangxi, Guizhou, Hainan, Hubei, Hunan, Jiangsu, Jiangxi, Sichuan, Yunnan, Zhejiang.
} 


\subsubsection{Impact Analysis}

From a policy perspective, it is particularly important to quantify the change in output following a marginal change in climate. Drawing on the mean yield function (Eq. (11)), we can calculate the change in mean yield following a $1^{\circ} \mathrm{C}$ increase in annual average temperatures or a $1 \mathrm{~mm}$ increase in total annual precipitation as follows:

$$
\widehat{\Delta y}_{c}=\frac{\partial E(y)}{\partial c}
$$

where $\widehat{\Delta y}_{c}$ is the change in mean yield induced by a change in climate factor $c$ (annual average temperature or total annual precipitation). $y$ denotes the average mean yield of the considered set of provinces in the last year of the data set. By multiplying the change in yield by the total area under grain cultivation and by the average price of grain products, it is furthermore possible to quantify the market value of the total change in output.

\subsection{Data}

A panel data set of 26 Chinese provinces comprising information on grain production and climate from 1985 through 2009 is used to carry out the analyses in this study. The main variables regarding grain production, which are used for the regressions, include annual observations of grain yield ${ }^{20}$ (tons $\cdot \mathrm{ha}^{-1}$ ), grain acreage (ha), rural labor per unit area of land under grain cultivation (persons $\cdot \mathrm{ha}^{-1}$ ), the irrigated share of the grain acreage (percentage), power of agricultural machinery per unit area of land under grain cultivation (watts. $\mathrm{ha}^{-1}$ ) as well as fertilizer use per unit area of land under grain cultivation (tons $\cdot \mathrm{ha}^{-1}$ ). The data on climate consist of monthly observations of temperature $\left({ }^{\circ} \mathrm{C}\right)$ and precipitation $\left(\mathrm{mm} \cdot \mathrm{m}^{-2}\right)$. The data set is constructed from various issues of the China Statistical Yearbook (National Bureau of Statistics of China, 19862010).

\footnotetext{
${ }^{20}$ Aggregate grain output (measured by weight), as reported by the National Bureau of Statistics of China (NBS), consists of the individual output quantities of the different varieties of rice, wheat, corn, sorghum, millet, tubers and beans. The total weight of harvested tubers (net of the share recorded as vegetables) has been converted by the NBS to grain-equivalent output by assuming that five kilograms of tubers are equivalent to one kilogram of the other grains (National Bureau of Statistics of China, 2008).
} 
Except for the land area under cultivation, the available raw input data generally represent aggregate input use regarding all sub-sectors of a province's agriculture and are thus not specific to grain farming. In order to approximate the province-specific quantities of labor, fertilizer and machine power as well as the size of the irrigated area used for the production of grain, the total input quantities have been multiplied by the share of the grain acreage in total cropland, which entails the simplifying assumption of equal input use per unit area of land for all crops. In the cases of labor and machinery, we furthermore acknowledge that these inputs are also substantially used in parts of agriculture not related to crop cultivation. Consequently, we adjust them a second time by also multiplying them with the share of the crop output value in the total agricultural output value. Similar adjustment procedures have also been applied by Zhang and Carter (1997) and Lin (1992). Summary statistics of grain yields, the derived input variables and the average climate conditions are presented in Table 3.

Table 3: Descriptive statistics

\begin{tabular}{|c|c|c|c|c|c|c|}
\hline & & \multicolumn{5}{|c|}{ North China } \\
\hline Variable & Measurement & Mean & Std. Dev. & Min & Max & Obs \\
\hline Yield & $10,000 \mathrm{t} / 1,000 \mathrm{ha}$ & 0.3753 & 0.1148 & 0.1476 & 0.7025 & 325 \\
\hline Area & 1,000 ha & $4,235.58$ & $2,757.52$ & 244.70 & $11,391.03$ & 325 \\
\hline Labor & 10,000 persons $/ 1,000$ ha & 0.1384 & 0.0569 & 0.0418 & 0.2508 & 296 \\
\hline Irrigation & Percentage of grain acreage & 0.3655 & 0.1763 & 0.0792 & 0.9500 & 313 \\
\hline Machinery & $10,000 \mathrm{kw} / 1,000$ ha & 0.1961 & 0.1001 & 0.0660 & 0.6013 & 309 \\
\hline Fertilizer & $10,000 \mathrm{t} / 1,000 \mathrm{ha}$ & 0.0260 & 0.0143 & 0.0044 & 0.0722 & 314 \\
\hline Annual avg. temp. & ${ }^{\circ} \mathrm{C}$ & 9.93 & 3.48 & 3.30 & 16.00 & 325 \\
\hline \multirow[t]{2}{*}{ Tot. annual precip. } & $\mathrm{mm} / \mathrm{m}^{2}$ & 481.14 & 195.85 & 74.90 & $1,212.90$ & 325 \\
\hline & & \multicolumn{5}{|c|}{ South China } \\
\hline Variable & Measurement & Mean & Std. Dev. & Min & Max & Obs \\
\hline Yield & $10,000 \mathrm{t} / 1,000 \mathrm{ha}$ & 0.4535 & 0.0844 & 0.2411 & 0.6127 & 322 \\
\hline Area & 1,000 ha & $3,876.07$ & $1,740.37$ & 402.64 & $7,337.73$ & 322 \\
\hline Labor & 10,000 persons / 1,000 ha & 0.2011 & 0.0548 & 0.0985 & 0.4349 & 309 \\
\hline Irrigation & Percentage of grain acreage & 0.3071 & 0.0875 & 0.1345 & 0.5812 & 309 \\
\hline Machinery & $10,000 \mathrm{kw} / 1,000 \mathrm{ha}$ & 0.1337 & 0.0647 & 0.0410 & 0.4466 & 309 \\
\hline Fertilizer & $10,000 \mathrm{t} / 1,000 \mathrm{ha}$ & 0.0305 & 0.0195 & 0.0093 & 0.1524 & 310 \\
\hline Annual avg. temp. & ${ }^{\circ} \mathrm{C}$ & 18.28 & 2.86 & 13.83 & 25.40 & 321 \\
\hline Tot. annual precip. & $\mathrm{mm} / \mathrm{m}^{2}$ & $1,291.83$ & 385.27 & 565.80 & $2,678.90$ & 321 \\
\hline
\end{tabular}

Data: National Bureau of Statistics of China (1986-2010)

Figures 5 and 6 show the development of the aggregate grain output and the grain yield in North and South China. 
Figure 5: Grain production in North China

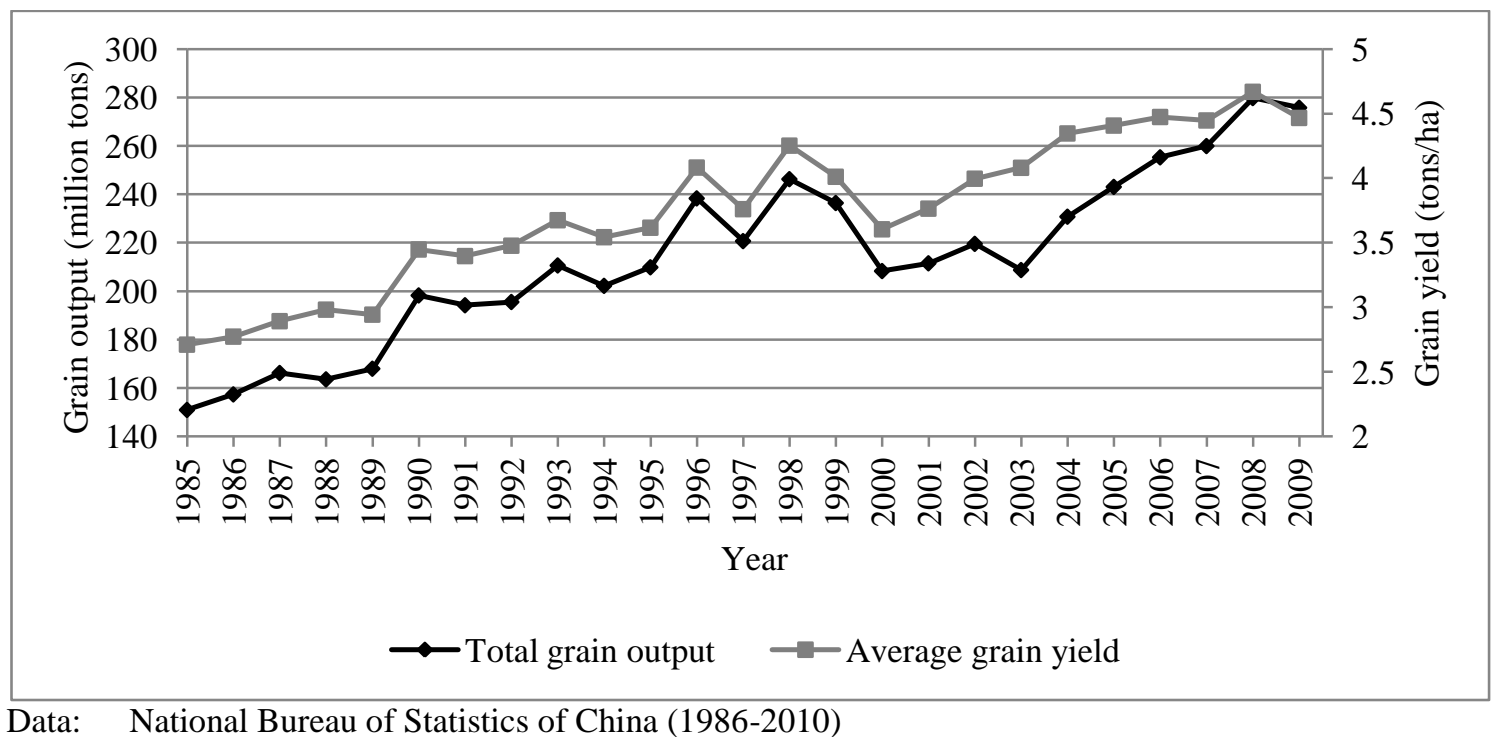

Figure 6: Grain production in South China

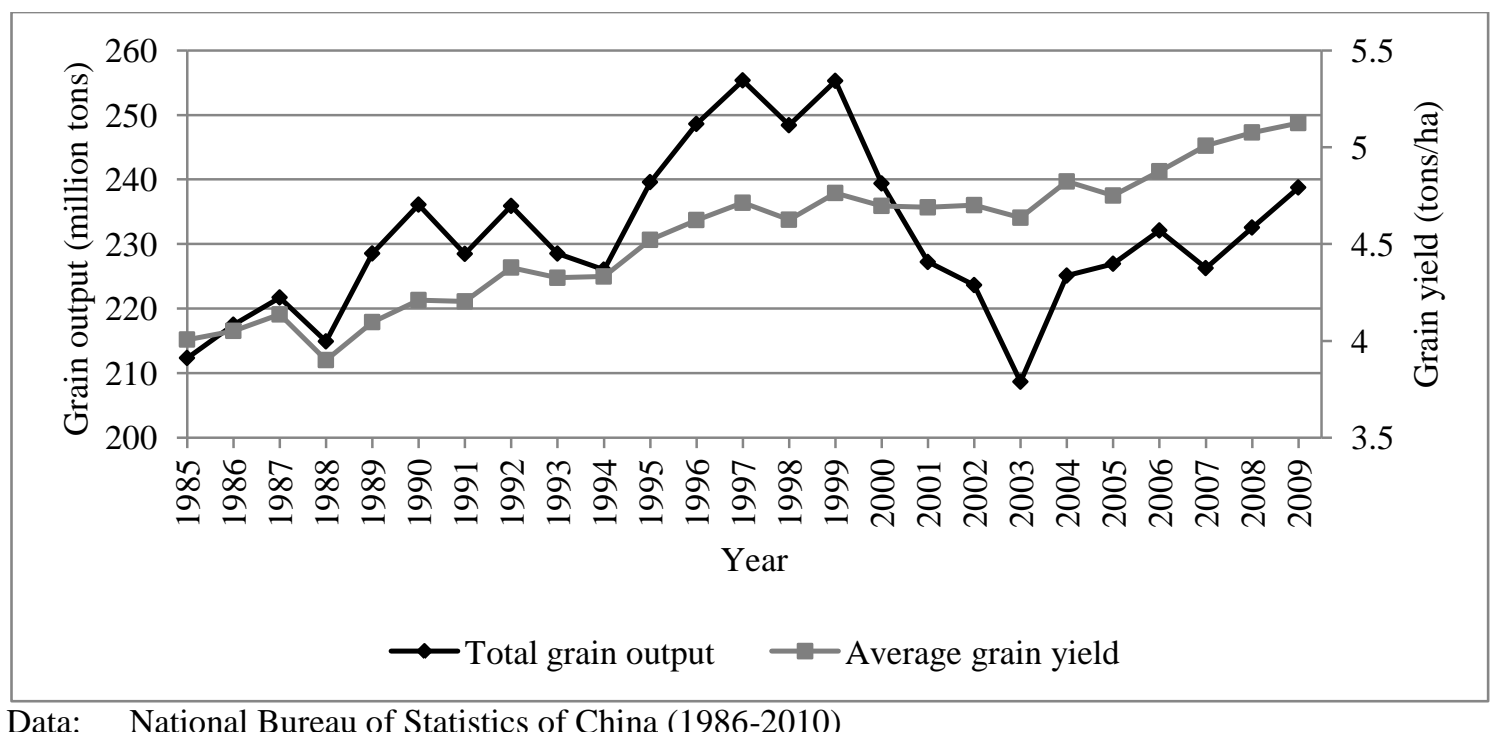

In this study, we use the climate observations of the provincial capital cities as proxies for the average climate of the corresponding provinces. We acknowledge that the temperature data might be affected by the urban heat island (UHI) effect, but we assume that this effect takes the form of a constant mark-up on the average temperatures of the surrounding rural areas over the limited time period analyzed here. Consequently, the intercept in the regressions should capture most of this effect as long as the climate variables are linear. The results of Li et al. (2004) support our assumption as they find that, while the UHI effect certainly exists, the difference between the decadal warming trends of urban and non-urban measurement stations is minor. 
From the available monthly climate data we construct a total of four different climate variables. The most elementary ones are the annual average temperature and the total annual amount of precipitation. Additionally, because climate change does not only change mean climate conditions but also affects the largely unpredictable climatic variability, which might be particularly relevant with respect to yield risks, we construct measures of aggregate deviation from long-term trends. They can be denoted as follows:

$A G D E V_{c i t}=\sum_{s=1}^{12}\left|c_{i t s}-\hat{c}_{i t s}\right|$

where $A G D E V_{\text {cit }}$ represents the aggregate deviation of climate factor $c$ (temperature or precipitation) in province $i$ during year $t$ from the linear trends of the individual months. $c_{i t s}$ are actual climate observations for month $s$ in the respective year and province and $\hat{c}_{i t s}$ are estimates obtained by calculating a linear trend for month $\mathrm{s}$ in province $i$ over the time period under consideration in this study (1985-2009).

Figures 7-10 show the development of North and South China's annual average temperatures and total annual precipitation levels between 1985 and 2009. Regressions of annual average temperatures against time find positive and highly significant trends for the past 25 years, which supports the hypothesis that China is already experiencing climatic changes.

Figure 7: Annual average temperature in North China (1985-2009)

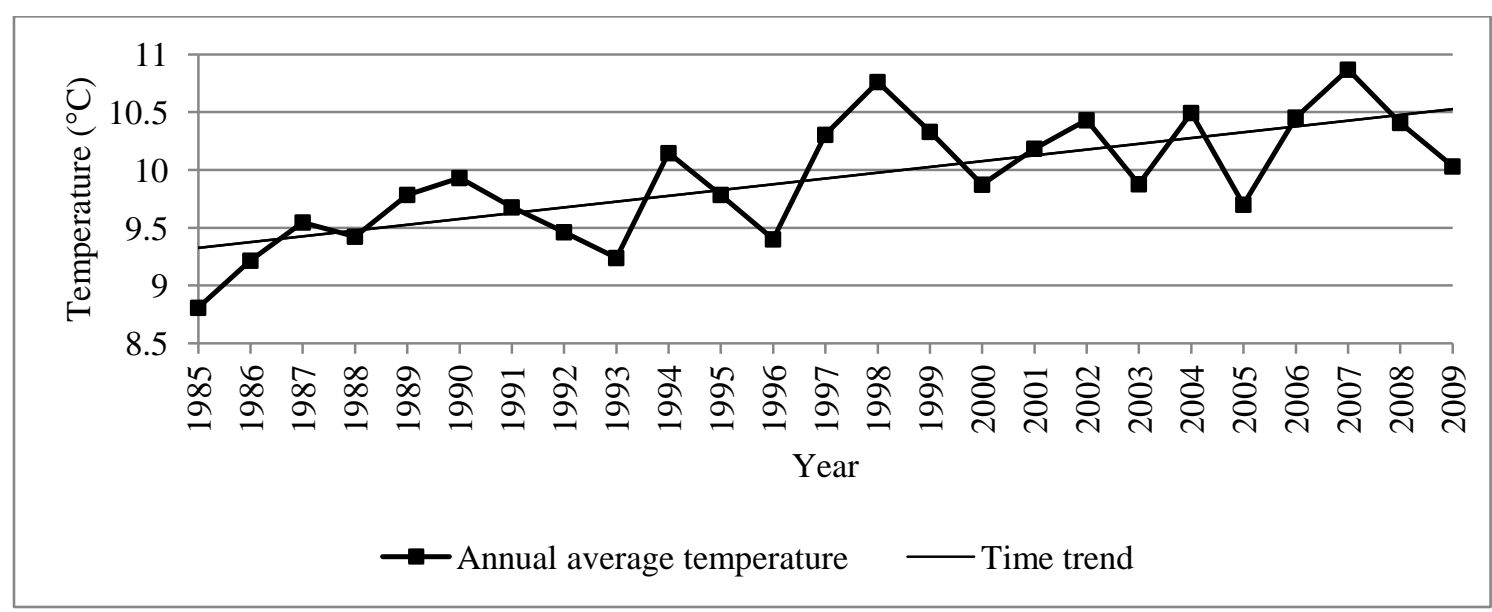

Note: Trend significant at 1\%-level, coefficient: 0.05 , t-value: 18.32

Data: National Bureau of Statistics of China (1986-2010) 
Figure 8: Annual average temperature in South China (1985-2009)

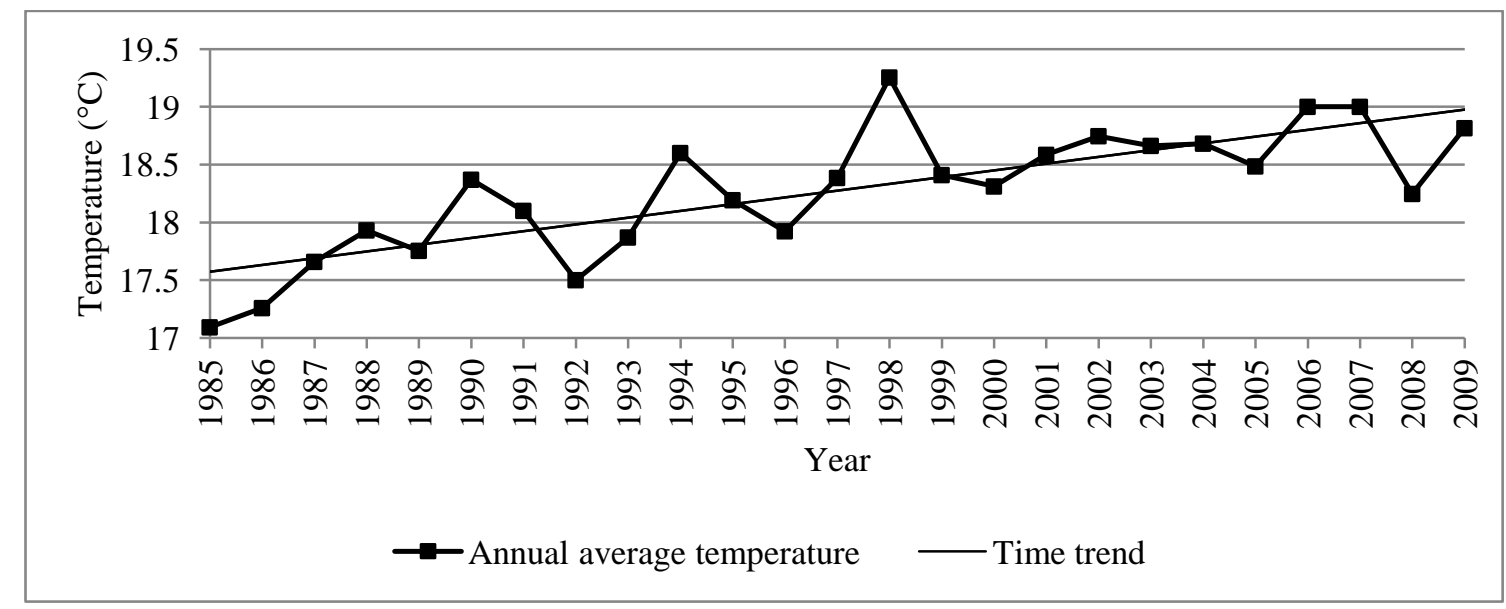

Note: Trend significant at 1\%-level, coefficient: 0.0578, t-value: 22.10

Data: National Bureau of Statistics of China (1986-2010)

Figure 9: Total annual precipitation in North China (1985-2009)

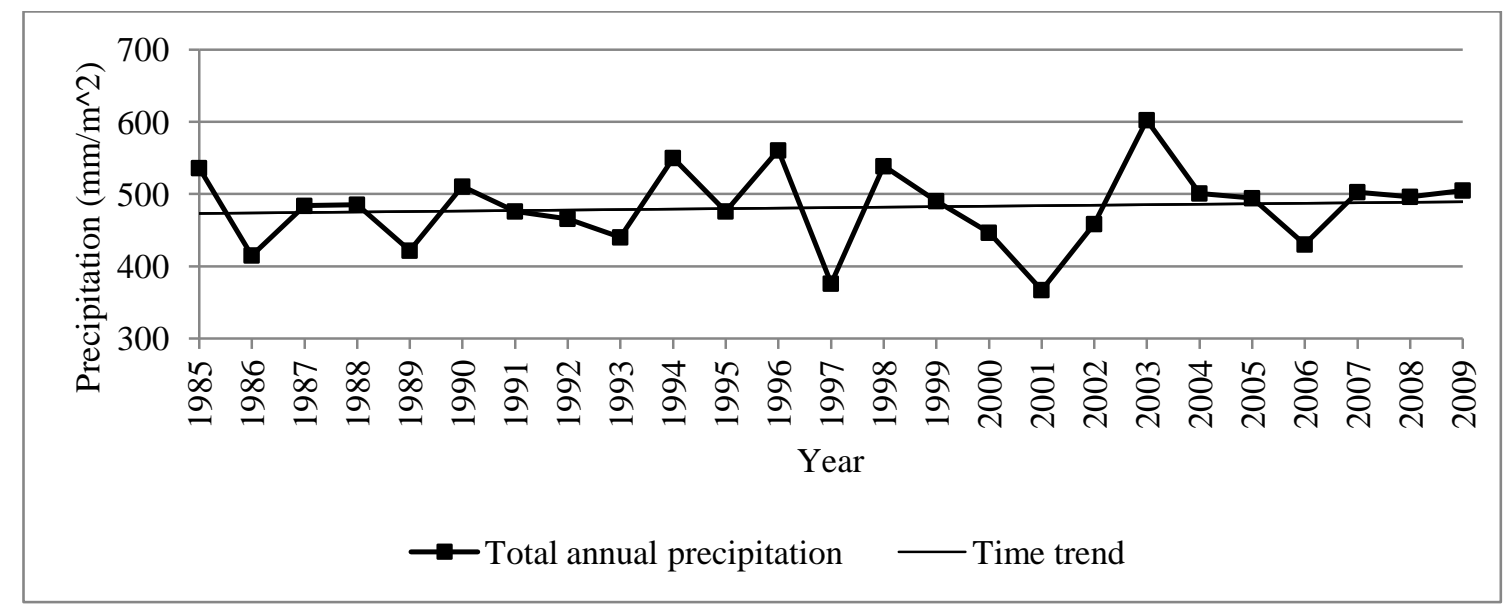

Note: Trend not significant, coefficient: 0.6581, t-value: 1.58

Data: National Bureau of Statistics of China (1986-2010)

Figure 10: Total annual precipitation in South China (1985-2009)

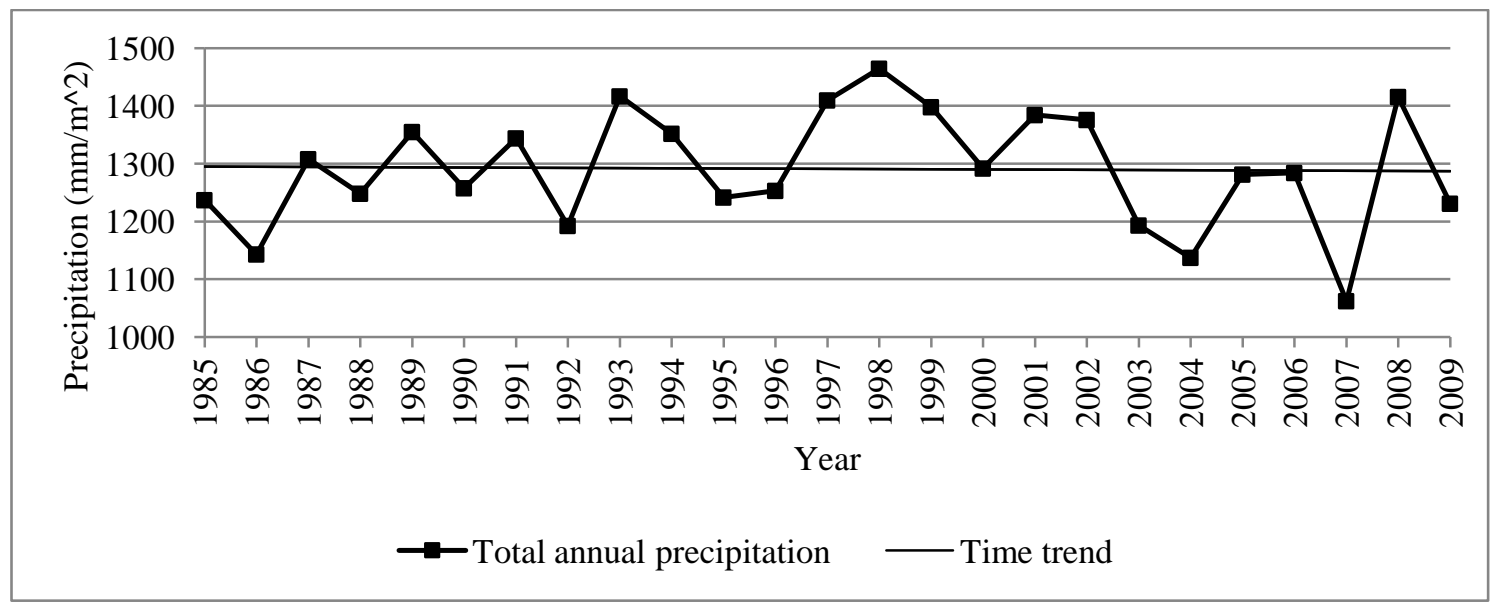

Note: Trend not significant, coefficient: -0.4552 , t-value: -0.59

Data: National Bureau of Statistics of China (1986-2010) 


\subsection{Estimation Results and Discussion}

\subsubsection{Model Comparison}

For the estimation of the yield functions, it is important to correctly specify the climate functions $h_{1}\left(C_{1 i t}\right)$ and $h_{2}\left(C_{2 i t}\right)$. In particular, some studies arrived at the conclusion that the impacts of climatic changes (particularly of changes in temperatures) are of a non-linear nature (e.g. Quiggin and Horowitz, 1999; Horowitz, 2009; Schlenker and Roberts, 2009). Hence, we estimated the Just and Pope models both with and without inclusion of second-order temperature and precipitation terms into the mean yield component of our model. The results revealed that when second-order climate terms are included, none of the second-order terms and nearly none of the first-order terms are statitistically significant. In contrast, without inclusion of second-order terms all firstorder terms are statistically significant ${ }^{21}$. Hence, the specification without second-order terms is obviously superior to the specification with second-order terms. This might be caused by the fact that we use highly aggregated data in our samples, which might have smoothed away the non-liearity in the present case and might also result in relatively small variances of annual temperatures and precipitation levels. Given the above arguments, we only report the results of the models, which feature only the first-order terms of the climate variables.

The regression results of our multi-stage analysis are presented in Table 4. Models A and B use FGLS estimation, whereas Models C and D report the results of the Just and Pope estimation procedure. In both cases the results are presented separately for North and South China ${ }^{22}$. Regarding the signs of the coefficients of the statistically significant climate variables, there are no contradictions between the FGLS and the Just and Pope models. Note, however, that their results are not directly comparable due to the aforementioned constraint on the marginal contributions to the output variance that affects the FGLS models as they are based on Eq. (9). Hence, it does not come as a surprise to find that Model B is unable to identify any climate impacts on grain

\footnotetext{
${ }^{21}$ See Table 4.

${ }^{22}$ F-tests reject the null-hypothesis of there being no significant differences between the provinces for both the North China and the South China sample. Therefore, irrespective of the sample, the introduction of province dummies is warranted. Furthermore, an LR-test also rejects the null-hypothesis of there being no significant differences between North China and South China, which supports our approach of separating the national sample into a North China and a South China sub-sample. The validity of the LR test and the F-test in a non-linear regression context is confirmed by Wooldridge (2002).
} 
production in South China, whereas Model D1 clearly shows that climate factors play a significant role in that region.

Moreover, while a small marginal effect of labor is reasonable due to factor's abundance in China, the above constraint on the FGLS model could also be responsible for the fact that the marginal effect of labor turns out to be negative in Model A (North China), which seems to be contrary to traditional economic theory. It cannot be ruled out that the coefficients in Models A and B confound the contributions to mean yield and to yield risk ${ }^{23}$. An indication that this might be the case with respect to labor in Model A can be seen in the fact that the point estimate of the marginal effect of labor on mean yield is positive (Model C1), whereas the marginal effect of labor on yield risk is negative (Model C2). This again shows the deficiency of the normal production functions.

Since the Just and Pope models are not affected by this constraint and additionally allow us to identify the marginal contributions of individual input factors to the yield variance (i.e. the level of yield risk), we generally consider them superior to Models A and B.

\footnotetext{
${ }^{23}$ As a result, these models might lead to wrong policy conclusions.
} 
Table 4: Analysis of Chinese grain yields

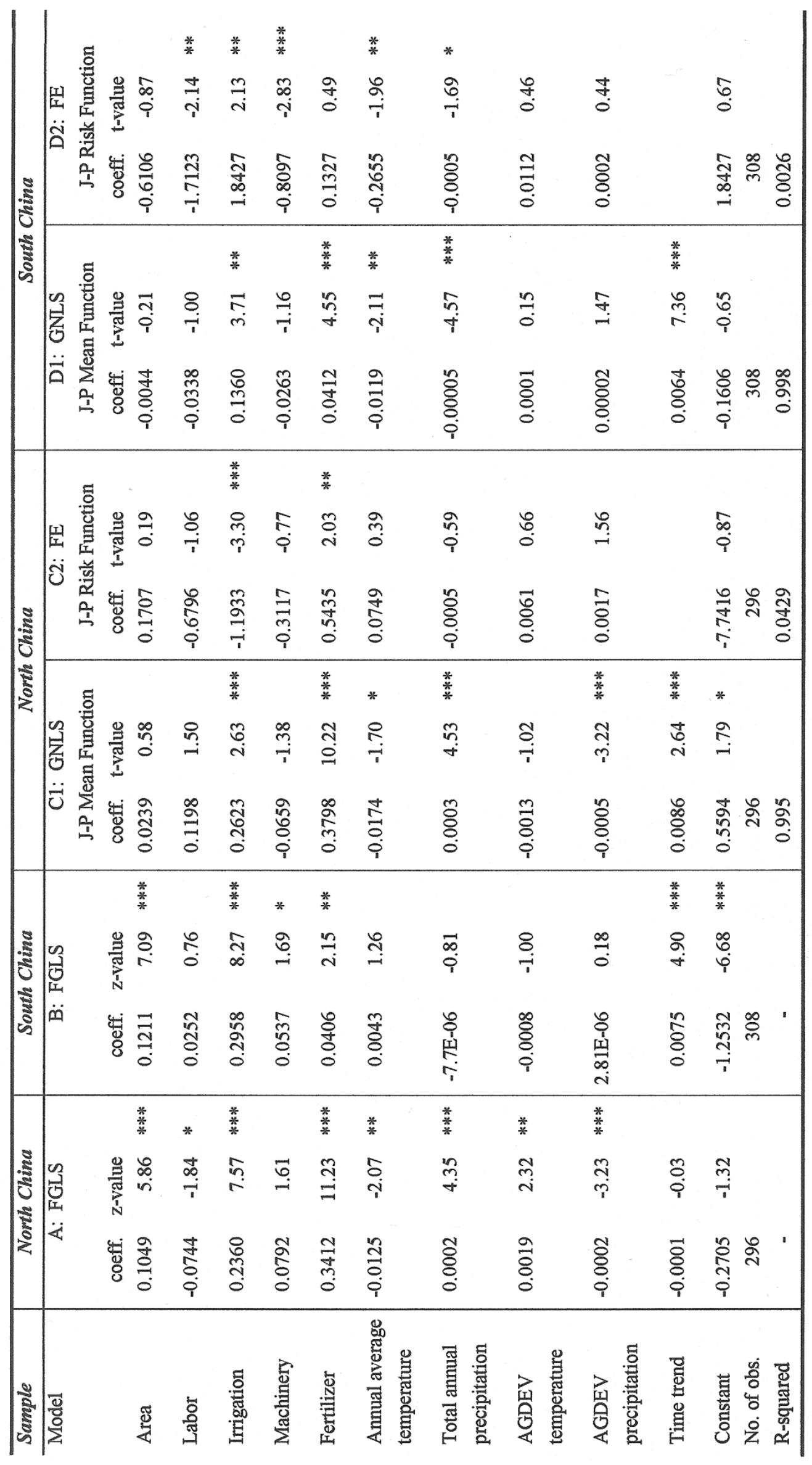


Notes on Table 4:

1. * significant at $10 \%$-level; ** significant at 5\%-level; *** significant at $1 \%$-level

2. Fixed-effects dummies are included in all regressions, but are not reported.

3. The R-squared values in Models C2 and D2, which are rather low, imply that the explanatory power of the risk functions is limited. This, however, makes sense, given the nature of production risks, most of which cannot be fully explained by farmers or economists. In addition, note that due to the non-linear nature of Models C1 and D1, their high R-squared values do not necessarily imply a high explanatory power of the mean-production function.

\subsubsection{Mean Yield Function}

Regarding the marginal contributions of the standard input factors to mean yield, we find a similar pattern for North China (Model C1) and South China (Model D1). The amount of fertilizer per unit area of land as well as the irrigated share of the grain acreage reach positive and highly significant output elasticities for both samples. This implies that increasing the use of chemical fertilizer and an expansion of irrigation can significantly increase mean grain yields in China.

Other regular input variables, such as the grain acreage, which in a yield regression captures scale effects, the number of laborers and the use of machinery per unit area of land have no significant impacts on mean yield at the margin. All these results are plausible and consistent with the current literature (e.g. Lin, 1992; Yu and Zhao, 2009; Ji et al., 2012), in which particularly machinery and labor input levels are believed to have reached a saturation point in Chinese agricultural production. However, since this study is focused on climate impacts, the regular input factors will only be discussed in as far as they are related to the climate factors under consideration.

In particular, it emerges that with an output elasticity of 0.262 , North China could benefit considerably from expanding the share of its grain acreage under irrigation, which stands in contrast to the relatively small elasticity of 0.136 estimated for South China. We attribute this to the fact that North China is more frequently affected by droughts and generally is a much more arid region than South China where precipitation is relatively abundant. However, any long-term benefits from increasing the irrigated share of the grain acreage are certainly conditional upon sufficient water availability, which cannot be taken for granted, especially not in North China, which suffers from a marked scarcity of surface water and already has to obtain a substantial part of the current irrigation water from ground water sources, which in turn has led to a drastic lowering of the ground water table in several regions, including the North China Plain (Smit and Cai, 1996; Wang et al., 2010). 
Comparing the marginal impacts of the climate factors on mean yield, it turns out that the impacts on North China are different from those on South China. With respect to the northern provinces we find that a higher annual average temperature would have a negative effect on the mean yield (coefficient: -0.017) and that a higher level of total annual precipitation would increase the mean yield (coefficient: 0.0003). For South China, the marginal effect of the annual average temperature is also negative (coefficient: -0.012), whereas increases in total annual precipitation would decrease mean yield (coefficient: -0.0001). All these effects are statistically significant.

The results regarding the negative impacts of higher annual average temperatures are essentially consistent with the current literature (Xiong et al., 2007; Mendelsohn, 2009; You et al., 2009). Wang et al. (2010) offer an explanation for these negative impacts by pointing out that higher temperatures, ceteris paribus, also increase the water requirements in agricultural production due to rising evaporation and transpiration losses, which in our case is aggravated by the fact that water resources are generally scarce in China, particularly in North China (Brown, 1995). Correspondingly, Wang et al. (2009, 2010) also find that farmers without access to irrigation are particularly vulnerable to increases in temperature. However, as compared to North China, South China features more abundant water resources, which can explain why the negative impact of increasing temperatures is smaller in the South.

In light of its serious water scarcity (Wang et al., 2013), it is also reasonable to find that North China could benefit from increases in precipitation, which would alleviate this problem and would hence improve grain yields. However, more precipitation in South China might harm grain production as it could cause or aggravate floods.

It furthermore turns out that the variability of precipitation, as measured by our aggregate deviation variable, significantly influences mean grain yields in North China. The estimated negative effect is likely due to the fact that particularly negative deviations of precipitation from the trend, perhaps in form of droughts, could have severe impacts on grain production. Obviously, the possibly beneficial effects of positive deviations cannot compensate for this. Due to the good local irrigation system (Wang et al., 2010), South China might better be able to compensate for negative deviations and might even benefit from positive deviations as long as they do not turn into destructive floods. Hence, the overall effect of an increasing aggregate deviation of 
precipitation from current trends on grain yields in South China is positive. However, it is not statistically significant.

Regarding temperature variability, we cannot find any significant impacts on the mean grain yields of either North or South China.

\subsubsection{Marginal Climate Change Impacts}

Drawing on the results just described and using information on grain production in the last year of our data set, we can calculate the economic net benefits or net losses of Chinese grain farming following marginal increases in annual average temperature and total annual precipitation. The results are reported in Table 5.

In 2009, North China was characterized by an average grain yield of 4.46 tons $\cdot \mathrm{ha}^{-1}$. Hence, drawing on the respective climate coefficients from Model $\mathrm{C} 1$, a $1{ }^{\circ} \mathrm{C}$ increase in annual average temperature would reduce North China's grain yield by around 0.078 tons $\cdot \mathrm{ha}^{-1}$, whereas a $100 \mathrm{~mm}$ increase in total annual precipitation would increase it by 0.134 tons $\cdot \mathrm{ha}^{-1}$. The changes correspond to a $1.74 \%$ decline and a $3 \%$ improvement, respectively. Given that the grain acreage in North China amounted to approximately 59.41 million ha in 2009, the changes in yield imply changes in total output of -4.61 million tons for the change in temperature and of +7.95 million tons for the change in precipitation. Assuming an average grain price of around $1.762 \mathrm{CNY} \cdot \mathrm{kg}^{-1}$ for 2009 (CPYEC, 2010), the corresponding economic gains (losses) would be around CNY -8.12 billion (USD -1.19 billion $^{24}$ ) and CNY +14.01 billion (USD 2.05 billion), respectively.

Based on South China's average grain yield of 5.12 tons $\cdot \mathrm{ha}^{-1}$ in 2009 , the effect of a $1^{\circ} \mathrm{C}$ increase in annual average temperature would be a decrease in grain yield of around 0.061 tons $\cdot \mathrm{ha}^{-1}$, which would represent a $1.2 \%$ decline. Given the fact that South China featured a grain acreage of approximately 46.46 million ha in that year, the corresponding change in output and value of output would be around -2.83 million tons and around CNY -4.98 billion (USD -0.73 billion), respectively. By similar calculations, we find that an increase in total annual precipitation by $100 \mathrm{~mm}$ would reduce the grain output of South China by 1.22 million tons $\left(-0.026\right.$ tons $\left.\cdot \mathrm{ha}^{-1}\right)$, which

\footnotetext{
${ }^{24}$ Average official exchange rate in 2009: USD $1 \cong$ CNY 6.83 (Source: People's Bank of China, http://www.pbc.gov.cn/publish/html/2009s08.htm). 
would be equivalent to $0.59 \%$ of the grain output in that region and would have a market value of CNY 2.14 billion (USD 0.31 billion).

Adding up the losses of North and South China, we find that a $1{ }^{\circ} \mathrm{C}$ increase in annual average temperature would reduce grain production in China as a whole by around 7.44 million tons, which would correspond to $1.45 \%$ of China's total grain production in 2009 and would have a value of CNY 13.10 billion (USD 1.92 billion). A $100 \mathrm{~mm}$ increase in precipitation, however, would increase grain output by 6.73 million tons, which would correspond to $1.31 \%$ of the national grain production in 2009 and would have a value of CNY 11.86 billion (USD 1.74 billion).

Table 5: Marginal impacts of climate change on grain production in China

\begin{tabular}{|c|c|c|c|c|c|c|}
\hline \multirow[t]{2}{*}{ Region } & \multirow[t]{2}{*}{ Climate Change } & Yield & \multicolumn{2}{|c|}{ Total Output Change } & \multirow{2}{*}{$\begin{array}{r}\text { CNY } \\
\text { Value } \\
\text { Billion } \\
\text { CNY }\end{array}$} & \multirow{2}{*}{$\begin{array}{r}\text { USD } \\
\text { Value } \\
\text { Billion } \\
\text { USD }\end{array}$} \\
\hline & & $\begin{array}{l}\text { Quantity } \\
\left(\mathrm{kg} \cdot \mathrm{ha}^{-1}\right)\end{array}$ & $\begin{array}{r}\text { Quantity } \\
\text { (million tons) }\end{array}$ & $\%$ & & \\
\hline \multirow[t]{2}{*}{$\begin{array}{l}\text { North } \\
\text { China }\end{array}$} & $\begin{array}{l}1^{\circ} \mathrm{C} \text { increase in } \\
\text { temperature }\end{array}$ & -77.60 & -4.61 & -1.74 & -8.12 & -1.19 \\
\hline & $\begin{array}{l}100 \mathrm{~mm} \text { increase in } \\
\text { precipitation }\end{array}$ & 133.80 & 7.95 & 3.00 & 14.01 & 2.05 \\
\hline \multirow[t]{2}{*}{$\begin{array}{l}\text { South } \\
\text { China }\end{array}$} & $\begin{array}{l}1^{\circ} \mathrm{C} \text { increase in } \\
\text { temperature }\end{array}$ & -60.82 & -2.83 & -1.19 & -4.98 & -0.73 \\
\hline & $\begin{array}{l}100 \mathrm{~mm} \text { increase in } \\
\text { precipitation }\end{array}$ & -26.16 & -1.22 & -0.59 & -2.14 & -0.31 \\
\hline \multirow[t]{2}{*}{$\begin{array}{l}\text { All of } \\
\text { China }\end{array}$} & $\begin{array}{l}1^{\circ} \mathrm{C} \text { increase in } \\
\text { temperature }\end{array}$ & & -7.44 & -1.45 & -13.10 & -1.92 \\
\hline & $\begin{array}{l}100 \mathrm{~mm} \text { increase in } \\
\text { precipitation }\end{array}$ & & 6.73 & 1.31 & 11.86 & 1.74 \\
\hline \multicolumn{7}{|l|}{ Notes: } \\
\hline
\end{tabular}

\subsubsection{Yield Risk Function}

Our analysis of the determinants of yield risk in Chinese grain farming by means of Just and Pope's procedure (see Table 4, Models C2 (North China) and D2 (South China)) reveals that several of the standard input factors have a highly significant influence. Generally, we acknowledge that yield risks are typically rather specific to the operational environment of farmers, to their specific crops and personal experiences in handling risks. Nevertheless, using a highly aggregate analysis (provinces as panel units and aggregate grain yield as dependent variable) we find that a higher irrigation share in 
North China would lead to a reduction in yield risk and that an increasing use of fertilizer would increase yield risk. Both would be reasonable due to the relative water scarcity in North China that renders using large amounts of fertilizer a risky procedure and that could at least partially be compensated for if a larger share of the grain acreage could be irrigated.

For South China, we find that increases in the input levels of labor and machinery can significantly reduce the yield variance, which does make sense as employing more labor or machinery would allow producers to better react to other downside risks in the long process of agricultural production and thus to at least partially compensate for them. It is, however, puzzling that the share of irrigated land is positively correlated with the yield variance, which is the opposite of what we find for North China. A possible explanation might be that an overcapacity of irrigation in South China could incentivize producers to inconsiderately convert non-irrigated land into irrigated land, so that the newly planted crops, such as rice, are unsuitable on that land, which would render them very susceptible to environmental influences.

In accordance with our earlier assumption that climatic changes affect yield risk, it emerges that increases in temperature and precipitation would both significantly reduce the yield variance in South China. The reason for this might be that an increase in temperature generally implies a decreasing probability of extreme cold events, which would be harmful for crops, particularly in South China. Moreover, due to its better irrigation systems, South China should be able to employ increasing precipitation quantities in a productive way, which could help to reduce the probability of drought losses. For North China, where the conditions are considerably different, the corresponding impacts are not statistically significant.

Moreover, we find the coefficient estimates regarding temperature and precipitation variability to be positive for both North and South China, which is consistent with our assumption that an increasing climatic variability would increase yield risks. However, these estimates do not reach conventional levels of significance.

\subsection{Conclusions}

This paper has contributed to the current literature in several ways. We have used recent data to analyze the influences of annual climate factors and of climatic variability on 
grain yields in China. In particular, we have modified the method of Just and Pope $(1978,1979)$ to be able to separately determine the marginal contributions of both regular input factors and climate factors to mean yield and to yield risk in a panel data context.

Our results have several implications for Chinese agricultural and climate-related policies. In an environment already characterized by a changing climate, a stabilization or expansion of grain yields can in both North and South China be achieved by increasing the quantity of fertilizer per unit area of land under grain cultivation, even though grain production in China is already highly fertilizer-intensive. However, it should also be kept in mind that further increments in the application of fertilizer could have adverse impacts on the environment, which could have a severe negative impact on agricultural production in the long-run. Moreover, since China is characterized by a relative water scarcity, it would benefit from increasing the percentage of its grain acreage under irrigation, particularly in the northern regions. Hence, building irrigation infrastructure and securing a steady and sustainable water supply for irrigation purposes are both important challenges.

It furthermore emerged that changes in input use can be employed to reduce yield risks. Specifically, an increase in irrigation in North China and increases in the use of labor or machinery in South China would all lead to reductions in yield risk.

One of the main results with respect to the influences of the different climate factors is that North and South China will be differently affected by climatic changes. Specifically, both North and South China would experience decreasing mean yields as a consequence of rising annual average temperatures, but the northern part would be more severely affected, which is consistent with the current literature (Xiong et al., 2007; Mendelsohn, 2009; You et al.; 2009). Here, the different levels of water availability in the two regions again seem to play a crucial role, which is also supported by the finding that the relatively water scarce northern provinces would likely benefit from increasing annual precipitation quantities, whereas the southern provinces, where water is relatively abundant, could be adversely affected. Moreover, we find that an increasing variability of precipitation, as measured by our aggregate deviation variable, would likely reduce mean yields in North China but would have no significant impact on South China. 
Regarding the influences of climate factors on yield risk, our main findings are that increases in temperature and precipitation can significantly reduce yield risks in South China, but would have no statistically significant impacts on yield risks in North China. In addition, we find that the variabilities of temperature and precipitation are positively correlated with the yield variance in both parts of the country. However, the relationships are not statistically significant.

Overall, these results indicate that global warming would harm grain production in China as a whole, but would have the benefit of reducing yield risks in South China. To what extent temperature-related losses can be compensated by increases in total annual precipitation in North China will depend on the exact future patterns of climate change with respect to temperatures and precipitation levels.

Moreover, our results allowed us to calculate the economic losses of a marginal increase in annual average temperature. It emerges that grain output, ceteris paribus, would decrease by 4.61 million tons in North China and by 2.83 million tons in South China in the scenario of a $1{ }^{\circ} \mathrm{C}$ increase in annual average temperature. Hence, the national loss would be 7.44 million tons, which would correspond to $1.45 \%$ of the overall grain output in 2009 and would have a value of CNY 13.1 billion.

For the scenario of a $100 \mathrm{~mm}$ increase in total annual precipitation, we find that grain output, ceteris paribus, would increase by 7.95 million tons in North China but would decrease by 1.22 million tons in South China. In total, the national output would increase by 6.73 million tons, which would amount to $1.31 \%$ of the overall grain output in 2009 and would have a value of CNY 11.86 billion.

As aforementioned, this study is consistent with the current literature, which finds that China will suffer losses in grain production due to global warming. Given the immense size of the country's population and the need for a stable food supply, China's government should take active measures to mitigate the negative impacts of global warming on the country's grain sector to ensure food security. 


\section{Total Factor Productivity and Technical Efficiency in Chinese}

\section{Inland Aquaculture}

\subsection{Introduction}

China features the largest aquaculture sector in the world. In 2010 it accounted for nearly $62 \%$ of the global aquaculture production (FAO, 2012). The importance of the Chinese aquaculture sector is also mirrored in the fact that its output growth of $5.2 \%$ in 2007 was responsible for $52.3 \%$ of the global growth in that year's aquaculture production (Bostock et al., 2010). The high output level presently enables the sector to provide around $20 \%$ of the domestically consumed animal protein (Weimin and Mengqing, 2007) and hence to make a substantial contribution to food security in China. Moreover, after its entry into the World Trade Organization China became the world's largest exporter of farmed aquatic products (Broughton and Walker, 2010). Currently, a key role in providing China with aquatic products is assumed by Chinese inland aquaculture production, which accounts for around $60 \%$ of total aquaculture output (Chinese Ministry of Agriculture, 2010) and, as shown in Figure 11, for around $43 \%$ of the country's total fishery output.

Figure 11: Chinese inland aquaculture output (1993-2009)

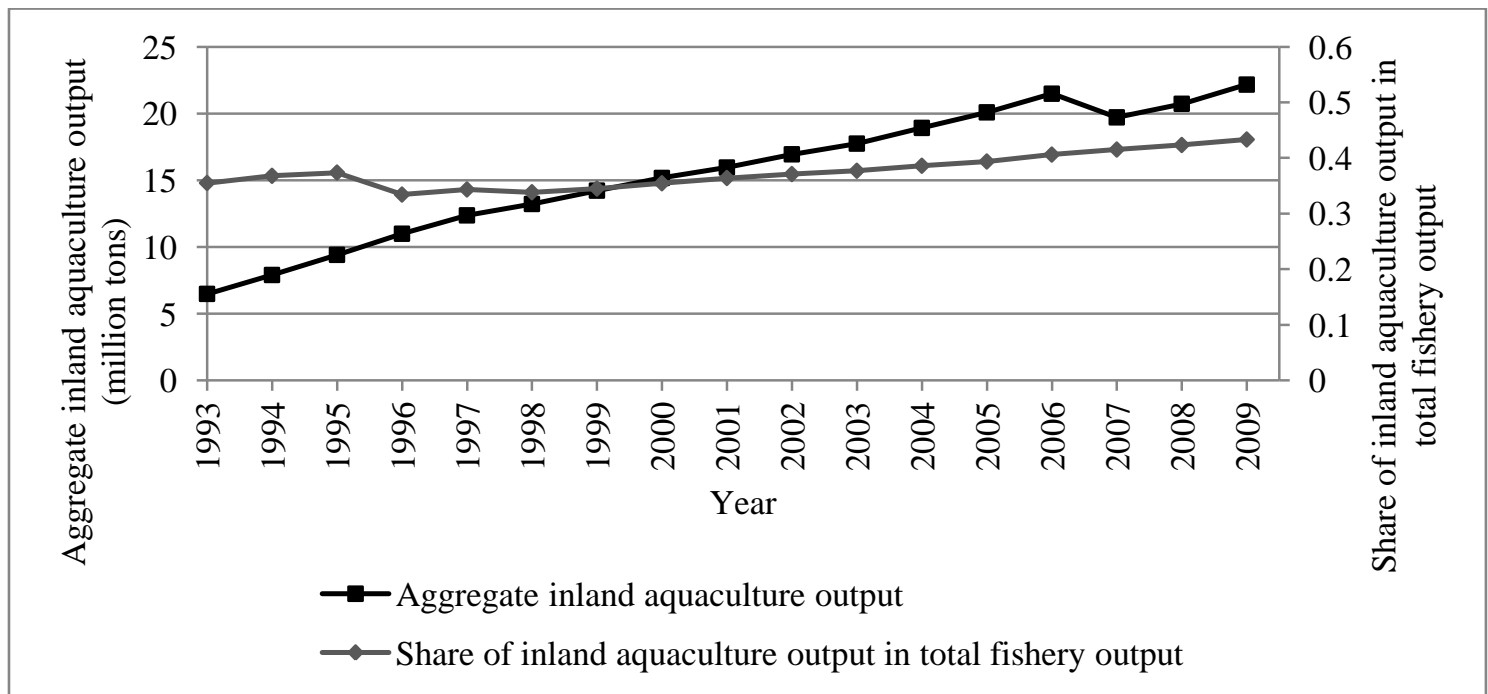

Data: Chinese Ministry of Agriculture (1994-2010) 
It has variously been pointed out that important factors in the development and expansion of the Chinese aquaculture sector over the past few decades have included technological advances, improved production- and management-related knowledge among producers as well as improved inputs and the development of a specialized support industry (Leung and Shang, 1993; Weimin and Mengqing, 2007). Improvements in technology and knowledge among producers would imply positive technical change and technical efficiency change, respectively, which would both contribute to improvements in total factor productivity. Empirical evidence on total factor productivity and its determinants in Chinese inland aquaculture, however, is extremely scarce, despite the sector's importance for food security in China.

Chen et al. (1995) find considerable heterogeneity in the productivity (as represented by the yield level) of integrated inland aquaculture farms across China, which they attribute to differences in environmental conditions (e.g. different levels of water availability), development and infrastructure. Sharma et al. (1999) in turn use data envelopment analysis (DEA) to analyze economic efficiency (i.e. technical and allocative efficiency) in Chinese fish polyculture, a form of pond aquaculture. They find that technical efficiency also varies considerably across producers and provinces and suggest that improvements in technical efficiency could lead to sizeable increases in total output. These studies however have several limitations. They only analyze individual aspects of productivity and consider no developments over time in their analyses. Hence, their results do not allow drawing conclusions regarding the development of total factor productivity or its components. Moreover, they are outdated, use data from only small numbers of provinces and concentrate on specific aquaculture techniques. As a result of these limitations, no comprehensive up-to-date information on the sources of growth in China's inland aquaculture sector is available.

Generally, productivity and technical efficiency have been important topics in analyses of China's agricultural sector. The output of agricultural products has increased substantially over the past decades, particularly since the start of the agricultural reforms in 1978. Besides institutional changes, increases in the use of inputs as well as improvements in technology and hence total factor productivity have contributed substantially to the expansion in output (Yu and Zhao, 2009). While the importance and strength of the contributions of the above factors to productivity and output growth during different periods after the introduction of the reforms are much-debated in the literature (Lin, 1992; Kalirajan et al., 1996; Fan and Pardey, 1997; Jin et al., 2002; Fan 
et al., 2004, Brümmer et al., 2006; Tian and Yu, 2012; Chen et al., 2013), it can be stated that China has certainly undertaken great efforts to improve its agricultural productivity, particularly by promoting the development and adoption of new technologies (Jin et al., 2002). This however leads directly to the question of technical efficiency because, as lined out by Kalirajan et al. (1996), the effectiveness of further technological innovations depends on the ability of producers to fully employ the potential of the current production technology.

Given that inland aquaculture, as a sub-sector of agriculture, is confronted with broadly the same institutional and economic framework as the wider agricultural sector in China (Leung \& Shang, 1993), the above literature represents a useful starting point for the analysis of the Chinese inland aquaculture sector. Specifically, it is the purpose of the present study to analyze the development of total factor productivity and its determinants (especially technical change and technical efficiency change) in this important sub-sector. This will allow drawing conclusions with respect to the drivers of past output growth and possible drivers of future output growth. Given the aforementioned importance of technical efficiency in this respect, the present study puts a particular focus on analyzing the development, geographical distribution and determinants of provincial technical efficiency scores.

For the purpose of these analyses, a stochastic frontier model is estimated using a panel data set that includes province-level data on aggregate inland aquaculture production over the period 1993-2009 and that covers all forms of inland aquaculture in all relevant production regions.

The remainder of this paper is organized as follows: In Section 4.2, the methodological framework underlying the productivity and efficiency analysis is outlined. Section 4.3 contains information on the data set, which is used for the analysis, and in Section 4.4, the empirical results are presented and discussed. Finally, in Section 4.5, conclusions and policy recommendations are provided. 


\subsection{Methodology}

\subsubsection{Empirical Approach}

Assuming Hicks-neutral technical change, total factor productivity (TFP) can be stated in a simplified form as:

$T F P_{i t} \equiv A_{i t}=\frac{\mathrm{y}_{i t}}{f\left(X_{i t}\right)} \Leftrightarrow \mathrm{y}_{i t}=A_{i t} f\left(X_{i t}\right)$

where $y_{i t}$ is the output of producer $i$ in time period $t$ and $f\left(X_{i t}\right)$ represents a production technology $f(\cdot)$, which employs the input vector $X_{i t}$ to produce $Y_{i t}$ (Del Gatto et al., 2011). An important question, then, is which factors are responsible for changes in TFP, or in other words for changes in output that are not attributable to changes in input use. In this respect, Färe et al. $(1992,1994)$ proposed a Malmquist productivity index for analyzing TFP and for decomposing it into technical change and technical efficiency ${ }^{25}$ change.

Frontier production functions represent an important approach to analyzing TFP and its components. They are rooted in the assumption that in reality many producers do not realize the frontier output (i.e. the maximum output it is possible to produce given their input levels and the available technology). This shortfall is caused by what is called technical inefficiency. Given this framework, frontier analysis directly recognizes the two sources of changes in TFP considered in the Malmquist productivity index: Changes in technical inefficiency (i.e. changes in the position of producers relative to the production frontier) and technological change, which changes the position of the production frontier itself (Hulten, 2001; Del Gatto, 2011) ${ }^{26}$.

The two predominant approaches to analyzing frontier production functions are the nonparametric data envelopment analysis (DEA) originally proposed by Charnes et al. (1978) and the parametric stochastic frontier analysis (SFA), which has been pioneered by Aigner et al. (1977) and Meeusen and van Den Broeck (1977). Both approaches have already been frequently applied in the context of agricultural production in China and

\footnotetext{
${ }^{25}$ The concept of technical efficiency employed by Färe et al. $(1992,1994)$ goes back to the contributions of Farrell (1957).

${ }^{26}$ Different approaches have been developed to decompose TFP into its individual components. See chapter 4.2.3 for details on the decomposition employed in this study.
} 
other countries. For a selected overview of various applications of frontier techniques to agricultural production (and other sectors) see Battese (1992) and Tian and Yu (2012).

In the present study, the SFA approach is prefered over the DEA approach primarily because the former is non-deterministic. Specifically, in addition to the technical inefficiency term it allows for the introduction of a random error term to model statistical noise. Due to its deterministic nature this is not possible in the DEA approach, where effects of random events, of external (e.g. environmental or regulatory) factors that cannot be influenced by the producers, and of model specification issues are captured as part of technical inefficiency (Murillo-Zamorano, 2004). Other benefits of the SFA approach are that the separate random error term captures measurement errors regarding the output variable (Aigner et al., 1977) and that the approach allows for formal statistical post-estimation tests (Hjalmarsson et al., 1996)

Particularly for the analysis of Chinese inland aquaculture, introducing a separate random error term seems required in order to obtain a clear picture of technical inefficiency and by implication technical efficiency. Specifically, it is known that aquaculture in general is a sensitive production process, which makes it particularly vulnerable to natural hazards and other production shocks (FAO, 2012), the effects of which should not be considered as part of technical inefficiency. Moreover, due to the fact that this study uses province-level (i.e. highly aggregated) production data, some degree of measurement error cannot be ruled out. A separate random error would at least partially capture these influences and would thus likely lead to more reliable technical efficiency scores.

The SFA approach has, however, been criticized for requiring the imposition of a specific frontier production technology and of specific distributions for the error terms capturing technical inefficiency and statistical noise, which results in the fact that the results of analyses relying on the SFA approach become sensitive to a priori assumptions (Kalirajan and Shand, 1999). While these points of criticism are certainly valid, having to make the above assumptions can be considered as a trade-off necessary to reap the benefits of the SFA approach (Del Gatto et al., 2011). Moreover, as Schmidt (1985) points out, resorting to a deterministic frontier approach instead, thereby assuming that no statistical noise is present, would also amount to making an a priori distributional assumption. Given the aforementioned sensitivity of aquaculture to external influences, this assumption would appear particularly questionable. Hence, 
SFA remains the most promising approach for the present study and it will be attempted to ease its drawbacks by selecting a flexible frontier production function and by choosing reasonable error term distributions.

\subsubsection{Model Specification}

The frontier production function to be estimated follows a translog functional form, which represents a local second-order differential approximation to an arbitrary frontier production function and is neither constrained by constant elasticities of substitution, nor by constant elasticities of transformation (Christensen et al., 1973). This lends the translog functional form a reasonable degree of flexibility. In the present study the stochastic frontier production function takes the following form:

$$
\begin{gathered}
\ln y_{i t}=\beta_{0}+\sum_{k=1}^{K} \beta_{k} \ln x_{k i t}+\beta_{t} t+\frac{1}{2} \sum_{k=1}^{K} \sum_{n=1}^{K} \beta_{k n} \ln x_{k i t} \ln x_{n i t}+\sum_{k=1}^{K} \beta_{k t} \ln x_{k i t} t \\
+\frac{1}{2} \beta_{t 2} t^{2}+\left(v_{i t}-u_{i t}\right),
\end{gathered}
$$

where $y_{i t}$ represents the aggregate output of inland aquaculture producers in province $i$ during year $t . x_{k i t}$ and $x_{n i t}(k, n=1,2, \ldots, K)$ in turn stand for amounts of input factors used in that province and year. $t$ as a variable is a time trend, which in the present model captures non-neutral technical change ${ }^{27} \cdot v_{i t}$ and $u_{i t}$ form the composite error term that is characteristic for stochastic frontier production functions. Adopting the specification suggested by Battese and Coelli (1992), $v_{i t}$ is a white noise error term that follows a normal distribution $\left(v_{i t} \sim N\left(0, \sigma_{v}^{2}\right)\right)$, whereas $u_{i t}$ is a non-negative error term that captures technical inefficiency and follows a truncated normal distribution ${ }^{28}$

\footnotetext{
${ }^{27}$ Non-neutral technical change is a common finding in the literature (see for example Førsund and Hjalmarsson (1979) or O’Neill and Matthews (2001)). Moreover, Liu and Wang (2005) specifically confirm the presence of non-neutral technical change in Chinese agriculture during the 1990s. Hence, non-neutral technical change is adopted as the preferred specification of technical change for the present model.

${ }^{28}$ An alternative set of distributional assumptions that is commonly used in the literature consists of a normal distribution with a mean value of zero for the random error term and of a half-normal distribution for the inefficiency term (see Aigner et al. (1977) or Battese and Corra (1977) for early examples using this specification). However, as lined out by Del Gatto et al. (2011), imposing a half-normal distribution on the inefficiency term would be most suitable if the mode of the inefficiency distribution is expected to be approximately zero. Given that the Chinese provinces are quite heterogeneous regarding various factors, including their general state of development and agricultural structure, there is no strong a priori
} 
$\left(u_{i t} \sim N^{+}\left(\mu, \sigma_{u}^{2}\right)\right)$. Both error term components are assumed to be independent and identically distributed. In addition, $u_{i t}$ is modeled under the assumption of time-varying technical inefficiency by employing the functional form proposed by Battese and Coelli (1992): $u_{i t}=(\exp (-\eta(t-T))) u_{i}$. Since $\mathrm{T}$ is the last year in the data set, this timevarying decay specification imposes a trend on the inefficiency term, which, depending on the sign of the inefficiency trend parameter $\eta$, results in provincial technical inefficiency scores that either increase or decrease towards $u_{i}$ over the time period considered in the analysis. If it should turn out that $\eta=0$, technical inefficiency becomes time-invariant. For a fully technically efficient province, $u_{i t}$ will assume the value zero.

\subsubsection{Total Factor Productivity}

In order to calculate the individual components of total factor productivity change (TFPC), the approach presented by Coelli et al. (2005), which relies on the work of Fuentes et al. (2001) and Orea (2002), is employed. Fuentes et al. (2001) show how to decompose a Malmquist productivity index in a parametric frontier production panel data context into separate components measuring technical efficiency change (TEC) and technical change (TC). Orea (2002), however, observes that the Malmquist productivity index neglects the influences of scale changes (SC) (i.e. of changes in the returns scale) on overall productivity change and hence is not an adequate measure of total factor productivity. Consequently, in order to obtain a comprehensive picture of the development of productivity, in the present study the estimation results of the stochastic frontier production model are used for the calculation of TEC, TC and SC. The product of these three components represents TFPC.

Given that output-oriented distance functions measure output-oriented technical efficiency (Kumbhakar and Lovell, 2004), Coelli et al. (2005) denote the distance function-based TEC index stated in Fuentes et al. (2001) as:

$T E C=\frac{T E_{i, t+1}}{T E_{i, t}}=\frac{E\left(\exp \left(-u_{i, t+1}\right) \mid v_{i, t+1}-u_{i, t+1}\right)}{E\left(\exp \left(-u_{i, t}\right) \mid v_{i, t}-u_{i, t}\right)}$

indication that this should be the case in the present study. Hence, in the interest of flexibility the truncated normal distribution is chosen for the inefficiency error term. 
where the technical efficiency of province $i$ in year $t, T E_{i, t}=E\left(\exp \left(-u_{i, t}\right) \mid v_{i, t}-u_{i, t}\right)$, is calculated directly from the inefficiency error term $\left(u_{i, t}\right)$ of the stochastic frontier production model.

Technical change in any time period of the above stochastic frontier model is measured by the derivative of the natural logarithm of output with respect to time. Fuentes et al. (2001), however, warn that for discrete data, the point estimate of technical change in one time period is not an appropriate indicator for the technical change between two consecutive time periods. To remedy this, Coelli et al. (2005) suggest using the geometric mean of the time derivatives in the two periods, which in the context of the present translog frontier production function implies:

$T C=\exp \left(0.5\left(\frac{\partial \ln y_{i, t}}{\partial t}+\frac{\partial \ln y_{i, t+1}}{\partial(t+1)}\right)\right)$

In order to incorporate the effects of scale changes into the calculation of TFPC, Coelli et al. (2005) propose the following scale change index (based on the generalized outputoriented Malmquist productivity index by Orea (2002)):

$S C=\exp \left(0.5 \sum_{k=1}^{K}\left(\varepsilon_{k, i, t} S F_{i, t}+\varepsilon_{k, i, t+1} S F_{i, t+1}\right) \ln \left(\frac{x_{k, i, t+1}}{x_{k, i, t}}\right)\right)$

where $S F_{i, t}=\frac{\left(\varepsilon_{i, t}-1\right)}{\varepsilon_{i, t}}$ is calculated from the returns to scale $\varepsilon_{i, t}=\sum_{k=1}^{K} \varepsilon_{k, i, t}$, which in turn are calculated from the individual output elasticities $\varepsilon_{k, i, t}=\frac{\partial \ln y_{i, t}}{\partial x_{k, i, t}}$. As Orea (2002) points out, the validity of his approach to modeling the effects of scale changes depends on variable returns to scale and on non-constant input quantities. This also emerges directly from Eq. (19), which would equal unity for $x_{k, i, t}=x_{k, i, t+1}$ or for $\varepsilon_{i, t}=\varepsilon_{i, t+1}=1$ and would in those cases have no effect on TFPC. 


\subsubsection{Distribution and Determinants of Technical Efficiency}

Technical efficiency is of interest not only in the context of total factor productivity, but also as an important economic factor in its own right. As lined out before, technical efficiency can be described as the degree to which the potential of the available production technology is used (Kalirajan et al., 1996). In order to be able to draw sensible conclusions with respect to technical efficiency in Chinese inland aquaculture and to obtain a foundation for developing additional policy advice, three aspects of the time-varying technical efficiency scores $\left(T E_{i t}\right)$ will be analyzed: $(1)$ Their development over time, (2) their geographical distribution and (3) their determinants.

The development over time and the geographical distribution of the efficiency scores can be directly analyzed employing the estimation results of the stochastic frontier model. For the purpose of analyzing the determinants of technical efficiency, a twostage approach is chosen, which involves regressing the technical efficiency scores obtained from the stochastic frontier production model (Stage 1) on a set of environmental and other explanatory variables (Stage 2). Such two-stage approaches are particularly common in the DEA literature (see Simar and Wilson (2007) for an extensive list of applied studies), but have also been used in the context of stochastic frontier models (e.g. Pitt and Lee, 1981; Kalirajan, 1984). Various factors have been found in the previous literature to affect the level of technical efficiency, including environmental conditions (Simar and Wilson, 2007), farm-level characteristics like management and ownership (Alam et al. 2012), input intensities (Pitt and Lee, 1981) as well as the education and experience of producers and their access to extension services (Bravo-Ureta and Pinheiro, 1993).

In the present study, environmental variables will be represented by the annual average climate conditions as climate has been found to influence aquaculture production (see Section 2). Moreover, the provincial number of aquaculture technical extension staff per unit of labor in aquaculture production will be included as a measure of the capacity of the extension system to offer services to producers. Despite their likely relevance for technical efficiency, farm-level characteristics, however, cannot easily be represented in the present study given its province-level nature and the poor data availability regarding aquaculture producers in China. Instead, the input levels will be considered as additional explanatory variables on Stage 2 because they carry important information 
about the characteristics of production, which in turn might be relevant for technical efficiency. The second-stage regression model then takes the following form:

$\ln T E_{i t}=\alpha_{0}+\sum_{k=1}^{K} \alpha_{k} \ln x_{k i t}+\alpha_{s} \ln s_{i t}+\sum_{m=1}^{M} \alpha_{m} c_{m i t}$

where $s_{i t}$ represents the total number of aquaculture technical extension staff per unit of labor in aquaculture production in province $i$ and year $t$, and $c_{m i t}$ stands for climate variable $m$ in the respective province and year. $\alpha$ represents the coefficients to be estimated and all other variables are defined as before.

The two-stage approach to analyzing the determinants of technical efficiency, however, has an econometric drawback. It has been criticized on the ground that regressing the technical efficiency scores on a set of explanatory variables in an auxiliary regression violates the assumption that the error term component $u_{i t}$ in the stochastic production frontier model is independent and identiacally distributed (Battese and Coelli, 1995). To remedy this issue, several authors (e.g. Reifschneider and Stevenson (1991); Battese and Coelli (1995)) have proposed procedures that involve incorporating a model determining technical inefficiency into the SFA model and allow for simultaneous estimation of both models. Pitt and Lee (1981), however, warn that methods aimed at avoiding biased estimation in an SFA context usually involve imposing further restrictions on the technical inefficiency term. Particularly given the aforementioned data limitations regarding farm-level characteristics of aquaculture producers in China, it would be unclear how to specify the technical inefficiency model in a way that would not be unduly restrictive. Hence, despite the above drawback, the two-stage approach will be employed in the present study in order to analyze which factors have a significant influence on technical efficiency.

\subsection{Data}

The panel data set employed for the present analyses contains data on inland aquaculture production and climate in 24 Chinese provinces over the period 1993-2009. The individual data were originally published in the corresponding issues of the Chinese 
Fishery Yearbook (Chinese Ministry of Agriculture, 1994-2010) and the China Statistical Yearbook (National Bureau of Statistics of China, 1994-2010).

The provinces included in the analysis are Anhui, Fujian, Gansu, Guangdong, Guangxi, Guizhou, Hainan, Hebei, Heilongjiang, Henan, Hubei, Hunan, Jiangsu, Jiangxi, Jilin, Liaoning, Inner Mongolia, Shaanxi, Shandong, Shanxi, Sichuan, Xinjiang, Yunnan and Zhejiang. The remaining provinces, province-level municipalities and special administrative regions were not considered due to their exceptional economic structures or due to insufficient data.

With respect to inland aquaculture production, the data set contains information on the aggregate provincial aquaculture output as well as on the aggregate use of input factors, including the water area, the amount of fry used for production, the number of professional laborers and the total capacity (i.e. weight) of boats. Moreover, it comprises information on the total number of aquaculture technical extension staff.

Table 6: Descriptive statistics of Chinese inland aquaculture production

\begin{tabular}{l|l|rrrrr}
\hline Variable & Unit & Mean & Std. Dev. & Min & Max & Obs \\
\hline Aggregate aquaculture output & tons & $620,047.4$ & $720,759.5$ & $5,314.0$ & $3,076,742.0$ & 408 \\
Water area & 1,000 ha & 207.6 & 174.4 & 6.8 & 683.7 & 408 \\
Fry & tons & $97,066.8$ & $140,222.1$ & 1.0 & $877,065.0$ & 408 \\
Labor & number & $129,631.0$ & $145,340.8$ & 354.0 & $758,649.0$ & 402 \\
Boat capacity & tons & $8,754.3$ & $24,709.2$ & 0.7 & $189,141.8$ & 408 \\
Extension staff & number & $1,677.2$ & $1,222.9$ & 132.0 & $6,981.0$ & 408 \\
Annual average temperature & ${ }^{\circ} \mathrm{C}$ & 14.9 & 5.1 & 4.4 & 25.4 & 408 \\
Total annual precipitation & $\mathrm{mm} / \mathrm{m}^{\wedge} 2$ & 944.3 & 510.7 & 159.8 & $2,678.9$ & 408 \\
\hline
\end{tabular}

Data: Chinese Ministry of Agriculture (1994-2010); National Bureau of Statistics of China (19942010)

Except for the total weight of boats used in aquaculture production, all data were either directly available or could be accurately calculated from the yearbooks. The total weight of boats in inland aquaculture (BIA) for province $i$ in year $t$ has been approximated by $B I A_{i t}=\overline{A B S}_{i} *\left(B F_{i t}-B M_{i t}\right)$, where $\overline{A B S}_{i}$ stands for the average share of the total weight of boats used for aquaculture (inland and marine production) in the total weight of boats used across all sub-sectors of fishery (capture fishery and aquaculture in inland and marine waters), $\mathrm{BF}^{29}$. $\mathrm{BM}$ in turn refers to the total weight of boats employed in marine fishery (marine capture fishery and marine aquaculture). Even though

\footnotetext{
${ }^{29}$ Due to poor data availability regarding the use of boats in aquaculture production, $A B S_{i}$ could not be calculated for each year but had to be calculated as the average over the period 2003-2007.
} 
approximations such as the above potentially introduce some degree of measurement error, they are not uncommon in the literature in cases where exact data are not available (e.g. Lin, 1992; Zhang and Carter, 1997). For the analysis of the determinants of technical efficiency, the total number of aquaculture technical extension staff in each province is normalized by the respective province's total number of laborers in inland and marine ${ }^{30}$ aquaculture because the extension system offers services to both types of aquaculture.

The provincial average climate conditions in each year are represented by the annual average air temperatures and the total annual precipitation levels of the respective capital cities. The approach of representing the climate of a wider geographical area by that of a single point in that area, like the capital city, is also followed in other studies (e.g. Horowitz, 2009). The above climate variables are chosen for this analysis because they can be considered to be key indicators of the environmental conditions under which inland aquaculture operates. Air temperatures critically determine the temperature of inland surface waters (Boyd and Tucker, 1998) and precipitation is an important source of those waters (Yoo and Boyd, 1993) ${ }^{31}$.

\subsection{Results and Discussion}

\subsubsection{Model Specification Tests}

The stochastic frontier model in this study (Eq. (16)) has been specified as a translog function with non-neutral technical change and time-varying technical efficiency. Moreover, the truncated normal distribution and the standard normal distribution have been imposed on the technical inefficiency error term and the white noise error term, respectively.

After maximum likelihood estimation of Eq. (16), the approach of Battese and Coelli (1992) and Battese et al. (2000) is followed, which involves testing the critical assumptions of the model using likelihood ratio tests (see Table 7).

\footnotetext{
${ }^{30}$ In the case of coastal provinces.

${ }^{31}$ See Section 2.3 for further details on the data. This study and the study in Section 2 draw on the same data set. 
Table 7: Likelihood ratio tests of model specification

\begin{tabular}{|c|c|c|c|c|}
\hline Null hypothesis $\left(H_{0}\right)$ & $H_{0}$ explanation & LR chi2 & Prob>chi2 & Implication \\
\hline $\mathrm{I}: \beta_{\mathrm{kn}}=\beta_{\mathrm{tk}}=\beta_{\mathrm{tt}}=0$ & $\begin{array}{l}\text { Model is of the Cobb-Douglas type } \\
\text { with neutral linear technical change }\end{array}$ & 296.10 & 0.0000 & $\mathrm{H}_{0}$ rejected \\
\hline II: $\beta_{\mathrm{tk}}=0$ & Technical change is neutral & 86.58 & 0.0000 & $\mathrm{H}_{0}$ rejected \\
\hline III: $\eta=0$ & Technical inefficiency is time-invariant & 31.98 & 0.0000 & $\mathrm{H}_{0}$ rejected \\
\hline $\mathrm{IV}: \mu=0$ & $\begin{array}{l}\text { Technical inefficiency follows a } \\
\text { half-normal distribution }\end{array}$ & 2.10 & 0.1474 & $\mathrm{H}_{0}$ accepted \\
\hline$V: \eta=\mu=0$ & $\begin{array}{l}\text { Technical inefficiency follows a half- } \\
\text { normal distribution and is time-invariant }\end{array}$ & 33.91 & 0.0000 & $\mathrm{H}_{0}$ rejected \\
\hline VI: $\eta=\mu=\gamma=0$ & All provinces are technically efficient & 685.13 & 0.0000 & $\mathrm{H}_{0}$ rejected \\
\hline
\end{tabular}

Notes:

1. The threshold for the rejection of the null hypothesis is marked by the $5 \%$-level of significance.

2. $\gamma=\sigma_{u}^{2} /\left(\sigma_{u}^{2}+\sigma_{v}^{2}\right)$

Based on the above tests, all null hypotheses are rejected, except for hypothesis no. III, which, contrary to prior expectations, supports the assumption that the technical inefficiency error term $u_{i t}$ follows a half-normal distribution $\left(N^{+}\left(0, \sigma_{u}^{2}\right)\right)$. Hence, the following results are based on a modified version of Eq. (16), which assumes a halfnormal distribution for $u_{i t}{ }^{32}$.

\subsubsection{Stochastic Frontier Model Estimation Results}

The results of a maximum likelihood estimation of the modified SFA model are presented in Table 12 in the appendix (Section 4.6). Employing these results, national output elasticities and returns to scale are calculated. The derivative of the natural logarithm of output with respect to time in turn yields point estimates regarding technical change. Table 8 provides an overview of the different elasticities.

\footnotetext{
${ }^{32}$ A comparison of the results regarding technical efficiency and the other components of TFP obtained under the different distributional assumptions however reveals only marginal differences.
} 
Table 8: Output elasticities

\begin{tabular}{r|rrrr|r|r}
\hline Year & Area & Fry & Labor & Boats & $\begin{array}{r}\text { Scale } \\
\text { Elasticity }\end{array}$ & Time \\
\hline 1993 & 0.2442 & 0.2485 & 0.0545 & 0.0389 & 0.5861 & 0.1354 \\
1994 & 0.2314 & 0.2454 & 0.0541 & 0.0390 & 0.5699 & 0.1269 \\
1995 & 0.2292 & 0.2355 & 0.0607 & 0.0395 & 0.5649 & 0.1193 \\
1996 & 0.2245 & 0.2212 & 0.0631 & 0.0442 & 0.5530 & 0.1128 \\
1997 & 0.2013 & 0.2271 & 0.0536 & 0.0404 & 0.5223 & 0.1042 \\
1998 & 0.1990 & 0.2154 & 0.0633 & 0.0392 & 0.5170 & 0.0975 \\
1999 & 0.1918 & 0.2070 & 0.0677 & 0.0382 & 0.5048 & 0.0905 \\
2000 & 0.1923 & 0.1876 & 0.0897 & 0.0333 & 0.5030 & 0.0861 \\
2001 & 0.1854 & 0.1765 & 0.0916 & 0.0349 & 0.4884 & 0.0797 \\
2002 & 0.1673 & 0.1702 & 0.0761 & 0.0436 & 0.4572 & 0.0722 \\
2003 & 0.1712 & 0.1579 & 0.0971 & 0.0360 & 0.4622 & 0.0658 \\
2004 & 0.1597 & 0.1493 & 0.0969 & 0.0370 & 0.4429 & 0.0592 \\
2005 & 0.1532 & 0.1391 & 0.1048 & 0.0357 & 0.4328 & 0.0524 \\
2006 & 0.1452 & 0.1320 & 0.1127 & 0.0337 & 0.4235 & 0.0447 \\
2007 & 0.1662 & 0.1337 & 0.1017 & 0.0119 & 0.4135 & 0.0424 \\
2008 & 0.1599 & 0.1084 & 0.1409 & 0.0148 & 0.4239 & 0.0350 \\
2009 & 0.1578 & 0.0821 & 0.1760 & 0.0103 & 0.4262 & 0.0313 \\
Average & $\mathbf{0 . 1 8 7 3}$ & $\mathbf{0 . 1 7 8 4}$ & $\mathbf{0 . 0 8 8 6}$ & $\mathbf{0 . 0 3 3 7}$ & $\mathbf{0 . 4 8 7 9}$ & $\mathbf{0 . 0 7 9 8}$ \\
\hline
\end{tabular}

It emerges from Table 8 that Chinese inland aquaculture is strongly characterized by decreasing returns to scale. Over the period under observation, a $1 \%$ increase in all input factors on average resulted only in a $0.49 \%$ increase in output. Moreover, the results show that the development of the scale elasticity follows a negative trend (from 0.59 in 1993 to 0.43 in 2009). This trend results from decreases in the output elasticities with respect to area (average elasticity: 0.19), fry (average elasticity: 0.18) and boats (average elasticity: 0.03). Only the output elasticity with respect to labor (average elasticity: 0.09) is increasing over time. The development of the elasticity of output with respect to time is again characterized by a marked negative trend between $1993(0.14)$ and 2009 (0.03), implying a slowdown in technological advances in Chinese aquaculture ${ }^{33}$.

According to the underlying data set on inland aquaculture, China has substantially increased the use of inputs over the time period under observation. However, the water area seems to emerge as a limiting factor in the expansion of aquaculture production. Naturally, inland waters are in nearly constant supply and it has to be assumed that, given the size of the national inland aquaculture sector, a large part of the suitable

\footnotetext{
${ }^{33}$ The use of point estimates for analyzing technical change has been criticized in the context of discrete data (see Section 4.2.3). See Section 4.4.3 for further details on technical change. 
inland waters of decent quality are already being used for production. Thus, it does not come as a surprise to find that the expansion in the use of water area has been comparatively small. After 2006, the national inland aquaculture area has even decreased to some degree. Consequently, it is reasonable to find the output elasticity with respect to the water area to be among the highest over the entire time period. The limited water area also offers an explanation for the decreasing output elasticities with respect to fry and boats because according to the law of diminishing marginal returns, strong increases in the use of certain input factors given only limited increases in the use of other input factors imply decreasing output elasticities with respect to the input factors being heavily used. Specifically, in the context of inland aquaculture production it should be noted that any aquatic environment has a limited carrying capacity, which implies an upper ceiling for the stocking density of fry (given a certain level of technology). Similarly, ever-increasing input levels regarding boats would lead to congestion effects, which would gradually reduce the corresponding marginal effect. Based on the output elasticities in 2009, the capacity of boats currently in use should already be very close to the limit of usefulness, while further increases in the use of fry could still have a positive marginal effect on output. Labor, however, emerges as a special case. Despite strong growth in the use of labor for aquaculture production, the output elasticity with respect to this factor has increased over time. One explanation for this is offered by the interaction term of labor and time in the SFA model. The corresponding coefficient estimate is positive, which means that technical change has been labor-saving over time. In other words, technical change has enabled a given number of laborers to produce more output, which has contributed to a growing elasticity of output with respect to labor.

The negative interaction terms of the other input factors with time reveal that technical change has been area-, fry- and boat-using. Thus, technical change fosters a development away from small-scale low-intensity production towards high-intensity production at larger scales.

\subsubsection{Total Factor Productivity}

The individual components of national TFPC are calculated according to Eq. (17) to (19). Table 9 shows the TEC, TC and SC in every year relative to the previous year as 
well as the cumulative changes with 1993 serving as the base period. Figure 12 gives a graphical impression of the cumulative changes.

Table 9: Change in total factor productivity and its components

\begin{tabular}{r|rrrrrr|rr}
\hline Year & TEC & TEC cum. & $T C$ & TC cum. & $S C$ & SC cum. & $T F P C$ & TFPC cum. \\
\hline 1993 & & $\mathbf{1}$ & & $\mathbf{1}$ & & $\mathbf{1}$ & & $\mathbf{1}$ \\
1994 & 0.9625 & $\mathbf{0 . 9 6 2 5}$ & 1.1402 & $\mathbf{1 . 1 4 0 2}$ & 0.9556 & $\mathbf{0 . 9 5 5 6}$ & 1.0486 & $\mathbf{1 . 0 4 8 6}$ \\
1995 & 0.9836 & $\mathbf{0 . 9 4 6 7}$ & 1.1310 & $\mathbf{1 . 2 8 9 6}$ & 0.9530 & $\mathbf{0 . 9 1 0 7}$ & 1.0602 & $\mathbf{1 . 1 1 1 8}$ \\
1996 & 0.9834 & $\mathbf{0 . 9 3 1 0}$ & 1.1230 & $\mathbf{1 . 4 4 8 2}$ & 0.9689 & $\mathbf{0 . 8 8 2 3}$ & 1.0700 & $\mathbf{1 . 1 8 9 7}$ \\
1997 & 0.9832 & $\mathbf{0 . 9 1 5 4}$ & 1.1146 & $\mathbf{1 . 6 1 4 2}$ & 0.9791 & $\mathbf{0 . 8 6 3 9}$ & 1.0729 & $\mathbf{1 . 2 7 6 4}$ \\
1998 & 0.9830 & $\mathbf{0 . 8 9 9 8}$ & 1.1061 & $\mathbf{1 . 7 8 5 4}$ & 0.9688 & $\mathbf{0 . 8 3 6 9}$ & 1.0533 & $\mathbf{1 . 3 4 4 5}$ \\
1999 & 0.9828 & $\mathbf{0 . 8 8 4 3}$ & 1.0985 & $\mathbf{1 . 9 6 1 4}$ & 0.9734 & $\mathbf{0 . 8 1 4 6}$ & 1.0509 & $\mathbf{1 . 4 1 2 9}$ \\
2000 & 0.9826 & $\mathbf{0 . 8 6 8 9}$ & 1.0923 & $\mathbf{2 . 1 4 2 4}$ & 1.0220 & $\mathbf{0 . 8 3 2 6}$ & 1.0969 & $\mathbf{1 . 5 4 9 8}$ \\
2001 & 0.9823 & $\mathbf{0 . 8 5 3 5}$ & 1.0864 & $\mathbf{2 . 3 2 7 6}$ & 0.9783 & $\mathbf{0 . 8 1 4 5}$ & 1.0441 & $\mathbf{1 . 6 1 8 1}$ \\
2002 & 0.9821 & $\mathbf{0 . 8 3 8 3}$ & 1.0789 & $\mathbf{2 . 5 1 1 2}$ & 0.9642 & $\mathbf{0 . 7 8 5 3}$ & 1.0216 & $\mathbf{1 . 6 5 3 1}$ \\
2003 & 0.9819 & $\mathbf{0 . 8 2 3 1}$ & 1.0714 & $\mathbf{2 . 6 9 0 7}$ & 0.9746 & $\mathbf{0 . 7 6 5 4}$ & 1.0254 & $\mathbf{1 . 6 9 5 0}$ \\
2004 & 0.9817 & $\mathbf{0 . 8 0 8 0}$ & 1.0645 & $\mathbf{2 . 8 6 4 3}$ & 0.9860 & $\mathbf{0 . 7 5 4 6}$ & 1.0304 & $\mathbf{1 . 7 4 6 5}$ \\
2005 & 0.9815 & $\mathbf{0 . 7 9 3 0}$ & 1.0574 & $\mathbf{3 . 0 2 8 7}$ & 0.9749 & $\mathbf{0 . 7 3 5 7}$ & 1.0118 & $\mathbf{1 . 7 6 7 1}$ \\
2006 & 0.9812 & $\mathbf{0 . 7 7 8 2}$ & 1.0498 & $\mathbf{3 . 1 7 9 5}$ & 0.9613 & $\mathbf{0 . 7 0 7 3}$ & 0.9903 & $\mathbf{1 . 7 4 9 9}$ \\
2007 & 0.9810 & $\mathbf{0 . 7 6 3 4}$ & 1.0445 & $\mathbf{3 . 3 2 1 1}$ & 1.0922 & $\mathbf{0 . 7 7 2 5}$ & 1.1192 & $\mathbf{1 . 9 5 8 5}$ \\
2008 & 0.9808 & $\mathbf{0 . 7 4 8 8}$ & 1.0395 & $\mathbf{3 . 4 5 2 2}$ & 0.9347 & $\mathbf{0 . 7 2 2 0}$ & 0.9529 & $\mathbf{1 . 8 6 6 3}$ \\
2009 & 0.9806 & $\mathbf{0 . 7 3 4 2}$ & 1.0337 & $\mathbf{3 . 5 6 8 7}$ & 1.0230 & $\mathbf{0 . 7 3 8 6}$ & 1.0369 & $\mathbf{1 . 9 3 5 3}$ \\
\hline
\end{tabular}

An inspection of the results reveals that technical efficiency has continually decreased over time. This is apparent from the fact that TEC in the above table is below unity over the entire time period ${ }^{34}$. The average annual decrease in technical efficiency has amounted to $1.9 \%$. In cumulative terms, this has resulted in a loss of technical efficiency of $26.6 \%$ between 1993 and 2009. By implication, aquaculture producers find it increasingly difficult to reach the frontier level of output. In the context of Chinese agriculture this result is not totally uncommon. In their study on grain production in China, Chen et al. (2013), for example, also find a negative trend regarding technical efficiency, for which they see one reason in insufficient management skills of farm households. Similarly, it is possible that a deterioration in the average management ability or skill level of aquaculture producers has contributed to the above reduction in technical efficiency.

Another reason why producers are not able to maintain their position relative to the production frontier could be the strong outward movements of the frontier apparent in

\footnotetext{
${ }^{34}$ A negative trend of the average technical efficiency also emerges directly from the estimation results of the SFA model wehere the inefficiency trend parameter $\eta$ is negative $(-0.02)$. 
the technical change component in Table 9. Specifically, it might be that the management abilities of producers are insufficient to cope with the rapid introduction of technical innovations. Brümmer et al. (2006) moreover see a reason for a slowdown in technical efficiency change in China's grain sector during the 1990's in the deteriorating state of the country's extension system. Given that inland aquaculture receives services from China's public agricultural extension system (PAES) just like the wider agricultural sector ( $\mathrm{Hu}$ et al., 2009), this might also be responsible for the decreasing technical efficiency in inland aquaculture ${ }^{35}$. Another possible explanation, which however cannot be fully evaluated in this study, is related to the increasing surface water pollution in many regions of China, which has been identified as a major health risk for the country's population (Wu et al., 1999; Zhang et al., 2010). It is reasonable to assume that increasing water pollution also negatively affects aquaculture production and increasingly prevents producers from utilizing the full potential of their production technology. Moreover, aquaculture itself might contribute to water pollution. With respect to China, Cao et al. (2007) note that concerns are growing regarding the detrimental impact of the waste from aquaculture on the sector's own productivity and the ecosystem.

\section{Figure 12: Cumulative change in total factor productivity and its components}

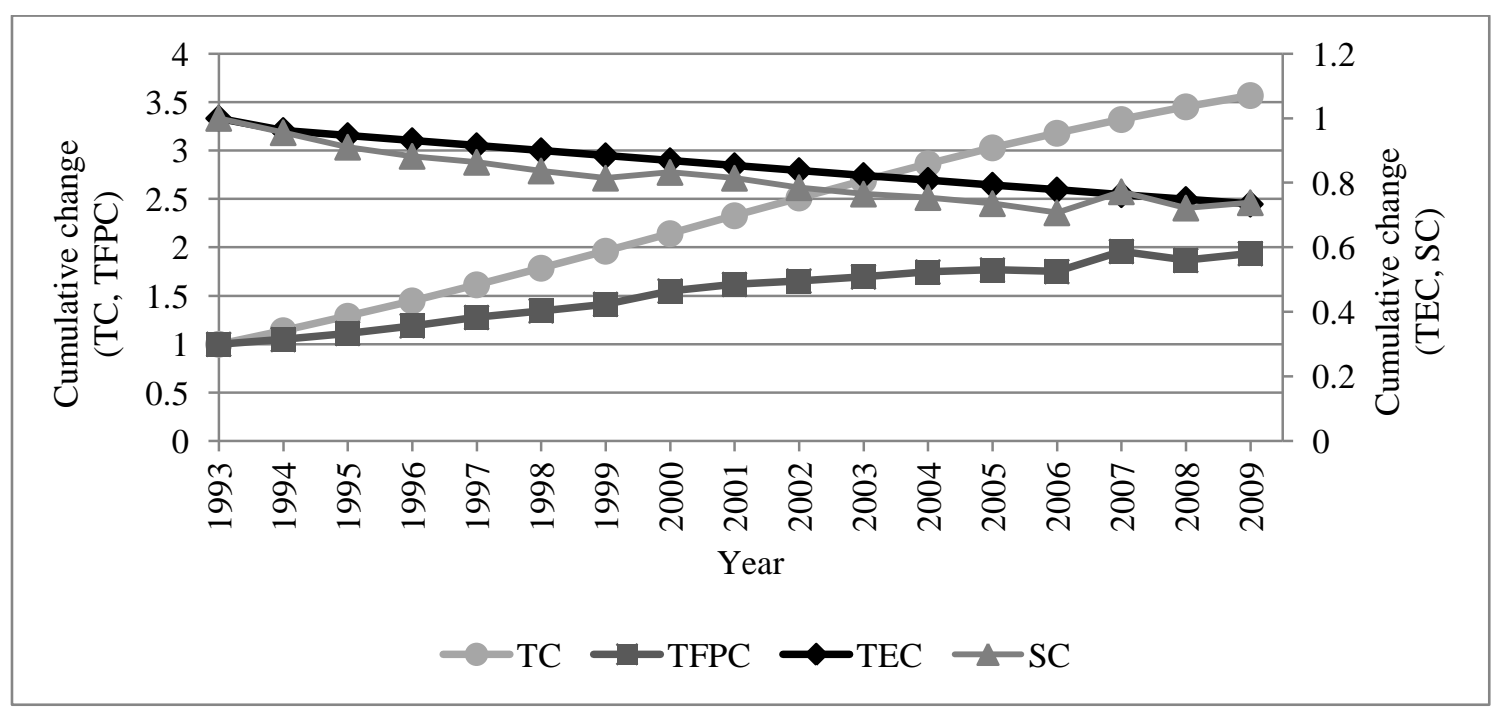

Note: $\quad$ Base period 1993

As outlined above, technical change in the aquaculture sector has been strongly positive between 1993 and 2009. The average rate of annual technical change amounted to $8.3 \%$, while, relative to the base period, technology has improved by $256.9 \%$ until 2009 .

\footnotetext{
${ }^{35}$ For a more detailed analysis see Section 4.4.4.
} 
This finding of substantial improvements in technology is well in line with the literature. Leung and Shang (1993) for example note that the expansion in China's inland aquaculture output has in part been due to the introduction of modern technologies. Weimin and Mengqing (2007) confirm that technological advances regarding production systems have continued to play an important role in shaping the development of Chinese aquaculture production until the present time ${ }^{36}$.

The development of the technical change index in Table 9, however, also reveals a notable slowdown in technical change, which has already been visible in the elasticities of output with respect to time. Possibly, the aforementioned deterioration of the extension system does not only hinder producers in their attempts to reach the frontier level of output, but also slows down the introduction and diffusion of new technologies, which would result in reduced rates of technical change. Another possibility is that some of the recent technological advances have not met the exact requirements of aquaculture producers and were hence not adopted ${ }^{37}$.

It has already been discussed in the previous section that Chinese inland aquaculture is characterized by decreasing returns to scale and that the level of the returns to scale has been shrinking between 1993 and 2009. Table 9 additionally shows that the changes in returns to scale have a negative effect on total factor productivity growth. In cumulative terms, the scale index has decreased by around $26.1 \%$ between 1993 and 2009. Given the situation of decreasing returns to scale and positive output elasticities found for Chinese inland aquaculture, Eq. (19) implies that an increasing input use and a decreasing level of scale elasticity will both contribute to reductions in total factor productivity growth. As stated above, input use in Chinese inland aquaculture as a whole has on average risen between 1993 and 2009. Together with the observed decreases in the level of returns to scale, this explains the negative contributions of the development of the scale index to TFP growth.

Overall, TFP has increased substantially over the time period 1993 until 2009. The cumulative improvement in TFP amounts to $93.5 \%$. The average annual TFPC has been around $4.3 \%$. Given the mostly negative contributions of technical efficiency change and scale change to TFPC, it emerges that technical change has, despite the observed

\footnotetext{
${ }^{36}$ These studies, however, did not provide concrete empirical evidence regarding technical change.

${ }^{37}$ Similar arguments have also been used by Chen et al. (2013) to explain a slowdown in technical change in Chinese grain farming.
} 
slowdown, been the dominant factor in the development of TFP in Chinese inland aquaculture.

Since increases in output are either due to an increasing use of inputs or due to improvements in TFP (Del Gatto, 2011), the results regarding TFPC also allow to draw conclusions with respect to the contributions of input growth to the observed growth in output. Specifically, the contribution of input growth is obtained as the residual between output growth and TFPC.

Table 10: Output growth decomposition

\begin{tabular}{r|r|rr}
\hline Year & Output growth rate & Due to TFP growth & Due to input growth \\
\hline 1994 & $22.23 \%$ & $4.86 \%$ & $17.37 \%$ \\
1995 & $19.51 \%$ & $6.02 \%$ & $13.49 \%$ \\
1996 & $17.36 \%$ & $7.00 \%$ & $10.35 \%$ \\
1997 & $11.22 \%$ & $7.29 \%$ & $3.93 \%$ \\
1998 & $6.79 \%$ & $5.33 \%$ & $1.46 \%$ \\
1999 & $7.59 \%$ & $5.09 \%$ & $2.50 \%$ \\
2000 & $6.71 \%$ & $9.69 \%$ & $-2.98 \%$ \\
2001 & $5.06 \%$ & $4.41 \%$ & $0.65 \%$ \\
2002 & $6.16 \%$ & $2.16 \%$ & $3.99 \%$ \\
2003 & $4.68 \%$ & $2.54 \%$ & $2.14 \%$ \\
2004 & $6.88 \%$ & $3.04 \%$ & $3.84 \%$ \\
2005 & $6.22 \%$ & $1.18 \%$ & $5.04 \%$ \\
2006 & $7.39 \%$ & $-0.97 \%$ & $8.36 \%$ \\
2007 & $-8.12 \%$ & $11.92 \%$ & $-20.04 \%$ \\
2008 & $5.32 \%$ & $-4.71 \%$ & $10.03 \%$ \\
2009 & $7.01 \%$ & $3.69 \%$ & $3.32 \%$ \\
\hline
\end{tabular}

Between 1994 and 1998, the growth in Chinese inland aquaculture output has slowed down noticeably from $22.2 \%$ to $6.8 \%$. Table 10 shows that this was primarily related to a decreasing contribution of input growth to output growth. The output growth rates remained positive after 1998 but ceased to display a clear trend. While the relative contributions of TFPC and input growth to output growth were subject to a fair degree of variability since then, it clearly emerges that input growth has lost its initially dominant influence on output growth. In 2009, the two factors made approximately equal contributions to output growth. This is well in line with the negative trend in returns to scale found in this study. Particularly before a background of constrained water resources and increasing environmental burdens, it has to be expected that the contributions of input growth to output growth will decrease further. Hence, 
improvements in TFP will likely become increasingly important for future output increases.

\subsubsection{Technical Efficiency}

The results discussed in the previous section confirm the important role, which technical change has played for the development of the Chinese inland aquaculture sector. However, the results have also revealed that on average producers have experienced a deterioration of their position relative to the production frontier. This is apparent in the decreasing level of technical efficiency. As technical change is slowing down, the question of effective utilization of the available technology becomes increasingly important. Hence, technical efficiency needs to be examined in greater detail.

Based on the error term component $u_{i t}$, which captures province- and year-specific technical inefficiency, the corresponding technical efficiency scores have been calculated. Figure 13 shows the results for the last year of the analysis, while Figure 14 shows the average technical efficiency scores over the period 1993 until 2009.

Figure 13: Technical efficiency in Chinese inland aquaculture (2009)

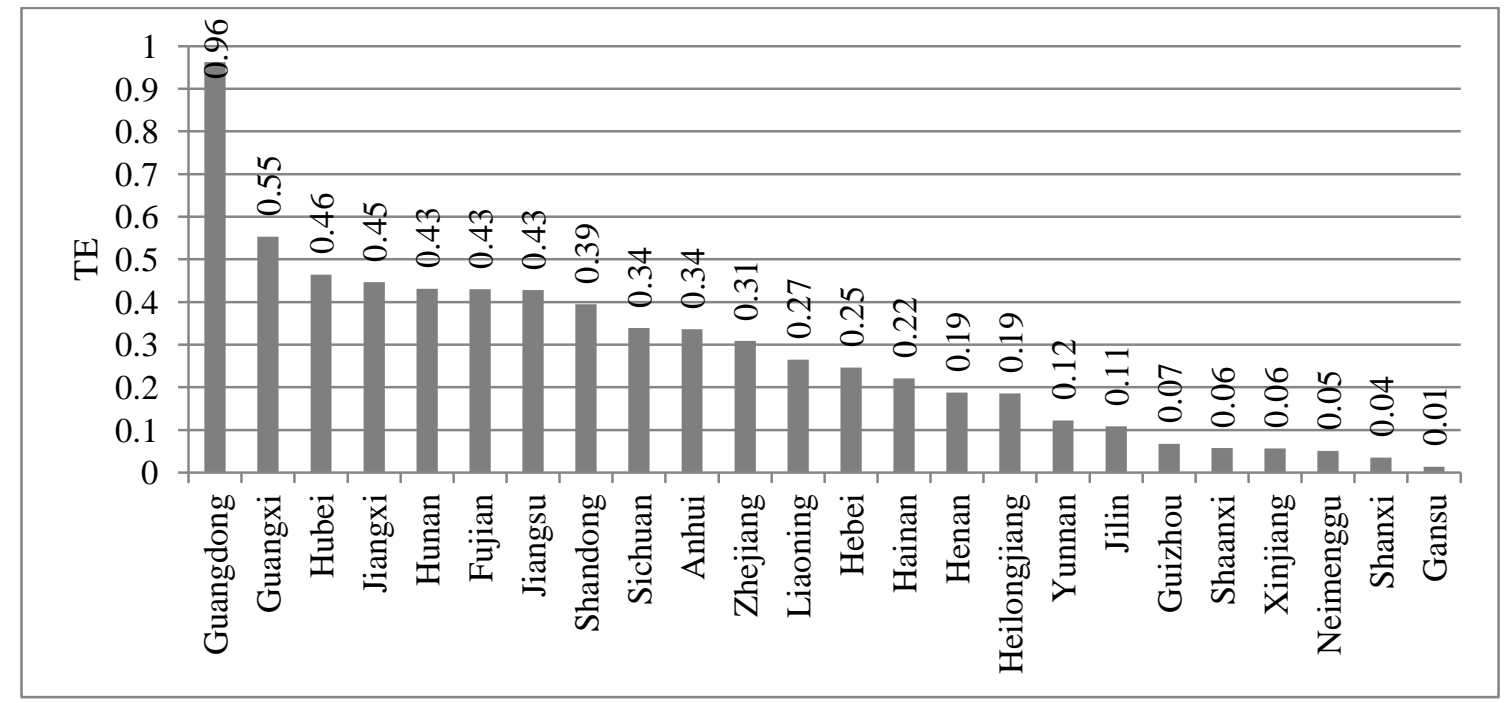

It emerges that Chinese inland aquaculture is characterized by a considerable heterogeneity with respect to the provincial levels of technical efficiency. In 2009, the scores range from 0.96 (Guangdong) to 0.01 (Gansu). The average technical efficiency in that year amounts to around 0.28 . 
Figure 14: Technical efficiency in Chinese inland aquaculture (average: 1993-2009)

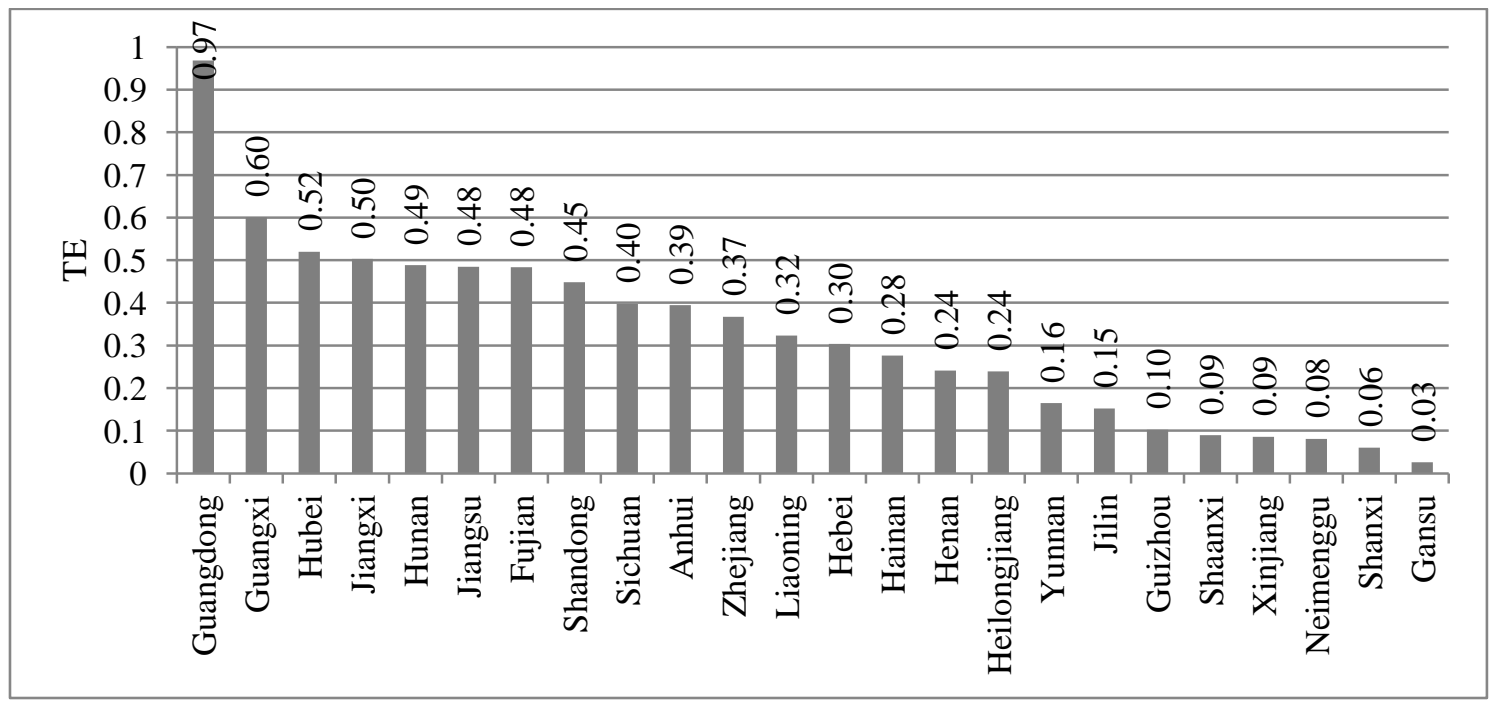

A comparison with the average provincial TE scores again reveals the negative trend in technical efficiency already discussed in the previous section. The national average of the average TE scores amounts to around 0.32 .

Based on the range of the TE scores in 2009, a classification of the provinces into four groups is suggested: A high efficiency (HE) group (TE $>0.8$ ), which in this case contains only the best-practice example (Guangdong), an upper middle efficiency (UME) group $(0.4<\mathrm{TE} \leq 0.8)^{38}$, a lower middle efficiency (LME) group $(0.2<\mathrm{TE} \leq 0.4)$ and a low efficiency (LE) group (TE $\leq 0.2)$.

The overall range and the average of the efficiency scores found in this study differ from the results found by Sharma et al. (1999), who find TE scores between 0.39 and 1.0 and an average score of 0.83 . There are, however, decisive differences between their study and the present one, which can explain the divergence in results. Besides methodological differences and different years of observation ${ }^{39}$, Sharma et al. (1999) use a much smaller data set comprising individual aquaculture farms from only eight provinces, all of which, except for Heilongjiang, are located in a geographically rather confined region in the east and southeast of China ${ }^{40}$. Moreover, they limit their analysis to only one variety of inland aquaculture production, namely fish polyculture in ponds. Given this narrower scope, as compared to the present study, and the likely more

\footnotetext{
${ }^{38}$ The TE range between 0.6 and 0.8 is empty for 2009 . Hence, for ease of exposition this TE range has been merged with the next lower one.

${ }^{39}$ Only 1985 in Sharma et al. (1999).

${ }^{40}$ Only one of these provinces falls into the LE group identified in this study.
} 
pronounced similarity between their objects of study, it is not surprising that they find a narrower distribution and a higher average TE score.

Figure 15 shows the geographical distribution of the TE scores obtained in the present study. Technical efficiency is highest in the south and southeast of China as well as in the other provinces along its eastern coast. This region is largely congruent with China's major production areas. Leung and Shang (1993) point out that Guangdong, Hubei, Hunan, Jiangsu, Shanghai and Zhejiang already accounted for a share in national pond aquaculture output in excess of $70 \%$ in 1988. In the data set used for the present study, the HE and the UME group together account for around 66\% of the aggregate inland aquaculture output in 2009, while the more efficient half of the 24 provinces under consideration together produce around $90 \%$ of the aggregate output. Hence, the size and by implication the development of a province's aquaculture sector seem to be correlated with technical efficiency.

Figure 15: Geographical distribution of technical efficiency (2009)

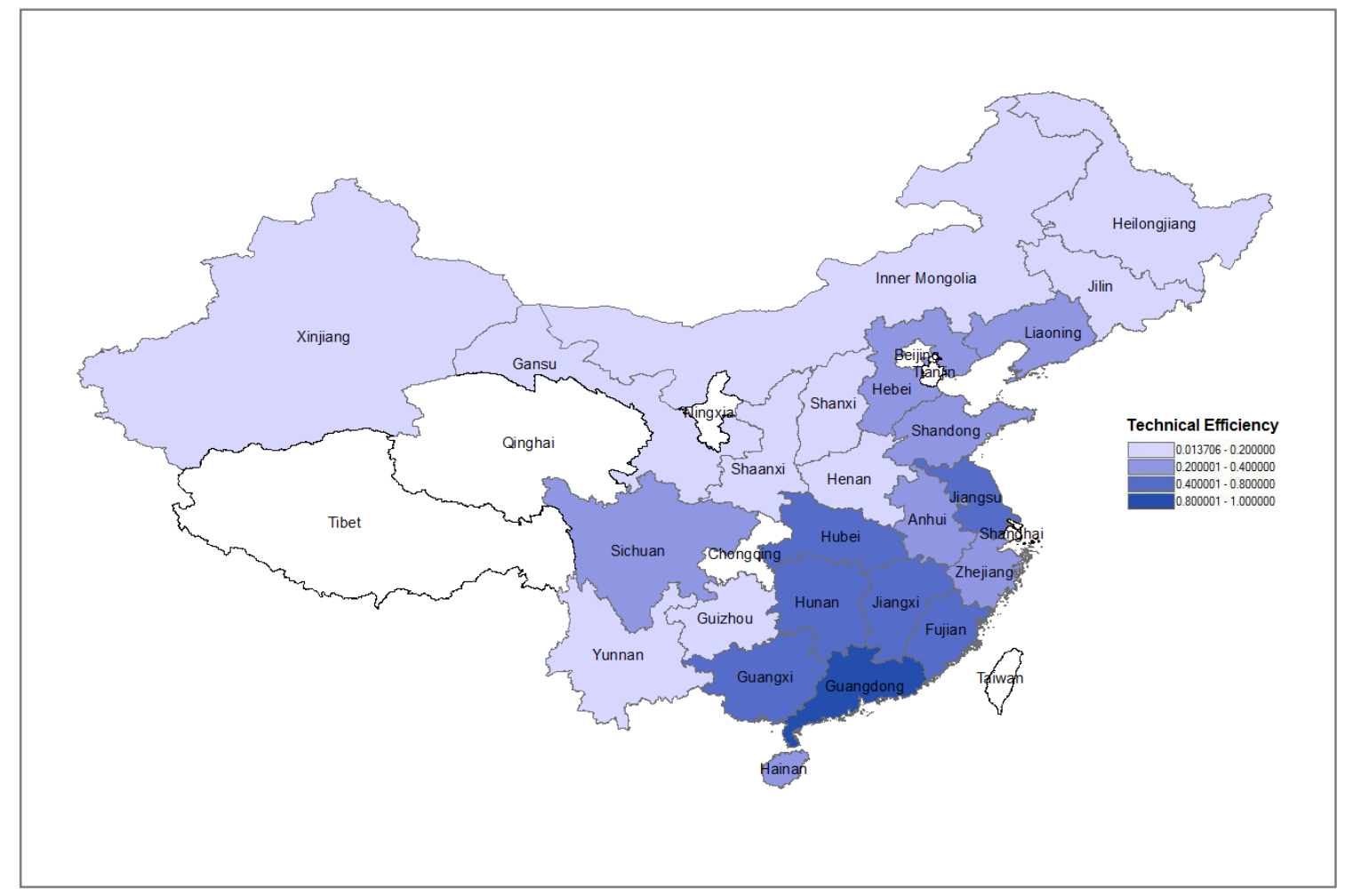

In addition, Chen et al. (1995) identify three sets of factors that are likely to have influenced the regional development of aquaculture in China. First, the provinces in the southeast and east have a much longer tradition of aquaculture production than those in the North, where much of the production was only established after the onset of the 
reforms (i.e. after 1978). Thus, producers in the former group of provinces can be expected to have accumulated considerably more experience and to have achieved higher average skill levels. Second, in comparison to the remainder of the country, the southeastern and eastern regions are characterized by generally high levels of water availability and a climate favorable to aquaculture production. Third, the general level of economic development and infrastructure is higher in China's eastern and southeastern regions, which eases access to capital, input factors, training and markets with a high demand for aquaculture products. Generally, these factors can explain why the provinces with high levels of technical efficiency in inland aquaculture production are clustered in the water-rich and developed southeast and east of China, which has a long aquaculture tradition, and why the comparatively water-scarce and less developed provinces in the west and north of China, which do not have such a long aquaculture tradition, mostly reach only very low levels of technical efficiency. Some of these factors diverge so strongly between the different regions of China (e.g. between the southeast and the northwest) that the substantial differences in TE between the most and the least efficient provinces are not surprising.

An auxiliary (i.e. second-stage) regression of the technical efficiency scores on the total number of aquaculture technical extension staff per unit of labor in aquaculture production as well as on input and climate variables (based on Eq. (20)) is applied to obtain further insights with respect to the determinants of technical efficiency. The results of two fixed effects panel regressions are displayed in Table 11.

Table 11: Analysis of technical efficiency

\begin{tabular}{|c|c|c|c|c|c|c|}
\hline Model & & $(F E)$ & & II & $(F E)$ & \\
\hline & coefficient & t-value & & coefficient & t-value & \\
\hline (ln)Extension & 0.0906 & 3.74 & $* * *$ & 0.0927 & 6.31 & $* * *$ \\
\hline (ln)Area & 0.0268 & 0.79 & & & & \\
\hline (ln)Fry & -0.0499 & -4.41 & $* * *$ & & & \\
\hline (ln)Labor & 0.0629 & 2.23 & $* *$ & & & \\
\hline (ln)Boats & -0.0744 & -7.52 & $* * *$ & & & \\
\hline Avg. temp. & -0.0238 & -1.97 & $* *$ & -0.0392 & -2.95 & $* * *$ \\
\hline Tot. precip. & 4.38E-05 & 1.36 & & $2.50 \mathrm{E}-05$ & 0.71 & \\
\hline Constant & -0.5772 & -1.70 & $*$ & -0.5065 & -2.47 & $* *$ \\
\hline Observations & 402 & & & 402 & & \\
\hline Provinces & 24 & & & 24 & & \\
\hline R-squared & 0.5379 & & & 0.4882 & & \\
\hline
\end{tabular}

Note: $*$ significant at $10 \%$-level; ** significant at $5 \%$-level; *** significant at $1 \%$-level 
Model I contains the full set of explanatory variables discussed in Section 4.2.4, whereas Model II contains a reduced set of explanatory variables, which does not include regular input variables. The latter model serves purely as a sensitivity test. A comparison of the results reveals that the coefficient estimates with respect to extension and climate are remarkably stable across the models. Since most of the regular input factors, except for the water area turn out to have a significant effect on the level of technical efficiency, Model $\mathrm{I}$ is more informative and hence remains the preferred specification.

What particularly stands out regarding the results is that an increase in the total number of aquaculture technical extension staff per unit of labor in aquaculture production would have the largest marginal effect on technical efficiency in Chinese inland aquaculture. Generally, the link between extension services and technical efficiency in agricultural production is well established. Bravo-Ureta and Pinheiro (1993) provide an overview of various studies analyzing the determinants of technical efficiency in agricultural production and find that all studies, which consider extension services, find them to have a positive and significant marginal effect on technical efficiency. Specifically, as Kalirajan (1984) points out, extension services can help producers to improve their knowledge and to efficiently employ their available production technologies.

With respect to the Chinese extension system, the available data, however, reveal that the total number of aquaculture technical extension staff has decreased noticeably over time. Figure 16 shows the development between 1993 and 2009. Since the number of laborers in aquaculture production has increased substantially over the same period, it emerges that the number of aquaculture technical extension staff per unit of labor in aquaculture production has decreased. Hence, the estimate in Model I (Table 11) implies that the decreasing capacity of the extension system to offer services to aquaculture producers has contributed to the decreases in technical efficiency discussed earlier ${ }^{41}$.

\footnotetext{
${ }^{41}$ This also supports the corresponding assumption in the previous section. 
Figure 16: Aquaculture technical extension staff in China

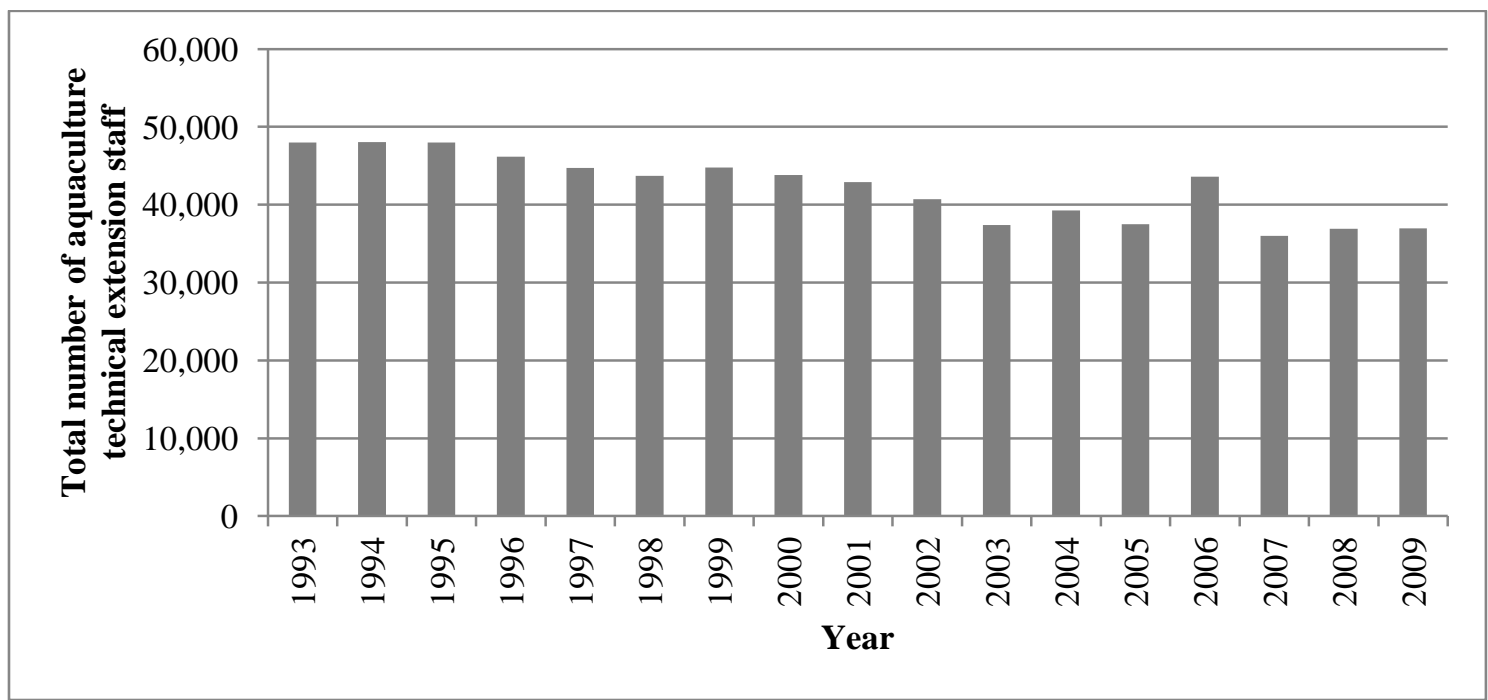

Data: Chinese Ministry of Agriculture (1994-2010)

Moreover, the results of Model I show that an intensification of production in terms of employing more labor would increase technical efficiency, whereas using larger quantities of fry or increasing the total capacity of boats used for production would reduce technical efficiency at the margin. It seems likely that employing more labor increases the management capacity of aquaculture operations, which would explain the positive effect on technical efficiency. Ceteris paribus increases in the use of fry in turn might imply a development towards more dense (i.e. more complicated) production procedures, whereas raising the capacity of boats in production could disturb fish growth, which would imply a lower output weight for given levels of technology and a given use of the other inputs.

Based on the results regarding the climate variables, the assumption that climate affects the level of technical efficiency in Chinese inland aquaculture is confirmed. Specifically, it emerged that increasing annual average temperatures due to changes in climate would, ceteris paribus, have a negative and statistically significant marginal effect on technical efficiency. Hence, it can be concluded that the rise in annual average temperatures, which has occurred in China over the observation period ${ }^{42}$, has also contributed to the observed reduction in technical efficiency. It seems possible that the rising water temperatures cause additional managerial and technical challenges, to which not all producers can suitably respond.

\footnotetext{
${ }^{42}$ See Section 2.1 .
} 
The total annual amount of precipitation however turns out to have no statistically significant effect on technical efficiency, which might be related to the fact that precipitation, despite its importance as a source of surface and pond water, represents only an imperfect proxy for overall water availability.

\subsubsection{Sensitivity Analysis}

The singular situation of Guangdong, which turns out to be the only province in the HE group, might raise the suspicion that this province is a statistical outlier that biases the results of the present study. It is however the case that Guangdong benefits from all of the above factors that have been identified as being conducive to high levels of technical efficiency in inland aquaculture. It had one of the highest output levels in 2009 , has a long tradition of aquaculture production, features plenty of water from the Pearl River and its tributaries as well as from high levels of precipitation, and it is characterized by a warm climate and one of the highest levels of development in China. Further support comes from Leung and Shang (1993) who already mentioned the Pearl River delta in Guangdong as one of the highest yielding regions in China. Thus, high levels of technical efficiency in Guangdong do not come as a surprise.

Nevertheless, for the purpose of sensitivity testing, the analyses of the previous chapters have been repeated using a reduced sample, from which the most and the least efficient province (Guangdong and Gansu) have been dropped. The results proved to be remarkably stable, which strengthens the validity of the initial results using the full sample. The values of the technical efficiency scores of the individual provinces experience a general upward shift if Guangdong is not included, which was to be expected, and a small number of provinces slightly change their position in the technical efficiency ranking. However, all major conclusions regarding output and scale elasticities and with respect to the development of TFP and its components are still valid. Differences emerge only with respect to the magnitude of individual effects. The reduction in technical efficiency and the improvement in technology over time for example both turn out to be slightly weaker. TFP growth however is not severely affected as these two differences seem to approximately balance out. Regarding the determinants of technical efficiency, the main conclusions also remain unaltered. Specifically, the marginal effect of changes in the number of aquaculture technical extension staff per unit of labor in aquaculture production is still positive and significant 
and that of changes in annual average temperatures is still negative and significant. However, the coefficient estimate regarding extension turns out to be smaller.

The results of the analysis using the reduced sample can be found in the appendix (Section 4.6, Tables 13-15, Figure 17).

\subsection{Conclusions}

This study has filled several gaps in the current literature on total factor productivity and its determinants in the context of Chinese inland aquaculture production. Specifically, it does not rely on a small sample of farm level data and is not specific to individual regions, culture techniques or species. Instead, the present study is based on a province-level panel data set on aggregate aquaculture production that covers all relevant production regions in China and all culture techniques and species. It hence provides a detailed analysis of the development of TFP and its components in the Chinese inland aquaculture sector as a whole between 1993 and 2009. Moreover, a particular focus has been placed on analyzing the development, geographical distribution and determinants of provincial technical efficiency scores. For the purpose of these analyses, a stochastic frontier approach based on the pioneering contributions of Aigner et al. (1977) and of Meeusen and van Den Broeck (1977) has been employed.

From the obtained output elasticities it is apparent that the water area likely acts as a bottle-neck for inland aquaculture production since it can be expanded only to a limited extent. Consequently, increasing stocking densities and boat usage have likely led to decreasing elasticities of output with respect to these input factors. Only the elasticity of output with respect to labor has on average increased over time, which might at least partly stem from technical change that renders labor more productive. Overall, Chinese inland aquaculture is characterized by decreasing returns to scale, which follow a negative trend over time. Hence, further expansions in the scale of production will lead to gradually declining marginal increases in output.

From the analysis of the components of TFP growth it emerged that technical efficiency has decreased noticeably over the time period under observation, while technical change was strongly positive, though at a decreasing rate. This has led to the conclusion that for different reasons, Chinese aquaculture producers cannot keep up with the strong technical change and hence experience a deterioration in their position relative to the 
production frontier. Nevertheless, despite the reduction in technical efficiency and the negative effects of scale changes on TFP growth, technical change has led to a near doubling of TFP between 1993 and 2009.

The level of technical efficiency has been found to vary strongly among the Chinese provinces, which has been explained by the considerable heterogeneity of the provinces. Several factors have been put forth to explain the geographical clustering of the more efficient provinces: A long history of aquaculture production, high levels of water availability, favorable climate conditions and high levels of economic development. In all these respects, the southeastern and eastern provinces of China are at an advantage, which should contribute to higher levels of technical efficiency.

A more detailed analysis of the determinants of technical efficiency has revealed the importance of extension services for the technical efficiency in aquaculture production. Specifically, it has been found that a larger number of aquaculture technical extension staff per unit of labor in aquaculture production would lead to a higher level of technical efficiency as extension services can help to improve the knowledge level of producers and their ability to fully employ the potential of their technology. Based on this finding, it has been concluded that the decreasing number of staff in China's aquaculture extension system is likely to have been an important reason for the observed decrease in technical efficiency levels over the observation period. Moreover, the analysis has shown that increasing annual average temperatures lead to decreasing levels of technical efficiency and that an intensification of production in terms of increasing the use of the different inputs would have mixed effects.

The results presented in this study allow drawing a number of policy-relevant conclusions. Since increases in total factor productivity have contributed strongly to output growth, future policies towards increasing inland aquaculture output should include measures aimed at total factor productivity and its determinants.

Technical change has been the dominant driver of the development of total factor productivity in Chinese inland aquaculture over the time period under analysis. Two developments, however, require attention: The slowdown in technical change and the decrease in technical efficiency. If producers become increasingly unable to fully use the potential of their technology, this results in an unnecessarily low level of TFP and hence output. Moreover, investments in research and development do not reach an optimal return, which might gradually degrade the incentives for future research into 
new technologies. Therefore, in addition to maintaining positive rates of technical change, promoting improvements in technical efficiency likely plays a key role for sustaining TFP growth. A number of different measures seem promising to contribute to this end:

First, the agricultural extension system should be strengthened, both with the goal of promoting technology diffusion and with the goal of improving the skill levels and management abilities of producers. Support for this approach comes from Jin et al. (2002) who find that promoting the extension system usually entails improvements in total factor productivity. Based on the above analysis of the determinants of technical efficiency, it is recommended to increase the capacity of the extension system to offer services to producers by increasing the number of staff per unit of labor in production. This would contribute positively to technical efficiency and hence total factor productivity. Such a measure could also help to compensate for the negative effects of increasing annual average temperatures on technical efficiency. However, according to Hu et al. (2009), a current flaw in the extension system is that extension specialists spend too much time on administrative and commercial activities instead of offering extension services. They also report that the commercial orientation in parts of the extension system has in some cases been found to lead producers to adopt less then optimal production procedures. Thus, reforms of the extension system aimed at improving technical efficiency should also pay due attention to the independence and time-allocation of extension specialists.

Secondly, both training and new technologies should be geared towards enabling producers to work efficiently in situations of constrained water resources and to operate sustainably, particularly with respect to managing and withstanding water pollution. If new technologies are specifically designed to cope with the particular environmental challenges that producers face, producers might find it easier to use those technologies efficiently. Godfray et al. (2010) moreover point out that, in general, future output increases in aquaculture could be promoted by the development of suitable technologies for large-scale aquaculture and for dealing with the challenges of intensive production (e.g. disease management). Particularly for the further development of China's major production regions, this should receive attention.

Thirdly, it seems advisable to focus efforts regarding the improvement of technical efficiency on regions with a comparative advantage in inland aquaculture production. 
Given the more difficult production environment in North and West China, it would likely be much more costly to improve technical efficiency in those regions. As the demand for aquaculture products is generally lower in the less developed provinces anyway (Chen et al., 1995), it thus appears to be more advisable to concentrate improvement efforts on the UME and LME provinces in Southeast and East China. 


\subsection{Appendix}

Table 12: Stochastic frontier model estimation results

\begin{tabular}{|c|c|c|c|c|c|c|}
\hline $\begin{array}{l}\text { Dependent variable: } \\
\ln (\text { aquaculture output) }\end{array}$ & \multirow{2}{*}{$\begin{array}{r}\text { Coef. } \\
-0.0958\end{array}$} & \multirow{2}{*}{$\begin{array}{r}\text { Std. Err. } \\
0.2246\end{array}$} & \multirow{2}{*}{$\begin{array}{r}z \\
-0.43\end{array}$} & \multirow{2}{*}{$\begin{array}{r}\boldsymbol{P}>\boldsymbol{z} \\
0.670\end{array}$} & \multicolumn{2}{|c|}{ [95\% Conf. Interval] } \\
\hline $\ln ($ area $)$ & & & & & -0.5360 & 0.3445 \\
\hline $\ln$ (fry) & 0.5348 & 0.1237 & 4.32 & 0.000 & 0.2924 & 0.7771 \\
\hline $\ln$ (labor) & 0.0230 & 0.1578 & 0.15 & 0.884 & -0.2862 & 0.3323 \\
\hline $\ln$ (boats) & -0.4139 & 0.0779 & -5.31 & 0.000 & -0.5667 & -0.2612 \\
\hline $\ln ($ fry $) * \ln ($ labor $)$ & -0.0653 & 0.0158 & -4.12 & 0.000 & -0.0963 & -0.0342 \\
\hline $\ln ($ fry $) * \ln$ (boats) & 0.0051 & 0.0062 & 0.82 & 0.413 & -0.0071 & 0.0172 \\
\hline $\ln ($ fry $) * \ln ($ area $)$ & -0.0255 & 0.0291 & -0.88 & 0.381 & -0.0825 & 0.0315 \\
\hline $\ln ($ labor)* $\ln$ (boats) & 0.0387 & 0.0110 & 3.53 & 0.000 & 0.0172 & 0.0601 \\
\hline $\ln ($ labor $) * \ln ($ area $)$ & 0.0544 & 0.0231 & 2.35 & 0.019 & 0.0090 & 0.0997 \\
\hline $\ln ($ boats $) * \ln ($ area $)$ & 0.0286 & 0.0133 & 2.16 & 0.031 & 0.0026 & 0.0546 \\
\hline$(\ln (\operatorname{area}))^{\wedge} 2$ & -0.0320 & 0.0447 & -0.72 & 0.474 & -0.1196 & 0.0556 \\
\hline$(\ln (\text { fry }))^{\wedge} 2$ & 0.0525 & 0.0127 & 4.12 & 0.000 & 0.0275 & 0.0775 \\
\hline$(\ln (\text { labor }))^{\wedge} 2$ & 0.0159 & 0.0126 & 1.26 & 0.209 & -0.0089 & 0.0406 \\
\hline$(\ln (\text { boats }))^{\wedge} 2$ & -0.0234 & 0.0058 & -4.03 & 0.000 & -0.0348 & -0.0120 \\
\hline $\ln ($ area $) *$ trend & -0.0077 & 0.0038 & -2.04 & 0.041 & -0.0151 & -0.0003 \\
\hline $\ln ($ fry $) *$ trend & -0.0113 & 0.0028 & -4.02 & 0.000 & -0.0169 & -0.0058 \\
\hline $\ln ($ labor $) *$ trend & 0.0064 & 0.0027 & 2.39 & 0.017 & 0.0012 & 0.0117 \\
\hline $\ln$ (boats)*trend & -0.0016 & 0.0010 & -1.56 & 0.118 & -0.0035 & 0.0004 \\
\hline Trend & 0.2278 & 0.0268 & 8.50 & 0.000 & 0.1753 & 0.2804 \\
\hline Trend*trend & -0.0058 & 0.0007 & -8.43 & 0.000 & -0.0072 & -0.0045 \\
\hline Constant & 9.2351 & 0.9825 & 9.40 & 0.000 & 7.3095 & 11.1608 \\
\hline Eta & -0.0200 & 0.0034 & -5.82 & 0.000 & -0.0267 & -0.0133 \\
\hline $\ln \left(\operatorname{sigma}{ }^{\wedge} 2\right)$ & 1.3390 & 0.3125 & 4.29 & 0.000 & 0.7266 & 1.9514 \\
\hline ilgt(gamma) & 5.7429 & 0.3238 & 17.73 & 0.000 & 5.1082 & 6.3776 \\
\hline $\operatorname{Sigma}^{\wedge} 2$ & 3.8153 & 1.1921 & & & 2.0680 & 7.0388 \\
\hline Gamma & 0.9968 & 0.0010 & & & 0.9940 & 0.9983 \\
\hline Sigma_u^2 & 3.8031 & 1.1922 & & & 1.4665 & 6.1397 \\
\hline Sigma_v^2 & 0.0122 & 0.0009 & & & 0.0104 & 0.0139 \\
\hline Log likelihood & 232.51 & & & & & \\
\hline No. of observations & 402 & & & & & \\
\hline Wald chi2(20) & 1955.05 & & & & & \\
\hline Prob > chi 2 & 0.0000 & & & & & \\
\hline
\end{tabular}


Table 13: Output elasticities (sensitivity test)

\begin{tabular}{r|rrrr|r|c}
\hline Year & Area & Fry & Labor & Boats & $\begin{array}{r}\text { Scale } \\
\text { Elasticity }\end{array}$ & Time \\
\hline 1993 & 0.2812 & 0.1761 & 0.0615 & 0.0287 & 0.5474 & 0.1255 \\
1994 & 0.2682 & 0.1796 & 0.0601 & 0.0295 & 0.5374 & 0.1173 \\
1995 & 0.2669 & 0.1779 & 0.0659 & 0.0293 & 0.5399 & 0.1094 \\
1996 & 0.2566 & 0.1708 & 0.0660 & 0.0347 & 0.5281 & 0.1027 \\
1997 & 0.2344 & 0.1829 & 0.0538 & 0.0294 & 0.5005 & 0.0949 \\
1998 & 0.2260 & 0.1788 & 0.0637 & 0.0276 & 0.4961 & 0.0877 \\
1999 & 0.2150 & 0.1777 & 0.0671 & 0.0259 & 0.4856 & 0.0804 \\
2000 & 0.1975 & 0.1691 & 0.0888 & 0.0195 & 0.4749 & 0.0741 \\
2001 & 0.1858 & 0.1650 & 0.0875 & 0.0212 & 0.4595 & 0.0675 \\
2002 & 0.1710 & 0.1637 & 0.0748 & 0.0276 & 0.4371 & 0.0607 \\
2003 & 0.1691 & 0.1609 & 0.0943 & 0.0189 & 0.4434 & 0.0531 \\
2004 & 0.1479 & 0.1595 & 0.0898 & 0.0210 & 0.4182 & 0.0465 \\
2005 & 0.1350 & 0.1585 & 0.0958 & 0.0192 & 0.4086 & 0.0390 \\
2006 & 0.1235 & 0.1598 & 0.1044 & 0.0166 & 0.4043 & 0.0308 \\
2007 & 0.1704 & 0.1350 & 0.1006 & -0.0121 & 0.3939 & 0.0330 \\
2008 & 0.1367 & 0.1420 & 0.1355 & -0.0084 & 0.4058 & 0.0202 \\
2009 & 0.1014 & 0.1350 & 0.1689 & -0.0134 & 0.3918 & 0.0125 \\
Average & $\mathbf{0 . 1 9 3 5}$ & $\mathbf{0 . 1 6 4 0}$ & $\mathbf{0 . 0 8 7 0}$ & $\mathbf{0 . 0 1 8 7}$ & $\mathbf{0 . 4 6 3 2}$ & $\mathbf{0 . 0 6 8 0}$ \\
\hline
\end{tabular}

Table 14: Change in total factor productivity and its components (sensitivity test)

\begin{tabular}{r|rrrrrr|rr}
\hline Year & TEC & TEC cum. & $T C$ & TC cum. & $S C$ & SC cum. & $T F P C$ & TFPC cum. \\
\hline 1993 & & $\mathbf{1}$ & & $\mathbf{1}$ & $\mathbf{1}$ & & $\mathbf{1}$ \\
1994 & 1.0429 & $\mathbf{1 . 0 4 2 9}$ & 1.1291 & $\mathbf{1 . 1 2 9 1}$ & 0.9569 & $\mathbf{0 . 9 5 6 9}$ & 1.1267 & $\mathbf{1 . 1 2 6 7}$ \\
1995 & 0.9932 & $\mathbf{1 . 0 3 5 8}$ & 1.1200 & $\mathbf{1 . 2 6 4 6}$ & 0.9514 & $\mathbf{0 . 9 1 0 4}$ & 1.0583 & $\mathbf{1 . 1 9 2 4}$ \\
1996 & 0.9931 & $\mathbf{1 . 0 2 8 6}$ & 1.1119 & $\mathbf{1 . 4 0 6 1}$ & 0.9700 & $\mathbf{0 . 8 8 3 1}$ & 1.0711 & $\mathbf{1 . 2 7 7 2}$ \\
1997 & 0.9931 & $\mathbf{1 . 0 2 1 5}$ & 1.1039 & $\mathbf{1 . 5 5 2 1}$ & 0.9805 & $\mathbf{0 . 8 6 5 9}$ & 1.0748 & $\mathbf{1 . 3 7 2 8}$ \\
1998 & 0.9930 & $\mathbf{1 . 0 1 4 4}$ & 1.0956 & $\mathbf{1 . 7 0 0 5}$ & 0.9734 & $\mathbf{0 . 8 4 2 8}$ & 1.0590 & $\mathbf{1 . 4 5 3 8}$ \\
1999 & 0.9930 & $\mathbf{1 . 0 0 7 2}$ & 1.0877 & $\mathbf{1 . 8 4 9 6}$ & 0.9734 & $\mathbf{0 . 8 2 0 4}$ & 1.0513 & $\mathbf{1 . 5 2 8 3}$ \\
2000 & 0.9929 & $\mathbf{1 . 0 0 0 1}$ & 1.0803 & $\mathbf{1 . 9 9 8 2}$ & 1.0245 & $\mathbf{0 . 8 4 0 5}$ & 1.0990 & $\mathbf{1 . 6 7 9 6}$ \\
2001 & 0.9929 & $\mathbf{0 . 9 9 3 0}$ & 1.0733 & $\mathbf{2 . 1 4 4 7}$ & 0.9736 & $\mathbf{0 . 8 1 8 3}$ & 1.0375 & $\mathbf{1 . 7 4 2 6}$ \\
2002 & 0.9928 & $\mathbf{0 . 9 8 5 8}$ & 1.0662 & $\mathbf{2 . 2 8 6 7}$ & 0.9561 & $\mathbf{0 . 7 8 2 3}$ & 1.0120 & $\mathbf{1 . 7 6 3 6}$ \\
2003 & 0.9928 & $\mathbf{0 . 9 7 8 7}$ & 1.0586 & $\mathbf{2 . 4 2 0 6}$ & 0.9730 & $\mathbf{0 . 7 6 1 2}$ & 1.0225 & $\mathbf{1 . 8 0 3 3}$ \\
2004 & 0.9927 & $\mathbf{0 . 9 7 1 6}$ & 1.0510 & $\mathbf{2 . 5 4 4 1}$ & 0.9871 & $\mathbf{0 . 7 5 1 4}$ & 1.0299 & $\mathbf{1 . 8 5 7 2}$ \\
2005 & 0.9927 & $\mathbf{0 . 9 6 4 4}$ & 1.0436 & $\mathbf{2 . 6 5 5 1}$ & 0.9701 & $\mathbf{0 . 7 2 8 9}$ & 1.0050 & $\mathbf{1 . 8 6 6 5}$ \\
2006 & 0.9926 & $\mathbf{0 . 9 5 7 3}$ & 1.0355 & $\mathbf{2 . 7 4 9 4}$ & 0.9582 & $\mathbf{0 . 6 9 8 4}$ & 0.9849 & $\mathbf{1 . 8 3 8 3}$ \\
2007 & 0.9926 & $\mathbf{0 . 9 5 0 2}$ & 1.0324 & $\mathbf{2 . 8 3 8 5}$ & 1.1061 & $\mathbf{0 . 7 7 2 5}$ & 1.1335 & $\mathbf{2 . 0 8 3 7}$ \\
2008 & 0.9925 & $\mathbf{0 . 9 4 3 1}$ & 1.0270 & $\mathbf{2 . 9 1 5 1}$ & 0.9298 & $\mathbf{0 . 7 1 8 3}$ & 0.9477 & $\mathbf{1 . 9 7 4 7}$ \\
2009 & 0.9925 & $\mathbf{0 . 9 3 6 0}$ & 1.0165 & $\mathbf{2 . 9 6 3 3}$ & 1.0623 & $\mathbf{0 . 7 6 3 1}$ & 1.0718 & $\mathbf{2 . 1 1 6 4}$ \\
\hline
\end{tabular}


Figure 17: Technical efficiency in Chinese inland aquaculture (2009) (sensitivity test)

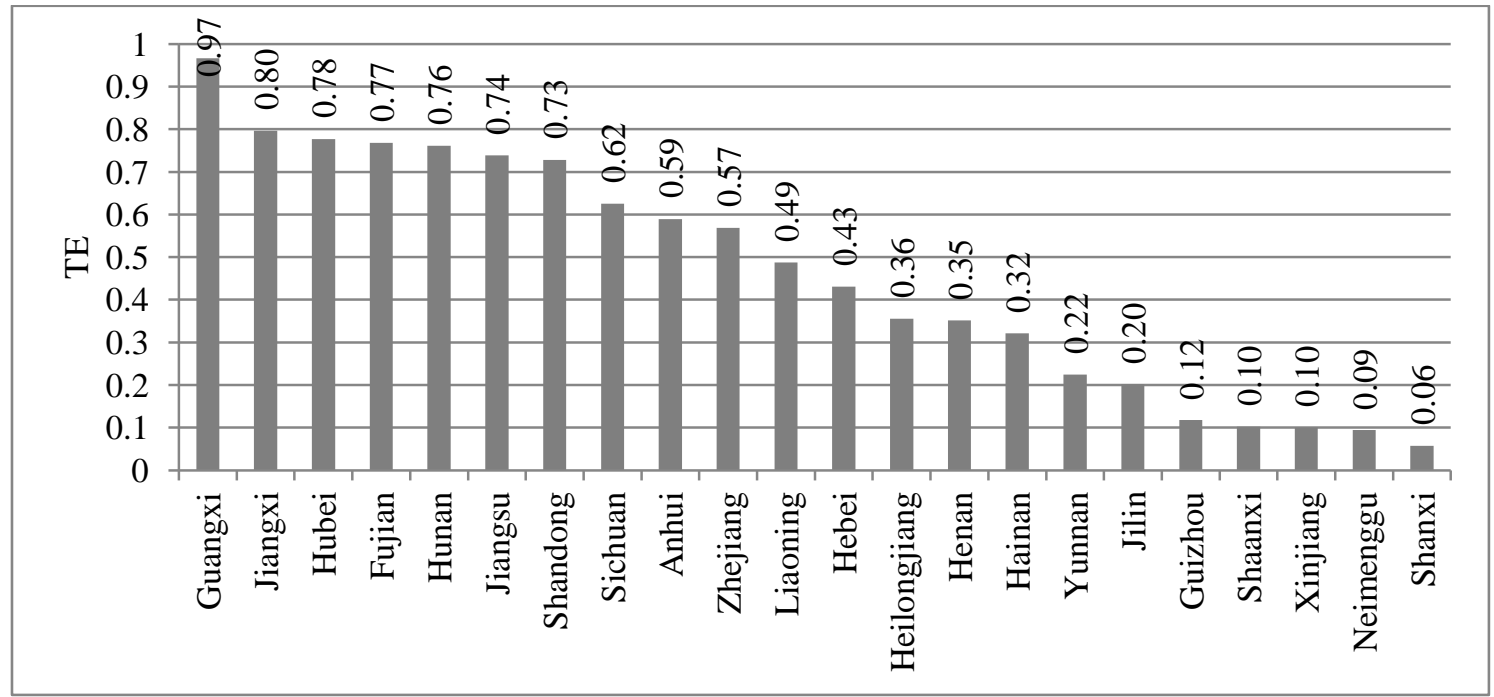

Table 15: Analysis of technical efficiency (sensitivity test)

\begin{tabular}{|c|c|c|c|c|c|c|}
\hline Model & $I$ & $(F E)$ & & II & $(F E)$ & \\
\hline & coefficient & t-value & & coefficient & t-value & \\
\hline (ln)Extension & 0.0258 & 2.31 & $* *$ & 0.0403 & 5.60 & $* * *$ \\
\hline (ln)Area & -0.0026 & -0.16 & & & & \\
\hline (ln)Fry & -0.0172 & -3.31 & $* * *$ & & & \\
\hline (ln)Labor & 0.0182 & 1.39 & & & & \\
\hline (ln)Boats & -0.0489 & -10.43 & $* * *$ & & & \\
\hline Avg. temp. & -0.0277 & -4.51 & $* * *$ & -0.0360 & -5.05 & $* * *$ \\
\hline Tot. precip. & $2.39 \mathrm{E}-06$ & 0.15 & & $-9.13 E-06$ & -0.50 & \\
\hline Constant & -0.1256 & -0.77 & & -0.2502 & -2.29 & $* *$ \\
\hline Observations & 369 & & & 369 & & \\
\hline Provinces & 22 & & & 22 & & \\
\hline R-squared & 0.5613 & & & 0.3686 & & \\
\hline
\end{tabular}

Note: * significant at $10 \%$-level; ** significant at 5\%-level; *** significant at $1 \%$-level 


\section{Discussion}

\subsection{Contributions}

China's agriculture can draw on only $7 \%$ of the globally available arable land to support around $22 \%$ of the world's population. Continuing population growth and a growing wealth imply that China will have to continue to increase the agricultural output generated from this land if the declared self-sufficiency goals are to be met. Due to the strong agricultural development of the past few decades, China has managed not only to substantially increase total agricultural output but also to notably raise the per capita availability of many food commodities, including grain, meat and aquatic products. This development, however, has created considerable pressure on agricultural resources (Zhao et al., 2008). It is hence an important question, whether Chinese agriculture will be able to continue growing or whether factors exist, which could adversely affect its future development.

Against this background, it has been the purpose of this thesis to contribute to the literature on Chinese agricultural production in two fields: First, according to the discussion in Section 1.1.2, global climate change could potentially have strong and adverse impacts on Chinese agriculture. Possible effects on grain farming and inland aquaculture, as two of its most important sub-sectors, have been discussed in greater detail. Nevertheless, the effects of climate change are still often neglected in studies on agricultural production in general, and virtually no economic empirical evidence exists regarding climate change impacts on Chinese inland aquaculture. Another issue, which has received insufficient attention in the agricultural economics literature on both grain farming and inland aquaculture in China, especially in connection with climate change, is that of output risks. A thorough analysis of climate change impacts on agricultural production should, however, include this issue, as risk-related findings might hold important policy implications.

Hence, two sector-specific climate impact studies have been conducted on the basis of newly assembled province-level panel data sets on grain and inland aquaculture production, which cover all relevant production regions of China. In order to be able to 
analyze the marginal effects of changes in different climate variables on both mean yield and on yield risk in the two sub-sectors without neglecting the contributions of regular input factors, modified Just and Pope (1978, 1979) yield models have been employed.

Secondly, despite the important contributions of the inland aquaculture sector to overall food and nutrient supply in China and despite the expected future increases in aggregate demand, the discussion in Section 1.1.3 has revealed a lack of systematic attempts to analyze the sources of the observed growth in inland aquaculture production. Specifically, the development of total factor productivity growth and its components (technical change, technical efficiency change and scale change) in the Chinese inland aquaculture sector is as yet largely unknown. Such knowledge, however, is indispensable for designing policies aimed at a further expansion and development of inland aquaculture production.

To remedy this deficit, a stochastic frontier panel data model employing the timevarying technical inefficiency specification by Battese and Coelli (1992) has been applied to the aforementioned data set on Chinese inland aquaculture production. This, in addition to serving as the foundation for estimating the above components of total factor productivity growth, also provides the necessary information for an analysis of the geographical distribution, development and determinants of technical efficiency.

\subsection{Results and Conclusions}

A cross-sectoral comparison of the obtained results regarding the marginal effects of climate change, i.e. of changes in the different temperature- and precipitation-related variables, reveals considerable heterogeneity. This generally supports the approach of sector-specific climate impact analyses to obtain clear and informative results.

With respect to Chinese inland aquaculture, the results indicate that both increasing annual average temperatures and increasing levels of total annual precipitation would lead to improvements in mean yields. More specifically, the relationship between the annual average temperature and the yield level has been found to be of a non-linear nature with a positive but gradually diminishing marginal product, whereas the relationship between the level of total annual precipitation and the yield level turns out to be linear. Employing the coefficient estimates of the temperature and precipitation 
variables from the mean yield function, it could be determined that a $1{ }^{\circ} \mathrm{C}$ increase in annual average temperature and a $100 \mathrm{~mm}$ increase in total annual precipitation would, ceteris paribus, increase the average aquaculture yield by $6.8 \%$ and $1.2 \%$, respectively. At market prices, the additional national output due to the increase in temperature would have a value of around USD 2.97 billion. The increase in precipitation in turn would lead to an additional output with a value of USD 0.52 billion. With respect to the effects of climate change on the risk level, it has been found that increasing annual average temperatures have a negative marginal effect on yield risk in the Chinese inland aquaculture sector as a whole.

In the case of Chinese grain farming, the results show that increasing annual average temperatures would reduce mean yields in both North and South China, though the effect on North China would be stronger. Increasing annual precipitation quantities in turn would benefit North China in terms of rising yields but would hurt South China. Based on the marginal effects of changes in the annual climate conditions, it has been calculated that China as a whole would experience a change in average grain yield of $-1.45 \%$ following a $1{ }^{\circ} \mathrm{C}$ increase in annual average temperature, whereas a $100 \mathrm{~mm}$ increase in total annual precipitation would raise the average grain yield by $1.31 \%$, which shows the dominant influence of the yield improvements in North China. The corresponding changes in total output would have a market value of USD -1.92 billion and USD 1.74 billion, respectively. Moreover, it has been found that North China also has to expect being affected by the predicted increases in climate variability. Specifically, it would experience decreasing mean grain yields in the case of an increasing variability of precipitation. Regarding yield risks, the results indicate that increasing temperatures and precipitation levels would both reduce the level of risk in South China, whereas they would have no statistically significant effect on North China. In order to fully understand the implications of climate change for the specific subsectors under analysis in the present thesis, it is necessary to interpret the above results before the background of the corresponding production processes. This is made possible by the use of yield functions, which incorporate both regular input factors and climate factors.

In the context of inland aquaculture production, the expected main changes in climate (i.e. a gradual warming and increasing precipitation levels) do not threaten the shortterm development of the sector given the current structure of production. To the 
contrary, it has been found that inland aquaculture would benefit from these changes. This implies that the species available for aquaculture production are well-suited for the environmental conditions expected for the near future, particularly in regard to their temperature tolerances, which likely enables them to benefit from increasing temperatures in terms of an improved growth.

In the case of Chinese grain farming, it has emerged that the specific environmental conditions under which grain production is carried out matter for the effect of climate change. Specifically, the general level of water availability has been concluded to be a key factor in this respect. North China, which is considerably more water-scarce than South China and which suffers more often from droughts, would be more severely affected by increasing annual average temperatures and the concomitantly rising evapotranspiration losses of water. Thus, it would benefit noticeably from increasing precipitation quantities. Correspondingly, it has been found that in terms of mean yield, North China would benefit substantially more than South China from increasing the share of its grain acreage under irrigation. Against this background it also does not come as surprise that increases in the extent of irrigation would reduce yield risks in North China. In the case of South China, the relative abundance of water and precipitation in turn might mitigate the effects of rising temperatures to some degree and can explain why increases in precipitation might rather lead to more intense floods, which would reduce mean yields. Overall, the existence of both beneficial and adverse impacts of climate change on grain yields implies that the net effects on this sector will depend strongly on the exact pattern of changes in the temperature- and precipitationrelated variables (i.e. on the climate change scenario).

The analysis of total factor productivity in Chinese inland aquaculture has provided important insights with respect to the drivers of past output growth. According to the results, total factor productivity has increased almost continuously between 1993 and 2009, though at a decreasing rate. In cumulative terms, total factor productivity has nearly doubled over this period. The driver of this development has been technical change, the index of which more than tripled until 2009. The observed improvements in technology have been more than sufficient to compensate for the negative development of technical efficiency and the negative contributions of scale changes. However, technical change has slowed down over time, which has been identified as the reason for the slowdown in total factor productivity change. Nevertheless, as a determinant of output growth, total factor productivity change has, despite some variability, over time 
become approximately equally important as growth in input use, after input use has initially been the dominant source of output growth.

An analysis of the geographical distribution of technical efficiency has shown considerable differences between the different regions of China. Specifically, the provinces with the highest levels of technical efficiency cluster in Southeast and East China, while the north and the west of the country are characterized by very low levels of technical efficiency, which has, among other reasons, been attributed to different levels of economic development, water availability and experience in aquaculture production.

A detailed analysis of the determinants of technical efficiency by means of a secondstage regression has revealed that an increasing number of aquaculture technical extension staff per unit of labor in aquaculture production would have an important positive marginal effect on technical efficiency in this sector. Drawing on this result, it has been concluded that the observed decrease in the number of aquaculture technical extensions staff per unit of labor in production has contributed to the decrease in technical efficiency over the observation period. Increasing annual average temperatures in turn were found to reduce technical efficiency at the margin, whereas a more intensive production could have positive or negative marginal effects, depending on the input variable.

These results have several main implications. The observed slowdown in technical change gives cause for concern regarding the future development of total factor productivity. Different factors have been suggested as possible reasons for this, including problems with respect to technology diffusion and unsuitable technological innovations. Moreover, the relatively low average level of technical efficiency and its negative trend suggest that aquaculture producers find it increasingly difficult to make full use of the potential of the available technology.

\subsection{Policy Recommendations}

The analyses with respect to inland aquaculture and grain farming presented in this thesis have contributed new insights regarding agricultural production in China. Based on the results and discussions regarding the impacts of climate change on inland aquaculture production and grain farming under special consideration of yield risks and 
regarding total factor productivity and its determinants in inland aquaculture production, conclusions regarding policies and advisable production adjustments can be drawn.

The analysis of climate change impacts on inland aquaculture production indicates positive marginal effects of increasing annual average temperatures and total annual precipitation levels on mean yields and a negative marginal effect of increasing temperatures on yield risks. All these effects are beneficial for the aquaculture sector. Hence, based on the present study, there is apparently no urgent need for policy interventions or changes in the structure of production to cope with the impending changes in climate. It should, however, be reemphasized that the results of the climate impact studies in this thesis only pertain to the short-run due to the focus on marginal effects. The long-run impacts might well be different and it would therefore be prudent to carefully observe whether the relationship between inland aquaculture yields and climate changes in the medium- to long-run.

For now, the effects of climate change on the inland aquaculture sector, however, do not threaten to bind resources that could otherwise be put to a productive use. Hence, efforts can be directed toward a further development and expansion of the sector. Specifically, based on the coefficient estimates regarding the regular input factors, it emerges that an increasing use of fry and labor in the production process would lead to higher mean yields and that using more fry would have the additional benefit of reducing the level of yield risk. Consequently, policies fostering a more intensive production will be beneficial for inland aquaculture production in terms of raising and stabilizing future output quantities. This should help the sector to cope with the projected increases in the demand for aquatic products in China. Moreover, the results imply that changes in the use of certain input factors represent a possible way to mitigate external risk effects from sources other than input use or climate change, which were not considered in the present study. A reduced variability of yield and hence output would moreover help to avoid supply and price fluctuations in domestic and international markets. It should however be considered that an intensification of production in terms of increasing stocking densities might only at first be beneficial as the sector develops away from production systems relying heavily on semi-intensive and extensive polyculture practices towards more intensive and more managed production systems. In the longer term, this strategy might cause problems as ever-increasing stocking densities are likely to lead to a deteriorating water quality. Hence, sustainability considerations and environmental regulations should be part of any long-term development strategies 
aimed at maintaining or improving the ability of the inland aquaculture sector to contribute to overall food supply in China.

The results regarding climate change impacts on grain farming give more cause for concern. Specifically, the projected increases in annual average temperatures would lead to reductions in mean grain yields throughout China. While it has been found that increasing precipitation levels could at least partially counter this effect in the case of North China, such a development would have a negative marginal effect on mean grain yields in South China. Hence, while the net effects of changes in the different climate variables will depend on the exact climate change scenario, there is a concrete possibility of a negative outcome in the near future. Given that the general level of water availability has been identified as a key factor determining the impact of climate change, it should receive special attention in the design of adaption measures, particularly in the case of North China.

As the benefits from increases in precipitation in North China are uncertain in magnitude and timing, improvements of the irrigation system seem particularly promising to stabilize or increase yield levels. Moreover, according to the results regarding yield risks in North China, a higher degree of irrigation would also be associated with more stable yield levels, which would represent an additional benefit. Possible measures could on the one hand include an increase of the share of the grain acreage under irrigation. On the other hand, investments in a more efficient irrigation infrastructure with the goal to reduce unproductive water losses, for example due to damages or evaporation, could be beneficial. However, as has been discussed before, water is generally a scarce resource in North China and the use of groundwater for agricultural purposes has already led to a considerable lowering of the ground water table in several regions. Consequently, if a sustainable supply of water for irrigation purposes is difficult to ensure, improvements in the reliability and efficiency of the existing system seem more promising. The importance of efficient water utilization in Chinese agriculture for coping with the effects of climate change is also emphasized by Wang et al. (2010), who additionally point out that the Chinese government and private farmers have already begun to invest in irrigation infrastructure and to adopt measures aimed at using water more efficiently. Based on the results presented in this thesis, these investments and efforts should be strengthened. 
Increasing fertilizer use has emerged as another way to increase mean grain yields in North China. However, given the already high level of fertilizer application, the potential environmental long-term consequences and the risk-increasing effect of such a measure would make policies encouraging further increases in fertilizer use seem less advisable.

For the case of South China, where the level of water availability in general and that of precipitation in particular is considerably higher, it turns out that an expansion of the irrigation system with the intention to compensate for climate-induced mean yield reductions would have a weaker effect and would aggravate yield risks. Hence, if such a strategy was chosen, it would be important to compensate for the concomitant increase in risk. In addition to the expected reductions in yield risk stemming from climate change, a further risk reduction could be achieved by employing more labor or machinery. A possible way to deal with the adverse effects of increasing precipitation levels on mean yields in South China would be to promote investments in improved flood control systems.

The third study in this thesis has shown that total factor productivity in China's inland aquaculture sector has nearly doubled between 1993 and 2009 and that technical change has been the driver of this remarkable development. Based on a detailed analysis of total factor productivity and its determinants, several issues have been found, which require attention. Specifically, technical change has experienced a slowdown while technical efficiency has even decreased over the observation period. In order not to endanger the future ability of the inland aquaculture sector to continue growing, it is necessary to address both issues. Technical change might be promoted by strengthening research into new technologies. For this to be an effective measure, the new technologies should be geared towards the specific challenges and environmental conditions faced by aquaculture producers, including an increasing scale and intensity of production, situations of water scarcity and increasing water pollution. A well-functioning agricultural extension system can help aquaculture producers to adopt new technologies.

However, the observed decrease in technical efficiency indicates that producers have in the past not been able to fully use the potential of the available technology and that their ability to do so has even decreased over time. To remedy this issue, it would be beneficial to provide more technical and managerial training to aquaculture operators. This would help them to efficiently utilize their resources and technologies and to deal 
with environmental and other challenges. Specifically, as a first measure, the negative trend in the number of aquaculture technical extension staff per unit of labor in aquaculture production should be reversed in order to improve the capacity of the extension system to offer services to aquaculture producers. More training could also enable producers to compensate for the negative effects of the expected increases in China's annual average temperature on technical efficiency. However, as discussed in the study, it might additionally be necessary to improve the efficiency of the extension system itself by allowing extension specialists to spend most of their time on actual extension-related work instead of other duties (e.g. administration) and by enabling them to give advice independent of any business interests.

The analysis of the geographical distribution of the technical efficiency scores in the Chinese inland aquaculture sector has moreover revealed considerable heterogeneity among the provinces. Given that the least efficient provinces make only small contributions to national output, it would be a more efficient measure to concentrate efforts aimed at promoting increases in technical efficiency on those provinces, which currently feature intermediate levels of technical efficiency. An intensification of domestic trade could assure that future increases in the demand for aquatic products in provinces with very low levels of technical efficiency are satisfied. 


\section{Bibliography}

Aigner, D., Lovell, C. A., \& Schmidt, P. (1977). Formulation and Estimation of Stochastic Frontier Production Function Models. Journal of Econometrics 6(1) , 21-37.

Alam, F., Khan, A., \& Huq, A. (2012). Technical efficiency in tilapia farming of Bangladesh: a stochastic frontier production approach. Aquaculture International 20(4) , 619-634.

Asche, F., \& Tveterås, R. (1999). Modeling Production Risk with a Two-Step Procedure. Journal of Agricultural Economics Association 24(2) , 424-439.

Battese, G. E. (1992). Frontier production functions and technical efficiency: a survey of empirical applications in agricultural economics. Agricultural Economics 7(3-4), 185-208.

Battese, G. E., \& Coelli, T. J. (1995). A Model for Technical Inefficiency Effects in a Stochastic Frontier Production Function for Panel Data. Empirical Economics 20(2), 325-332.

Battese, G. E., \& Coelli, T. J. (1992). Frontier Production Functions, Technical Efficiency and Panel Data: With Application to Paddy Farmers in India. Journal of Productivity Analysis 3(1-2) , 153-169.

Battese, G. E., \& Corra, G. S. (1977). Estimation of a Production Frontier Model: With Application to the Pastoral Zone of Eastern Australia. Australian Journal of Agricultural Economics 21(3), 169-179.

Battese, G. E., Heshmati, A., \& Hjalmarsson, L. (2000). Efficiency of labour use in the Swedish banking industry: a stochastic frontier approach. Empirical Economics 25(4), 623-640.

Bostock, J., McAndrew, B., Richards, R., Jauncey, K., Telfer, T., Lorenzen, K., et al. (2010). Aquaculture: global status and trends. Philosophical Transactions of the Royal Society B 365(1554), 2897-2912.

Boyd, C. E., \& Tucker, C. S. (1998). Aquaculture water quality management. Boston: Kluwer Academic.

Brander, K. M. (2007). Global fish production and climate change. Proceedings of the National Academy of Sciences of the United States of America 104(50) , 19709-19714.

Bravo-Ureta, B. E., \& Pinheiro, A. E. (1993). Efficiency Analysis of Developing Country Agriculture: A Review of the Frontier Function Literature. Agricultural and Resource Economics Review 22(1) , 88-101. 
Broughton, E. I., \& Walker, D. G. (2010). Policies and practices for aquaculture food safety in China. Food Policy 35(5) , 471-478.

Brown, L. R. (1995). Who Will Feed China?: Wake-Up Call for a Small Planet. New York: W. W. Norton \& Company.

Brümmer, B., Glauben, T., \& Lu, W. (2006). Policy reform and productivity change in Chinese agriculture: A distance function approach. Journal of Development Economics 81(1), 61-79.

Cao, L., Wang, W., Yang, Y., Yang, C., Yuan, C., Xiong, S., et al. (2007).

Environmental Impact of Aquaculture and Countermeasures to Aquaculture Pollution in China. Environmental Science and Pollution Research 14(7) , 452-462.

Caves, D. W., Christensen, L. R., \& Diewert, W. E. (1982). Multilateral Comparisons of Output, Input, and Productivity using Superlative Index Numbers. The Economic Journal 92(365) , 73-86.

Charnes, A., Cooper, W. W., \& Rhodes, E. (1978). Measuring the efficiency of decision making units. European Journal of Operational Research 2(6) , 429-444.

Chen, C.-C., McCarl, B. A., \& Schimmelpfennig, D. E. (2004). Yield Variability as Influenced by Climate: A Statistical Investigation. Climatic Change 66(1-2) , 239-261.

Chen, H., Hu, B., \& Charles, A. T. (1995). Chinese integrated fish farming: a comparative bioeconomic analysis. Aquaculture Research 26(2), 81-94.

Chen, J. (2007). Rapid urbanization in China: A real challenge to soil protection and food security. Catena 69(1), 1-15.

Chen, X., Hong, H., \& Nekipelov, D. (2011). Nonlinear Models of Measurement Errors. Journal of Economic Literature 49(4) , 901-937.

Chen, Y.-F., Wu, Z.-G., Zhu, T.-H., Yang, L., Ma, G.-Y., \& Chien, H.-P. (2013). Agricultural Policy, Climate Factors and Grain Output: Evidence from Household Survey Data in Rural China. Journal of Integrative Agriculture 12(1) , 169-183.

Chinese Ministry of Agriculture. (1994-2010). Chinese Fishery Yearbook (Various Editions). Beijing: China Agricultural Press.

Christensen, J. H., Hewitson, B., Busuioc, A., Chen, A., Gao, X., Held, I., et al. (2007). Regional Climate Projections. In S. Solomon, D. Qin, M. Manning, Z. Chen, M.

Marquis, K. B. Averyt, et al., Climate Change 2007: The Physical Science Basis. Contribution of Working Group I to the Fourth Assessment Report of the Intergovernmental Panel on Climate Change (pp. 847-940). Cambridge and New York: Cambridge University Press.

Christensen, L. R., Jorgenson, D. W., \& Lau, L. J. (1973). Transcendental Logarithmic Production Frontiers. The Review of Economics and Statistics 55(1) , 28-45. 
Coelli, T. J., Prasada Rao, D. S., O'Donnell, C. J., \& Battese, G. E. (2005). An introduction to efficiency and productivity analysis. New York: Springer.

CPYEC. (2010). China Price Yearbook 2010. Beijing: China Price Yearbook Editorial Committee.

De Silva, S. S., \& Soto, D. (2009). Climate change and aquaculture: potential impacts, adaption and mitigation . In K. Cochrane, C. De Young, D. Soto, \& T. Bahri, Climate Change implications for fisheries and aquaculture: overview of current scientific knowledge. FAO Fisheries and Aquaculture Technical Paper No. 530 (pp. 151-212). Rome: FAO.

Del Gatto, M., Di Liberto, A., \& Petraglia, C. (2011). Measuring Productivity. Journal of Economic Surveys 25(5) , 952-1008.

Deschênes, O., \& Greenstone, M. (2007). The Economic Impacts of Climate Change: Evidence from Agricultural Output and Random Fluctuations in Weather. The American Economic Review 97(1) , 354-385.

Fan, S., \& Pardey, P. G. (1997). Research, productivity, and output growth in Chinese agriculture. Journal of Development Economics 53(1), 115-137.

Fan, S., Zhang, L., \& Zhang, X. (2004). Reforms, Investment, and Poverty in Rural China. Economic Development and Cultural Change 52(2) , 395-421.

FAO. (2005b). Increasing the contribution of small-scale fisheries to poverty alleviation and food security. FAO Technical Guidelines for Responsible Fisheries, No. 10. Rome: FAO.

FAO. (2005a). National Aquaculture Sector Overview China. Retrieved February 15, 2013, from FAO Fisheries and Aquaculture Department:

http://www.fao.org/fishery/countrysector/naso_china/en\#tcN9009B

FAO. (2012). The State of World Fisheries and Aquaculture 2012. Rome: Food and Agriculture Organization of the United Nations.

Färe, R. G., Lindgren, B., \& Roos, P. (1992). Productivity Changes in Swedish Pharamacies 1980-1989: A Non-Parametric Malmquist Approach. The Journal of Productivity Analysis 3(1-2), 85-101.

Färe, R., Grosskopf, S., Norris, M., \& Zhang, Z. (1994). Productivity Growth, Technical Progress, and Efficiency Change in Industrialized Countries. The American Economic Review 84(1), 66-83.

Farrell, M. J. (1957). The Measurement of Productive Efficiency. Journal of the Royal Statistical Society 120(3), 253-290. 
Féres, J. G., Reis, E. J., \& Speranza, J. (2008). Assessing the Impact of Climate Change on the Brazilian Agricultural Sector. Retrieved November 6, 2012, from http://purl.umn.edu/108136

Ficke, A. D., Myrick, C. A., \& Hansen, L. J. (2007). Potential impacts of global climate change on freshwater fisheries. Reviews in Fish Biology and Fisheries 17(4), 581-613.

Førsund, F. R., \& Hjalmarsson, L. (1979). Frontier Production Functions and Technical Progress: A Study of General Milk Processing in Swedish Dairy Plants. Econometrica 47(4), 883-900.

Fuentes, H. J., Grifell-Tatjé, E., \& Perelman, S. (2001). A Parametric Distance Function Approach for Malmquist Productivity Index Estimation. Journal of Productivity Analysis 15(2) , 79-94.

Godfray, H. C., Beddington, J. R., Crute, I. R., Haddad, L., Lawrence, D., Muir, J. F., et al. (2010). Food Security: The Challenges of Feeding 9 Billion People. Science 327(5967), 812-818.

Hjalmarsson, L., Kumbhakar, S. C., \& Heshmati, A. (1996). DEA, DFA and SFA: A Comparison. The Journal of Productivity Analysis 7(2-3), 303-327.

Holst, R., \& Yu, X. (2013). Climate Change and Chinese Fresh-Water Aquaculture. Working Paper (Submitted to Environmental and Resource Economics) .

Holst, R., \& Yu, X. (2013). Total Factor Productivity and Technical Efficiency in Chinese Inland Aquaculture. Working Paper.

Holst, R., Yu, X., \& Grün, C. (2013). Climate Change, Risk and Grain Yields in China. Journal of Integrative Agriculture 12(7) , 1279-1291.

Horowitz, J. K. (2009). The Income-Temperature Relationship in a Cross-Section of Countries and its Implications for Predicting the Effects of Global Warming. Environmental and Resource Economics 44(4) , 475-493.

Hu, R., Yang, Z., Kelly, P., \& Huang, J. (2009). Agricultural extension system reform and agent time allocation in China. China Economic Review 20(2), 303-315.

Hulten, C. R. (2001). Total Factor Productivity. A Short Biography. In C. R. Hulten, E. R. Dean, \& M. J. Harper, New Developments in Productivity Analysis (pp. 1-54). Chicago: University of Chicago Press.

Isik, M., \& Devadoss, S. (2006). An analysis of the impact of climate change on crop yields and yield variability. Applied Economics 38(7), 835-844.

Ji, Y., Yu, X., \& Zhong, F. (2012). Machinery investment decision and off-farm employment in rural China. China Economic Review 23(1), 71-80. 
Jin, S., Huang, J., Hu, R., \& Rozelle, S. (2002). The Creation and Spread of Technology and Total Factor Productivity in China's Agriculture. American Journal of Agricultural Economics 84(4), 916-930.

Just, R. E., \& Pope, R. D. (1979). Production Function Estimation and Related Risk Considerations. American Journal of Agricultural Economics 61(2) , 276-284.

Just, R. E., \& Pope, R. D. (1978). Stochastic specification of production functions and economic implications. Journal of Econometrics 7(1) , 67-86.

Kalirajan, K. (1984). Farm-Specific Technical Efficiencies and Development Policies. Journal of Economic Studies 11(3) , 3-13.

Kalirajan, K. P., \& Shand, R. T. (1999). Frontier Production Functions and Technical Efficiency Measures. Journal of Economic Surveys 13(2), 149-172.

Kalirajan, K. P., Obwona, M. B., \& Zhao, S. (1996). A Decomposition of Total Factor Productivity Growth: The Case of Chinese Agricultural Growth before and after Reforms. American Journal of Agricultural Economics 78(2) , 331-338.

Kato, E., Ringler, C., Yesuf, M., \& Bryan, E. (2011). Soil and water conservation technologies: a buffer against production risk in the face of climate change? Insights from the Nile basin in Ethiopia. Agricultural Economics 42(5), 593-604.

Kumbhakar, S. C., \& Tsionas, E. G. (2008). Estimation of production risk and risk preference function: a nonparametric approach. Annals of Operations Research 176(1), 369-378.

Kumbhakar, S., \& Lovell, C. A. (2004). Stochastic frontier analysis. Cambridge: Cambridge University Press.

Leung, P., \& Shang, Y. C. (1993). Impacts of the Production Responsibility System on the Development of Freshwater Pond Fish Culture in China. Asian Fisheries Science 6(3) , 303-329.

Li, Q., Zhang, H., Liu, X., \& Huang, J. (2004). Urban heat island effect on annual mean temperature during the last 50 years in China. Theoretical and Applied Climatology $79(3-4), 165-174$.

Liao, H., \& Chern, W. S. (2007). A Dynamic Analysis of Food Demand Patterns in Urban China. Retrieved October 2, 2012, from http://purl.umn.edu/9770

Lin, J. Y. (1992). Rural Reforms and Agricultural Growth in China. The American Economic Review 82(1), 34-51.

Lippert, C., Krimly, T., \& Aurbacher, J. (2009). A Ricardian analysis of the impact of climate change on agriculture in Germany. Climatic Change 97(3-4), 593-610. 
Liu, H., Li, X., Fischer, G., \& Sun, L. (2004). Study on the Impacts of Climate Change on China's Agriculture. Climatic Change 65(1-2), 125-148.

Liu, Y., \& Wang, X. (2005). Technological progress and Chinese agricultural growth in the 1990s. China Economic Review 16(4) , 419-440.

Meeusen, W., \& van Den Broeck, J. (1977). Efficiency Estimation from Cobb-Douglas Production Functions with Composed Error. International Economic Review 18(2), 435-444.

Mendelsohn, R. (2009). The Impact of Climate Change on Agriculture in Developing Countries. Journal of Natural Resources Policy Research 1(1) , 5-19.

Mendelsohn, R., \& Dinar, A. (2003). Climate, Water, and Agriculture. Land Economics 79(3), 328-341.

Mendelsohn, R., Nordhaus, W. D., \& Shaw, D. (1994). The Impact of Global Warming on Agriculture: A Ricardian Analysis. American Economic Review 84(4), 753-771.

Meyer, S., \& Yu, X. (2013). The Impacts of Production Uncertainties on World Food Prices. China Agricultural Economic Review (forthcoming) .

Murillo-Zamorano, L. R. (2004). Economic Efficiency and Frontier Techniques. Journal of Economic Surveys 18(1), 33-77.

National Bureau of Statistics of China. (1986-2010). China Statistical Yearbook (Various Editions). Beijing: China Statistics Press.

National Bureau of Statistics of China. (2012). China Statistical Yearbook 2012. Beijing: China Statistics Press.

Neuheimer, A. B., Thresher, R. E., Lyle, J. M., \& Semmens, J. M. (2011). Tolerance limit for fish growth exceeded by warming waters. Nature Climate Change 1, 110-113.

O'Neill, S., \& Matthews, A. (2001). Technical Change and Efficiency in Irish Agriculture. The Economic and Social Review 32(3), 263-284.

Orea, L. (2002). Parametric Decomposition of a Generalized Malmquist Productivity Index. Journal of Productivity Analysis 18(1), 5-22.

Ortega, D. L., Wang, H. H., \& Eales, J. S. (2009). Meat demand in China. China Agricultural Economic Review 1(4), 410-419.

Parry, M. L., Canziani, O. F., Palutikof, J. P., van der Linden, P. J., \& Hanson, C. E. (Eds.). (2007). Climate Change 2007: Impacts, Adaptation and Vulnerability.

Contribution of Working Group II to the Fourth Assessment Report of the Intergovernmental Panel on Climate Change. Cambridge: Cambridge University Press. 
Pitt, M. M., \& Lee, L.-F. (1981). The Measurement and Sources of Technical Inefficiency in the Indonesian Weaving Industry. Journal of Development Economics 9(1) , 43-64.

Pörtner, H. O., \& Knust, R. (2007). Climate Change Affects Marine Fishes Through the Oxygen Limitation of Thermal Tolerance. Science 315(5808) , 95-97.

Quiggin, J., \& Horowitz, J. K. (1999). The Impact of Global Warming on Agriculture: A Ricardian Analysis: Comment. The American Economic Review 89(4) , 1044-1045.

Reifschneider, D., \& Stevenson, R. (1991). Systematic Departures from the Frontier: A Framework for the Analysis of Firm Inefficiency. International Economic Review 32(3) , 715-723.

Schlenker, W., \& Roberts, M. J. (2006). Nonlinear Effects of Weather on Corn Fields. Review of Agricultural Economics 28(3), 391-398.

Schlenker, W., \& Roberts, M. J. (2009). Nonlinear temperature effects indicate severe damages to U.S. crop yields under climate change. Proceedings of the National Academy of Sciences of the United States of America 106(37), 15594-15598.

Schmidt, P. (1985). Frontier production functions. Econometric Reviews 4(2), 289-328.

Sharma, K. R., Leung, P., Chen, H., \& Peterson, A. (1999). Economic efficiency and optimum stocking density in fish polyculture: an application of data envelopment analysis (DEA) to Chinese fish farms. Aquaculture 180(3-4) , 207-221.

Shortle, J., Abler, D., Blumsack, S., Crane, R., Kaufman, Z., McDill, M., et al. (2009). Pennsylvania Climate Impact Assessment, Report to the Pennsylvania Department of Environmental Protection. Environment and Natural Resources Institute, The Pennsylvania State University.

Simar, L., \& Wilson, P. W. (2007). Estimation and inference in two-stage, semiparametric models of production processes. Journal of Econometrics 136(1), 31-64.

Simelton, E. (2011). Food self-sufficiency and natural hazards in China. Food Security $3(1), 35-52$.

Smit, B., \& Cai, Y. (1996). Climate change and agriculture in China. Global Environmental Change 6(3), 205-214.

Solow, R. M. (1957). Technical Change and the Aggregate Production Function. The Review of Economics and Statistics 39(3) , 312-320.

Tao, F., Yokozawa, M., Zhang, Z., Hayashi, Y., Grassl, H., \& Fu, C. (2004). Variability in climatology and agricultural production in China in association with the East Asian summer monsoon and El Niño Southern Oscillation. Climate Research 28(1) , 23-30. 
Tian, X., \& Yu, X. (2012). The Enigmas of TFP in China: A meta-analysis. China Economic Review 23(2), 396-414.

Tveterås, R. (1999). Production Risk and Productivity Growth: Some Findings for Norwegian Salmon Aquaculture. Journal of Productivity Analysis 12(2) , 161-179.

Tveterås, R., \& Wan, G. H. (2000). Flexible panel data models for risky production technologies with an application to salmon aquaculture. Econometric Reviews 19(3), 367-389.

UN. (2013). World Population Prospects: The 2012 Revision, Volume I:

Comprehensive Tables ST/ESA/SER.A/336. New York: United Nations, Department of Economic and Social Affairs, Population Division.

von Braun, J. (2007). The World Food Situation, New Driving Forces and Required Actions. IFPRI Food Policy Report 18 , 1-18.

Wang, J., Huang, J., \& Rozelle, S. (2010). Climate Change and China's Agricultural Sector: An Overview of Impacts, Adaption and Mitigation. ICTSD-IPC Platform on Climate Change, Agriculture and Trade, Issue Brief No. 5 , 1-31.

Wang, J., Huang, J., \& Yan, T. (2013). Impacts of Climate Change on Water and Agricultural Production in Ten Large River Basins in China. Journal of Integrative Agriculture 12(7), 1267-1278.

Wang, J., Mendelsohn, R., Dinar, A., Huang, J., Rozelle, S., \& Zhang, L. (2009). The impact of climate change on China's agriculture. Agricultural Economics 40(3) , 323337.

Weimin, M., \& Mengqing, L. (2007). Analysis of feeds and fertilizers for sustainable aquaculture development in China. In M. R. Hasan, T. Hecht, S. De Silva, \& A. G. Tacon, Study and analysis of feeds and fertilizers for sustainable aquaculture development. FAO Fisheries Technical Paper No. 497 (pp. 141-190). Rome: FAO.

Wooldridge, J. M. (2002). Econometric Analysis of Cross Section and Panel Data. Cambridge and London: The MIT Press.

Wu, C., Maurer, C., Wang, Y., Xue, S., \& Davis, D. L. (1999). Water Pollution and Human Health in China. Environmental Health Perspectives 107(4), 251-256.

Xiong, W., Lin, E., Ju, H., \& Xu, Y. (2007). Climate change and critical thresholds in China's food security. Climatic Change 81(2), 205-221.

Yang, Y., \& Tyers, R. (1989). The Economic Costs of Food Self-Sufficiency in China. World Development 17(2), 237-253.

Yoo, K. H., \& Boyd, C. E. (1993). Hydrology and water supply for pond aquaculture. New York: Van Nostrand Reinhold. 
You, L., Rosegrant, M. W., Wood, S., \& Sun, D. (2009). Impact of growing season temperature on wheat productivity in China. Agricultural and Forest Meteorology 149(6-7) , 1009-1014.

Yu, X. (2012). Productivity, efficiency and structural problems in Chinese dairy farms. China Agricultural Economic Review 4(2) , 168-175.

Yu, X., \& Abler, D. (2009). The Demand for Food Quality in Rural China. American Journal of Agricultural Economics 91(1) , 57-69.

Yu, X., \& Zhao, G. (2009). Chinese agricultural development in 30 years: A literature review. Frontiers of Economics in China 4(4) , 633-648.

Zhang, B., \& Carter, C. A. (1997). Reforms, the Weather, and Productivity Growth in China's Grain Sector. American Journal of Agricultural Economics 79(4) , 1266-1277.

Zhang, J., Mauzerall, D. L., Zhu, T., Liang, S., Ezzati, M., \& Remais, J. V. (2010). Environmental health in China: progress towards clean air and safe water. The Lancet 375(9720) , 1110-1119.

Zhao, J., Luo, Q., Deng, H., \& Yan, Y. (2008). Opportunities and challenges of sustainable agricultural development in China. Philosophical Transactions of the Royal Society B 363(1492) , 893-904. 